UNIVERSIDADE DE SÃO PAULO

FACULDADE DE ODONTOLOGIA DE BAURU

GABRIELA PEREIRA DE SOUZA

\title{
Efeitos do captopril sobre a doença periodontal induzida experimentalmente em ratos
}





\section{Efeitos do captopril sobre a doença periodontal induzida experimentalmente em ratos}

Dissertação apresentada a Faculdade de Odontologia de Bauru da Universidade de São Paulo para obtenção do título de Mestre em Ciências no Programa de Ciências Odontológicas Aplicadas, na área de concentração Biologia Oral.

Orientador: Prof. Dr. Carlos Ferreira dos Santos

Versão Corrigida

BAURU

2014 


\section{So89e \\ De Souza, Gabriela Pereira ida experimentalmente em ratos / Gabriela Pereira de Souza. - Bauru, 2014. \\ 127 p. : il. ; $31 \mathrm{~cm}$. \\ Dissertação. (Mestrado) - Faculdade de Odontologia de Bauru. Universidade de São Paulo. \\ Orientador: Prof. Dr. Carlos Ferreira dos Santos}

Nota: A versão original desta dissertação encontra-se disponível no Serviço de Biblioteca e Documentação da Faculdade de Odontologia de Bauru - FOB/USP.

Autorizo, exclusivamente para fins acadêmicos e científicos, a reprodução total ou parcial desta dissertação, por processos fotocopiadores e/ou outros meios eletrônicos.

Comitê de Ética no Ensino e Pesquisa em Animais da FOB-USP : projeto de pesquisa aprovado em 28 de junho de 2013.

Protocolo no: 014/2013 


\section{DEDICATÓRIA}

Dedico essa dissertação ao meu filho Nicolas Pereira e a minha amada avó Ana Pereira de Souza. Amo muito vocês. 



\section{AGRADECIMENTOS}

Agradeço a Deus por me dar força e saúde para concluir mais uma fase de minha jornada acadêmica. 



\section{AGRADECIMENTOS ESPECIAIS}

À minha amada mãe Maria Aparecida Pereira de Souza, quem sempre contribuiu em minha jornada acadêmica, com tudo o que estava ao seu alcance, sempre mantendo os meus pés no chão e me estimulando, e quem eu amo muito.

Ao meu pai Mauro de Souza por ter dado o que mais tenho de precioso hoje, a vida!

As minhas amadas tias Maria Darci Pereira e lanir Pereira Costa, muito obrigada por tudo.

À amiga Maria de Fátima Cantareira, funcionária do Hospital de Reabilitação de Anomalias Crânio Faciais, quem também contribuiu com minha formação acadêmica, muito obrigada.

Ao meu querido Mestre Prof. Dr. Carlos Ferreira dos Santos, que me acolheu, ensinou, contribuiu e com toda certeza sempre contribuirá com o meu crescimento acadêmico, um verdadeiro exemplo a ser seguido, demonstrou que a plena dedicação à ciência e a família são essenciais para o crescimento pessoal.

Ao Thiago José Dionísio, quem sempre esteve ao meu lado, ensinando e auxiliando na concretização dessa dissertação.

As amigas de pós-graduação Lilian Gabrielle Gobbo e Cláudia Bighetti, muito obrigada por sempre estarem ao meu lado e me auxiliarem durante toda a jornada acadêmica.

À Ana Paula Akashi, pelo companheirismo e por estar sempre ao meu lado durante toda a pesquisa.

À Profa Dra. Bella Luna Colombini Ishikiriama, pelo auxílio na indução da doença periodontal.

À Prof ${ }^{a}$ Dra. Thaís Oliveira, quem também ensinou e auxiliou muito durante o procedimento de indução da doença periodontal. 

Aos colegas de laboratório, Thais Garbieri e Túlio Olano, por auxiliarem durante os procedimentos de indução da doença periodontal.

Aos funcionários do biotério central da Faculdade de Odontologia de Bauru, da Universidade de São Paulo (FOB/USP), Luiz, Erasmo e Elias, sempre muito prestativos. Obrigada pela ajuda.

À Dra Elza Torres, pelo incentivo e apoio durante as etapas da pesquisa.

As funcionárias do Departamento de Ciências Biológicas, Vera Lúcia Rufino, Dalva de Oliveira e Viviane Aparecida Parisi, serei eternamente grata por todo o auxílio e orientação. 

"Se o dinheiro for a sua esperança de independência, você jamais a terá. A única segurança verdadeira consiste numa reserva de sabedoria, de experiência e de competência." Henry Ford 



\section{RESUMO}

A doença periodontal corresponde a um grupo de doenças inflamatórias que resultam na destruição das estruturas de suporte dental. São doenças infecciosas e possuem etiologia relacionada a microrganismos gram-negativos podendo manifestar-se de inúmeras maneiras. Estes possuem uma variedade de fatores que permitem o aumento de sua virulência e capacidade de se multiplicarem e persistirem no periodonto. Experimentos recentes de nosso laboratório mostraram que no tecido gengival de rato existe a expressão de RNAm para todos os componentes do Sistema Renina-Angiotensina (SRA), presença da renina e atividade da Enzima Conversora de Angiotensina I (ECA) em tecido gengival de ratos, sugerindo, assim, possível correlação entre o SRA e a doença periodontal (DP). Portanto, o objetivo do presente trabalho foi investigar se o captopril, um inibidor da ECA, altera a progressão da DP induzida experimentalmente em ratos. Para tanto, foi utilizado o modelo de indução da DP por colocação de ligadura ao redor do primeiro molar inferior de ratos divididos em grupos com 10 animais cada, que foram tratados com captopril (via gavagem, $30 \mathrm{mg} / \mathrm{kg} / \mathrm{dia}$ ) ou água (veículo). Foi realizado pré-tratamento com esta droga por 7 ou 14 dias previamente à indução da DP e após este período, o captopril foi administrado por 14 e 21 dias. Além disso, foi realizada cirurgia fictícia para indução da DP (grupo SHAM). As técnicas utilizadas neste trabalho foram: indução da DP em ratos, extração de RNA total, transcrição reversa seguida de reação em cadeia da polimerase quantitativa (RT-qPCR) e análise de perda óssea alveolar. Os dados foram analisados por meio de gráficos. Todos os resultados foram submetidos à análise unidirecional de variância (ANOVA) e representaram médias e respectivos desvios-padrão. Diferenças entre os grupos foram consideradas estatisticamente significativas quando $p<0,05$. Com base nos resultados obtidos neste trabalho, foi possível concluir que o captopril não foi capaz de diminuir a perda óssea na doença periodontal induzida experimentalmente em ratos, apesar desta droga ter alterado a expressão de RNAm para um alvo do RAS (AT1a) e alguns mediadores do processo inflamatório no tecido periodontal, tais como COX-2, ECA-2, IL-6, RANKL, VEGF-R1 e VEGF-R2.

Palavras-chave: Doença periodontal, sistema renina-angiotensina, captopril, inflamação. 



\section{ABSTRACT \\ Effects of captopril on experimentally-induced periodontal disease induced in rats}

Periodontal disease (PD) consists of a group of inflammatory diseases which result in the destruction of tooth supporting structures. They are of infectious nature, with etiological factors related to gram-negative microorganisms, and may have manifestations in several ways. These comprise a variety of factors that allow the increase in its virulence and ability to multiply and persist in the periodontal tissue. Recent findings form our laboratory showed that mRNA expression exists in rat gingival tissue for all components of the Renin-Angiotensin System (RAS), the presence of renin as well as Angiotensin Converting Enzyme I (ACE) activity in rat gingival tissue, thus suggesting a possible correlation between the RAS and periodontal disease. Therefore, the aim of this study was to investigate whether captopril, an ACE inhibitor, alters the progression of experimentally-induced PD in rats. Thus, the model of PD induction by ligature placement around rat lower first molar was used. Animals were divided groups of 10 animals each, which were treated with captopril (via gavage, $30 \mathrm{mg} / \mathrm{kg} / \mathrm{day}$ ) or water (vehicle). Pre-treatment with this drug during 7 or 14 days was performed previously to PD induction, and after this period captopril was administered during 14 or 21 days. In addition, fictitious operation (SHAM group) was performed to induce PD. The techniques used in this study were: PD induction in rats, total RNA extraction, reverse transcriptionquantitative polymerase chain reaction (RT-qPCR) and alveolar bone loss. Data were analyzed by means of graphs. All the results were subjected to one-way analysis of variance (ANOVA) and represented means and respective standard errors. Differences between groups were considered statistically significant when $p<0.05$. Based on the results obtained in this study, it was concluded that captopril was not able to decrease bone loss in experimentally-induced PD in rats, although this drug altered the expression of mRNA for one RAS target (AT1a) and some mediators of inflammation in periodontal tissue such as, COX-2, ACE-2, IL-6, RANKL, VEGF-R1 and VEGF-R2.

Keywords: periodontal disease, renin-angiotensin system, captopril, inflammation. 



\section{LISTA DE ILUSTRAÇÕES}

- FIGURAS

Figura 1 - Principais componentes do sistema renina-angiotensina. 28

Figura 2 - Renina é uma glicoproteína que atua clivando o angiotensinogênio, transformando-o em um decapeptídeo, a angiotensina I

Figura 3 - O esquema mostra os locais de atuação da ECA no sistema renina-angiotensina.

Figura 4 - O esquema mostra os locais de atuação da ECA-2 no sistema renina-angiotensina.

Figura 5 - Clivagem da Angiotensina I em outros peptídeos 31

Figura 6 - Formação da Angiotensina II após clivagem da Angiotensina I . 33

Figura 7 - Formação da Angiotensina 1-7 a partir da clivagem da Angiotensina I, Angiotensina II ou Angiotensina 1-9....

Figura 8 - Formação da Angiotensina 1-9 a partir da ação da ECA-2, que atua clivando a Angiotensina I

Figura 9 - Receptores que interagem com a Angiotensina II. 36

Figura 10 - Recetor MAS interage com a Angiotensina 1-7 36

Figura 11 - Aplicação de anestésico na artéria peniana (eutanásia). 54 

Figura 12 - Hemimandíbula de um dos animais, comparada ao tamanho da lâmina do bisturi .

Figura 13 - Demonstração da área de perda óssea demarcada em uma hemimandíbula de rato tratado com captopril. Imagem analisada no software DinoCapture 2.0 versão 1.4.5.B

Figura 14 - Evolução do peso corporal dos animais ao longo das 6 semanas do período experimental .....

Figura 15 - Perdas ósseas em $\mathrm{mm}^{2}$ dos animais do grupo Sham $(n=5$, submetidos à indução fictícia), do grupo DP-14 $\mathrm{H}_{2} \mathrm{O}(\mathrm{n}=5$, Tratados com veículo durante 14 dias após a indução), do grupo DP-14 Capto ( $n=5$, Tratados com captopril durante 14 dias após a indução), do grupo 7-DP-14 Capto $(n=5$, tratados com captopril 7 dias antes da indução e 14 dias após a indução), do grupo 14-DP-14 Capto ( $n=5$, tratados com captopril 14 dias antes da indução e 14 dias após a indução). * $p<0,05$ em relação a todos os demais grupos 64

Figura 16 - Perdas ósseas em $\mathrm{mm}^{2}$ dos animais do grupo Sham $(n=5$, submetidos à indução fictícia), do grupo DP-21 $\mathrm{H}_{2} \mathrm{O}(\mathrm{n}=5$, tratados com veículo 21 dias após a indução), do grupo DP21 Capto ( $n=5$, tratados com captopril 21 dias após a indução), do grupo 7-DP-21 Capto ( $n=5$, tratados com captopril 7 dias antes da indução e 21 dias após a indução) e do grupo 14-DP-21 Capto ( $n=5$, tratados com captopril 14 dias antes da indução e 21 dias após a indução). * $p<0,05$ em relação a todos os demais grupos.

Figura 17 - Expressão de RNAm para angiotensinogênio relativa à expressão de $\beta$-actina nos animais do grupo Sham $(n=5$, submetidos à indução fictícia), do grupo DP-14 $\mathrm{H}_{2} \mathrm{O}(\mathrm{n}=5$, Tratados com veículo durante 14 dias após a indução), do grupo DP-14 Capto ( $n=5$, Tratados com captopril durante 14 dias após a indução) do grupo 7-DP-14 Capto $(n=5$, tratados com captopril 7 dias antes da indução e 14 dias após a indução), do grupo 14-DP-14 Capto ( $n=5$, tratados com captopril 14 dias antes da indução e 14 dias após a indução) 

Figura 18 - Expressão de RNAm para angiotensinogênio relativa à expressão de $\beta$-actina nos animais do grupo Sham $(n=5$, submetidos à indução fictícia), do grupo DP-21 $\mathrm{H}_{2} \mathrm{O}(\mathrm{n}=5$, tratados com veículo 21 dias após a indução), do grupo DP21 Capto $(n=5$, tratados com captopril 21 dias após a indução), do grupo 7-DP-21 Capto ( $n=5$, tratados com captopril 7 dias antes da indução e 21 dias após a indução) e do grupo 14-DP-21 Capto ( $n=5$, tratados com captopril 14 dias antes da indução e 21 dias após a indução)

Figura 19 - Expressão de RNAm para o receptor AT1a relativa à expressão de $\beta$-actina nos animais do grupo Sham $(n=5$, submetidos a indução fictícia), do grupo DP-14 $\mathrm{H}_{2} \mathrm{O}(\mathrm{n}=5$, Tratados com veículo durante 14 dias após a indução), do grupo DP-14 Capto ( $n=5$, Tratados com captopril durante 14 dias após a indução), do grupo 7-DP-14 Capto $(n=5$, tratados com captopril 7 dias antes da indução e 14 dias após a indução), do grupo 14-DP-14 Capto ( $n=5$, tratados com captopril 14 dias antes da indução e 14 dias após a indução) 68

Figura 20 - Expressão de RNAm para o receptor AT1a relativa à expressão de $\beta$-actina nos animais do grupo Sham $(n=5$, submetidos a indução fictícia), do grupo DP-21 $\mathrm{H}_{2} \mathrm{O}(\mathrm{n}=5$, tratados com veículo 21 dias após a indução), do grupo DP21 Capto $(n=5$, tratados com captopril 21 dias após a indução), do grupo 7-DP-21 Capto ( $\mathrm{n}=5$, tratados com captopril 7 dias antes da indução e 21 dias após a indução) e do grupo 14-DP-21 Capto ( $n=5$, tratados com captopril 14 dias antes da indução e 21 dias após a indução). * vs DP-21 $\mathrm{H}_{2} \mathrm{O}$

Figura 21 - Expressão de RNAm para o receptor AT1a relativa à expressão de $\beta$-actina nos animais do grupo Sham $(n=5$, submetidos a indução fictícia), do grupo DP-21 $\mathrm{H}_{2} \mathrm{O}(\mathrm{n}=5$, tratados com veículo 21 dias após a indução), do grupo DP21 Capto $(n=5$, tratados com captopril 21 dias após a indução), do grupo 7-DP-21 Capto ( $\mathrm{n}=5$, tratados com captopril 7 dias antes da indução e 21 dias após a indução) e do grupo 14-DP-21 Capto ( $n=5$, tratados com captopril 14 dias antes da indução e 21 dias após a indução). * vs DP-21 $\mathrm{H}_{2} \mathrm{O}$ 

Figura 22 - Expressão de RNAm para o receptor AT2 relativa à expressão de $\beta$-actina nos animais do grupo Sham $(n=5$, submetidos a indução fictícia), do grupo DP- $21 \mathrm{H}_{2} \mathrm{O}(\mathrm{n}=5$, tratados com veículo 21 dias após a indução), do grupo DP21 Capto ( $n=5$, tratados com captopril 21 dias após a indução), do grupo 7-DP-21 Capto ( $n=5$, tratados com captopril 7 dias antes da indução e 21 dias após a indução) e do grupo 14-DP-21 Capto ( $n=5$, tratados com captopril 14 dias antes da indução e 21 dias após a indução)

Figura 23 - Expressão de RNAm para ECA relativa à expressão de $\beta$ actina nos animais do grupo Sham $(n=5$, submetidos a indução fictícia), do grupo DP-14 $\mathrm{H}_{2} \mathrm{O}$ ( $n=5$, Tratados com veículo durante 14 dias após a indução), do grupo DP-14 Capto $(n=5$, Tratados com captopril durante 14 dias após a indução), do grupo 7-DP-14 Capto ( $\mathrm{n}=5$, tratados com captopril 7 dias antes da indução e 14 dias após a indução), do grupo 14-DP-14 Capto ( $n=5$, tratados com captopril 14 dias antes da indução e 14 dias após a indução).

Figura 24 - Expressão de RNAm para ECA relativa à expressão de $\beta$ actina nos animais do grupo Sham $(n=5$, submetidos a indução fictícia), do grupo DP-21 $\mathrm{H}_{2} \mathrm{O}(\mathrm{n}=5$, tratados com veículo 21 dias após a indução), do grupo DP-21 Capto $(n=5$, tratados com captopril 21 dias após a indução), do grupo 7-DP-21 Capto ( $n=5$, tratados com captopril 7 dias antes da indução e 21 dias após a indução) e do grupo 14DP-21 Capto $(n=5$, tratados com captopril 14 dias antes da indução e 21 dias após a indução)...

Figura 25 - Expressão de RNAm para ECA-2 relativa à expressão de $\beta$ actina nos animais do grupo Sham $(n=5$, submetidos a indução fictícia), do grupo DP-14 $\mathrm{H}_{2} \mathrm{O}(\mathrm{n}=5$, Tratados com veículo durante 14 dias após a indução), do grupo DP-14 Capto $(n=5$, Tratados com captopril durante 14 dias após a indução), do grupo 7-DP-14 Capto ( $n=5$, tratados com captopril 7 dias antes da indução e 14 dias após a indução), do grupo 14-DP-14 Capto ( $n=5$, tratados com captopril 14 dias antes da indução e 14 dias após a indução). * vs Sham 

Figura 26 - Expressão de RNAm para ECA-2 relativa à expressão de $\beta$ actina nos animais do grupo Sham $(n=5$, submetidos a indução fictícia), do grupo DP-21 $\mathrm{H}_{2} \mathrm{O}(\mathrm{n}=5$, tratados com veículo 21 dias após a indução), do grupo DP-21 Capto $(n=5$, tratados com captopril 21 dias após a indução), do grupo 7-DP-21 Capto ( $n=5$, tratados com captopril 7 dias antes da indução e 21 dias após a indução) e do grupo 14DP-21 Capto $(n=5$, tratados com captopril 14 dias antes da indução e 21 dias após a indução). * vs Sham

Figura 27 - Expressão de RNAm para receptor MAS relativa à expressão de $\beta$-actina nos animais do grupo Sham $(n=5$, submetidos a indução fictícia), do grupo DP-14 $\mathrm{H}_{2} \mathrm{O}(\mathrm{n}=5$, Tratados com veículo durante 14 dias após a indução), do grupo DP-14 Capto $(n=5$, Tratados com captopril durante 14 dias após a indução), do grupo 7-DP-14 Capto $(n=5$, tratados com captopril 7 dias antes da indução e 14 dias após a indução), do grupo 14-DP-14 Capto ( $n=5$, tratados com captopril 14 dias antes da indução e 14 dias após a indução).

Figura 28 - Expressão de RNAm para receptor MAS relativa à expressão de $\beta$-actina nos animais do grupo Sham $(n=5$, submetidos a indução fictícia), do grupo DP-21 $\mathrm{H}_{2} \mathrm{O}(\mathrm{n}=5$, tratados com veículo 21 dias após a indução), do grupo DP21 Capto $(n=5$, tratados com captopril 21 dias após a indução), do grupo 7-DP-21 Capto ( $n=5$, tratados com captopril 7 dias antes da indução e 21 dias após a indução) e do grupo 14-DP-21 Capto ( $n=5$, tratados com captopril 14 dias antes da indução e 21 dias após a indução)

Figura 29 - Expressão de RNAm para COX-2 relativa à expressão de $\beta$ actina nos animais do grupo Sham $(n=5$, submetidos a indução fictícia), do grupo DP-14 $\mathrm{H}_{2} \mathrm{O} \quad(\mathrm{n}=5$, Tratados com veículo durante 14 dias após a indução), do grupo DP-14 Capto $(n=5$, Tratados com captopril durante 14 dias após a indução), do grupo 7-DP-14 Capto ( $n=5$, tratados com captopril 7 dias antes da indução e 14 dias após a indução), do grupo 14-DP-14 Capto ( $n=5$, tratados com captopril 14 dias antes da indução e 14 dias após a indução). * vs Sham e Dp-14 $\mathrm{H}_{2} \mathrm{O}$ 

Figura 30 - Expressão de RNAm para COX-2 relativa à expressão de $\beta$ actina nos animais do grupo Sham $(n=5$, submetidos a indução fictícia), do grupo DP-21 $\mathrm{H}_{2} \mathrm{O}(\mathrm{n}=5$, tratados com veículo 21 dias após a indução), do grupo DP-21 Capto $(n=5$, tratados com captopril 21 dias após a indução), do grupo 7-DP-21 Capto ( $n=5$, tratados com captopril 7 dias antes da indução e 21 dias após a indução) e do grupo 14DP-21 Capto $(n=5$, tratados com captopril 14 dias antes da indução e 21 dias após a indução).

Figura 31 - Expressão de RNAm para IL-1 $\beta$ relativa à expressão de $\beta$ actina nos animais do grupo Sham $(n=5$, submetidos a indução fictícia), do grupo DP-14 $\mathrm{H}_{2} \mathrm{O}(\mathrm{n}=5$, Tratados com veículo durante 14 dias após a indução), do grupo DP-14 Capto $(n=5$, Tratados com captopril durante 14 dias após a indução), do grupo 7-DP-14 Capto $(n=5$, tratados com captopril 7 dias antes da indução e 14 dias após a indução), do grupo 14-DP-14 Capto ( $n=5$, tratados com captopril 14 dias antes da indução e 14 dias após a indução). 80

Figura 32 - Expressão de RNAm para IL-1 $\beta$ relativa à expressão de $\beta$ actina nos animais do grupo Sham $(n=5$, submetidos a indução fictícia), do grupo DP-21 $\mathrm{H}_{2} \mathrm{O}(\mathrm{n}=5$, tratados com veículo 21 dias após a indução), do grupo DP-21 Capto $(n=5$, tratados com captopril 21 dias após a indução), do grupo 7-DP-21 Capto ( $n=5$, tratados com captopril 7 dias antes da indução e 21 dias após a indução) e do grupo 14DP-21 Capto $(n=5$, tratados com captopril 14 dias antes da indução e 21 dias após a indução)...

Figura 33 - Expressão de RNAm para IL-6 relativa à expressão de $\beta$ actina nos animais do grupo Sham $(n=5$, submetidos a indução fictícia), do grupo DP-14 $\mathrm{H}_{2} \mathrm{O}$ ( $n=5$, Tratados com veículo durante 14 dias após a indução), do grupo DP-14 Capto $(n=5$, Tratados com captopril durante 14 dias após a indução), do grupo 7-DP-14 Capto ( $n=5$, tratados com captopril 7 dias antes da indução e 14 dias após a indução), do grupo 14-DP-14 Capto ( $n=5$, tratados com captopril 14 dias antes da indução e 14 dias após a indução). 

Figura 34 - Expressão de RNAm para IL-6 relativa à expressão de $\beta$ actina nos animais do grupo Sham $(n=5$, submetidos a indução fictícia), do grupo DP-21 $\mathrm{H}_{2} \mathrm{O}(\mathrm{n}=5$, tratados com veículo 21 dias após a indução), do grupo DP-21 Capto $(n=5$, tratados com captopril 21 dias após a indução), do grupo 7-DP-21 Capto ( $n=5$, tratados com captopril 7 dias antes da indução e 21 dias após a indução) e do grupo 14DP-21 Capto $(n=5$, tratados com captopril 14 dias antes da indução e 21 dias após a indução). * vs 14-DP-21 $\mathrm{H}_{2} \mathrm{O}$.

Figura 35 - Expressão de RNAm para TNF relativa à expressão de $\beta$ actina nos animais do grupo Sham $(n=5$, submetidos a indução fictícia), do grupo DP-14 $\mathrm{H}_{2} \mathrm{O}$ ( $n=5$, Tratados com veículo durante 14 dias após a indução), do grupo DP-14 Capto $(n=5$, Tratados com captopril durante 14 dias após a indução), do grupo 7-DP-14 Capto (tratados com captopril 7 dias antes da indução e 14 dias após a indução), do grupo 14-DP-14 Capto ( $n=5$, tratados com captopril 14 dias antes da indução e 14 dias após a indução)

Figura 36 - Expressão de RNAm para TNF relativa à expressão de $\beta$ actina nos animais do grupo Sham $(n=5$, submetidos a indução fictícia), do grupo DP-21 $\mathrm{H}_{2} \mathrm{O}(\mathrm{n}=5$, tratados com veículo 21 dias após a indução), do grupo DP-21 Capto ( $n=5$, tratados com captopril 21 dias após a indução), do grupo 7-DP-21 Capto ( $n=5$, tratados com captopril 7 dias antes da indução e 21 dias após a indução) e do grupo 14DP-21 Capto $(n=5$, tratados com captopril 14 dias antes da indução e 21 dias após a indução)...

Figura 37 - Expressão de RNAm para OPG relativa à expressão de $\beta$ actina nos animais do grupo Sham $(n=5$, submetidos a indução fictícia), do grupo DP-14 $\mathrm{H}_{2} \mathrm{O}(\mathrm{n}=5$, Tratados com veículo durante 14 dias após a indução), do grupo DP-14 Capto $(n=5$, Tratados com captopril durante 14 dias após a indução), do grupo 7-DP-14 Capto ( $n=5$, tratados com captopril 7 dias antes da indução e 14 dias após a indução), do grupo 14-DP-14 Capto ( $n=5$, tratados com captopril 14 dias antes da indução e 14 dias após a indução). 

Figura 38 - Expressão de RNAm para OPG relativa à expressão de $\beta$ actina nos animais do grupo Sham $(n=5$, submetidos a indução fictícia), do grupo DP-21 $\mathrm{H}_{2} \mathrm{O}(\mathrm{n}=5$, tratados com veículo 21 dias após a indução), do grupo DP-21 Capto $(n=5$, tratados com captopril 21 dias após a indução), do grupo 7-DP-21 Capto ( $n=5$, tratados com captopril 7 dias antes da indução e 21 dias após a indução) e do grupo 14DP-21 Capto $(n=5$, tratados com captopril 14 dias antes da indução e 21 dias após a indução).

Figura 39 - Expressão de RNAm para RANK relativa à expressão de $\beta$ actina nos animais do grupo Sham $(n=5$, submetidos a indução fictícia), do grupo DP-14 $\mathrm{H}_{2} \mathrm{O}(\mathrm{n}=5$, Tratados com veículo durante 14 dias após a indução), do grupo DP-14 Capto $(n=5$, Tratados com captopril durante 14 dias após a indução), do grupo 7-DP-14 Capto (tratados com captopril 7 dias antes da indução e 14 dias após a indução), do grupo 14-DP-14 Capto ( $n=5$, tratados com captopril 14 dias antes da indução e 14 dias após a indução).

Figura 40 - Expressão de RNAm para RANK relativa à expressão de $\beta$ actina nos animais do grupo Sham $(n=5$, submetidos a indução fictícia), do grupo DP-21 $\mathrm{H}_{2} \mathrm{O}(\mathrm{n}=5$, tratados com veículo 21 dias após a indução), do grupo DP-21 Capto $(n=5$, tratados com captopril 21 dias após a indução), do grupo 7-DP-21 Capto ( $n=5$, tratados com captopril 7 dias antes da indução e 21 dias após a indução) e do grupo 14DP-21 Capto $(n=5$, tratados com captopril 14 dias antes da indução e 21 dias após a indução).... 89

Figura 41 - Expressão de RNAm para RANKL relativa à expressão de $\beta$ actina nos animais do grupo Sham $(n=5$, submetidos a indução fictícia), do grupo DP-14 $\mathrm{H}_{2} \mathrm{O}(\mathrm{n}=5$, Tratados com veículo durante 14 dias após a indução), do grupo DP-14 Capto $(n=5$, Tratados com captopril durante 14 dias após a indução), do grupo 7-DP-14 Capto $(n=5$, tratados com captopril 7 dias antes da indução e 14 dias após a indução), do grupo 14-DP-14 Capto ( $n=5$, tratados com captopril 14 dias antes da indução e 14 dias após a indução). * vs Sham e DP-14 $\mathrm{H}_{2} \mathrm{O}$ 

Figura 42 - Expressão de RNAm para RANKL relativa à expressão de $\beta$ actina nos animais do grupo Sham $(n=5$, submetidos a indução fictícia), do grupo DP-21 $\mathrm{H}_{2} \mathrm{O}(\mathrm{n}=5$, tratados com veículo 21 dias após a indução), do grupo DP-21 Capto $(n=5$, tratados com captopril 21 dias após a indução), do grupo 7-DP-21 Capto ( $n=5$, tratados com captopril 7 dias antes da indução e 21 dias após a indução) e do grupo 14DP-21 Capto $(n=5$, tratados com captopril 14 dias antes da indução e 21 dias após a indução).

Figura 43 - Expressão de RNAm para VEGF relativa à expressão de $\beta$ actina nos animais do grupo Sham $(n=5$, submetidos a indução fictícia), do grupo DP-14 $\mathrm{H}_{2} \mathrm{O}(\mathrm{n}=5$, Tratados com veículo durante 14 dias após a indução), do grupo DP-14 Capto $(n=5$, Tratados com captopril durante 14 dias após a indução), do grupo 7-DP-14 Capto ( $\mathrm{n}=5$, tratados com captopril 7 dias antes da indução e 14 dias após a indução), do grupo 14-DP-14 Capto ( $n=5$, tratados com captopril 14 dias antes da indução e 14 dias após a indução).

Figura 44 - Expressão de RNAm para VEGF relativa à expressão de $\beta$ actina nos animais do grupo Sham $(n=5$, submetidos a indução fictícia), do grupo DP-21 $\mathrm{H}_{2} \mathrm{O}(\mathrm{n}=5$, tratados com veículo 21 dias após a indução), do grupo DP-21 Capto $(n=5$, tratados com captopril 21 dias após a indução), do grupo 7-DP-21 Capto ( $n=5$, tratados com captopril 7 dias antes da indução e 21 dias após a indução) e do grupo 14DP-21 Capto $(n=5$, tratados com captopril 14 dias antes da indução e 21 dias após a indução)...

Figura 45 - Expressão de RNAm para VEGF-R1 relativa à expressão de $\beta$-actina nos animais do grupo Sham ( $n=5$, submetidos a indução fictícia), do grupo DP-14 $\mathrm{H}_{2} \mathrm{O}(\mathrm{n}=5$, Tratados com veículo durante 14 dias após a indução), do grupo DP-14 Capto $(n=5$, Tratados com captopril durante 14 dias após a indução), do grupo 7-DP-14 Capto ( $n=5$, tratados com captopril 7 dias antes da indução e 14 dias após a indução), do grupo 14-DP-14 Capto ( $n=5$, tratados com captopril 14 dias antes da indução e 14 dias após a indução). * vs Sham 

Figura 46 - Expressão de RNAm para VEGF-R1 relativa à expressão de $\beta$-actina nos animais do grupo Sham $(n=5$, submetidos a indução fictícia), do grupo DP-21 $\mathrm{H}_{2} \mathrm{O}(\mathrm{n}=5$, tratados com veículo 21 dias após a indução), do grupo DP-21 Capto $(n=5$, tratados com captopril 21 dias após a indução), do grupo 7-DP-21 Capto ( $n=5$, tratados com captopril 7 dias antes da indução e 21 dias após a indução) e do grupo 14DP-21 Capto $(n=5$, tratados com captopril 14 dias antes da indução e 21 dias após a indução). * vs Sham

Figura 47 - Expressão de RNAm para VEGF-R2 relativa à expressão de $\beta$-actina nos animais do grupo Sham $(n=5$, submetidos a indução fictícia), do grupo DP-14 $\mathrm{H}_{2} \mathrm{O}$ ( $n=5$, Tratados com veículo durante 14 dias após a indução), do grupo DP-14 Capto $(n=5$, Tratados com captopril durante 14 dias após a indução), do grupo 7-DP-14 Capto ( $\mathrm{n}=5$, tratados com captopril 7 dias antes da indução e 14 dias após a indução), do grupo 14-DP-14 Capto ( $n=5$, tratados com captopril 14 dias antes da indução e 14 dias após a indução). * vs Sham ...... 96

Figura 48 - Expressão de RNAm para VEGF-R2 relativa à expressão de $\beta$-actina nos animais do grupo Sham $(n=5$, submetidos a indução fictícia), do grupo DP-21 $\mathrm{H}_{2} \mathrm{O}(\mathrm{n}=5$, tratados com veículo 21 dias após a indução), do grupo DP-21 Capto $(n=5$, tratados com captopril 21 dias após a indução), do grupo 7-DP-21 Capto ( $n=5$, tratados com captopril 7 dias antes da indução e 21 dias após a indução) e do grupo 14DP-21 Capto $(n=5$, tratados com captopril 14 dias antes da indução e 21 dias após a indução). * vs Sham

Figura 49 - a. Escore 1. Infiltrado Inflamatório Ausente, Epitélio Juncional Normal, Cemento preservado ou com áreas eventuais de reabsorção cervical, Crista óssea alveolar preservada.

b. Escore 2. Infiltrado Inflamatório leve, Epitélio Juncional Normal, Cemento parcialmente destruído, Crista óssea alveolar com reabsorção mínima.

c. Escore 3. Infiltrado Inflamatório moderado, Epitélio Juncional Apical, Cemento parcialmente destruído, Crista óssea alveolar com reabsorção moderada.

d. Escore 4. Infiltrado Inflamatório intenso, Epitélio Juncional Apical, Cemento gravemente destruído, Crista óssea alveolar com reabsorção intensa, ocasionalmente com sequestro ósseo 

Figura 50 - Escore histológico representativo das amostras de animais com doença periodontal induzida por 14 ou 21 dias. O escore representa a soma dos parâmetros de Infiltrado Inflamatório, posição de epitélio juncional, grau de reabsorção do cemento e crista óssea alveolar. Os escores estão descritos detalhadamente na figura 49 (a,b,c,d) 



\section{LISTA DE TABELAS}

Tabela 1 - Número de catálogo dos kits de PCR inventoriados (Applied Biosystems) utilizados nesta pesquisa. 



\section{LISTA DE ABREVIATURA E SIGLAS}

AGT $=\quad$ angiotensinogênio

Ang $=\quad$ angiotensina 1

Ang- $I I=\quad$ angiotensina 2

AT1 $=\quad$ receptor de angiotensina tipo 1

$\mathrm{AT} 1 \mathrm{a}=\quad$ receptor de angiotensina tipo $1 \mathrm{a}$

$\mathrm{AT} 1 \mathrm{~b}=\quad$ receptor de angiotensina tipo $1 \mathrm{~b}$

AT2 $=\quad$ receptor de angiotensina tipo 2

COX-2 = ciclo-oxigenase-2

$\mathrm{DP}=\quad$ doença periodontal

$\mathrm{ECA}=\quad$ enzima conversora de angiotensina

ECA-2 = enzima conversora de angiotensina 2

et al. $=\quad$ e colaboradores

FOB/USP = Faculdade de Odontologia de Bauru / Universidade de São Paulo

LPS $=\quad$ lipopolissacarídeo

$\mu \mathrm{l}=\quad$ microlitros

$\mathrm{OPG}=\quad$ osteoprotegerina

RANK $=$ receptor ativador do fator nuclear kapa $B$

$\mathrm{RANKL}=$ ligante do receptor do fator nuclear kapa $\mathrm{B}$

RNAm = RNA mensageiro

$\mathrm{RT}=\quad$ transcrição reversa

RT-PCR = transcrição reversa seguida de reação em cadeia de polimerase

SHAM $=$ grupo controle

$\mathrm{SRA}=\quad$ sistema renina-angiotensina

TNF- $\alpha=$ fator de necrose tumoral alfa

VEGF $=$ fator de crescimento endotelial vascular

VEGF-R1 $=$ receptor 1 do fator de crescimento endotelial vascular

VEGF-R2 = receptor 2 do fator de crescimento endotelial vascular 

7-DP-14 CAPTO = 7 dias de pré-tratamento com captopril; indução da doença periodontal; 14 dias de pós-tratamento com captopril

7-DP-21 CAPTO = 7 dias de pré-tratamento com captopril; indução da doença periodontal; 21 dias de pós-tratamento com captopril

DP-14 $\mathrm{H} 2 \mathrm{O}=\quad$ indução da doença periodontal; 14 dias de pós-tratamento com veículo

DP-21 H2O = indução da doença periodontal; 21 dias de pós-tratamento com veículo

DP-14 CAPTO = indução da doença periodontal; 14 dias de pós-tratamento com captopril

DP-21 CAPTO = indução da doença periodontal; 21 dias de pós-tratamento com captopril

14-DP-14 CAPTO = 14 dias de pré-tratamento com captopril; indução da doença periodontal; 14 dias de pós-tratamento com captopril

14-DP-21 CAPTO = 14 dias de pré-tratamento com captopril; indução da doença periodontal; 21 dias de pós-tratamento com captopril 



\section{SUMÁRIO}

$1 \quad$ INTRODUÇÃO E SÍNTESE BIBLIOGRÁFICA …................................. 025

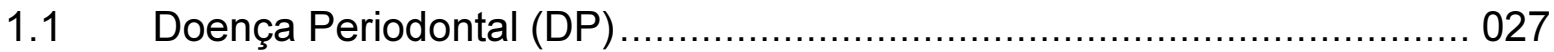

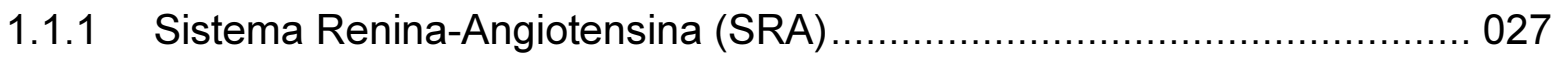

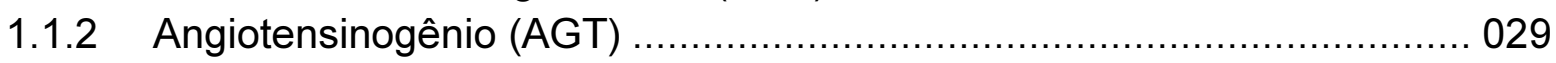

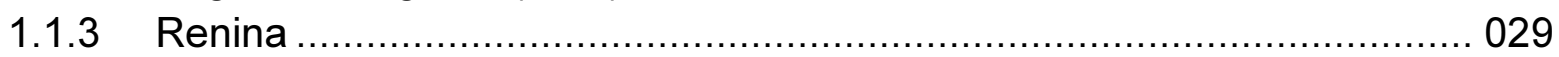

1.1.4 Enzima Conversora de Angiotensina (ECA) ....................................... 030

1.1.5 Enzima Conversora de Angiotensina 2 (ECA-2) .................................. 030

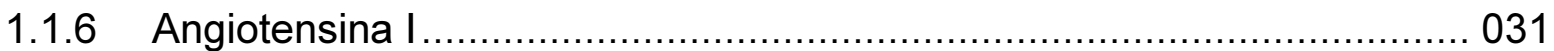

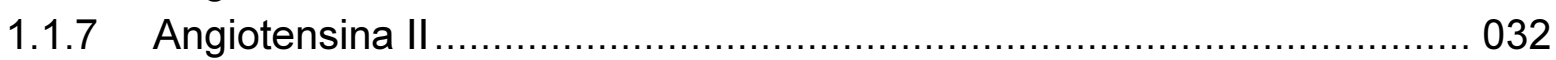

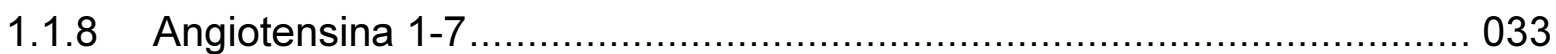

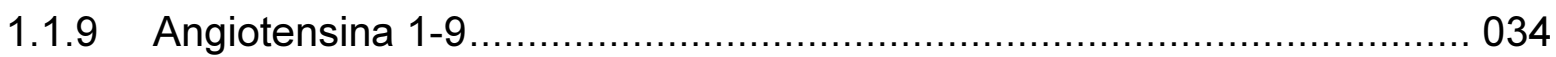

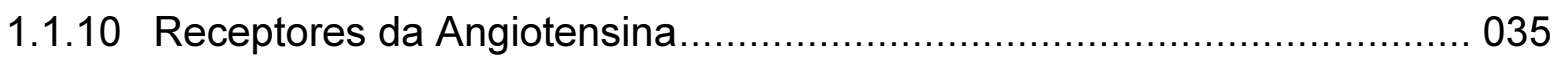

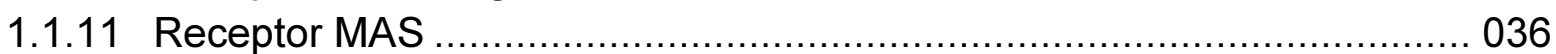

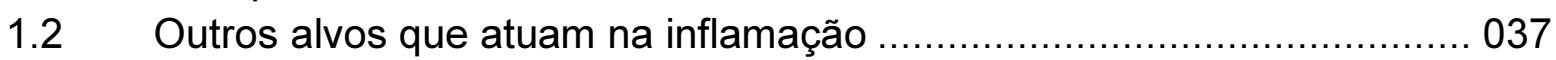

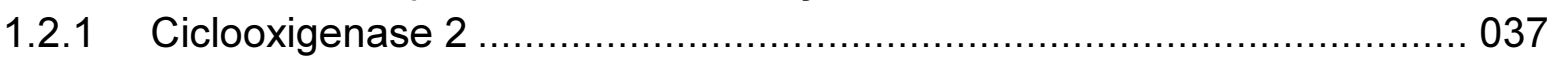

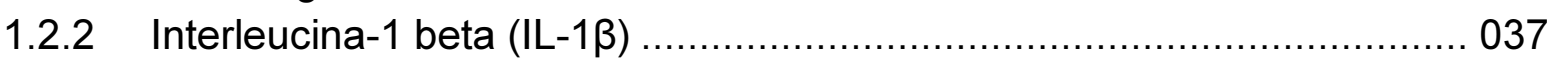

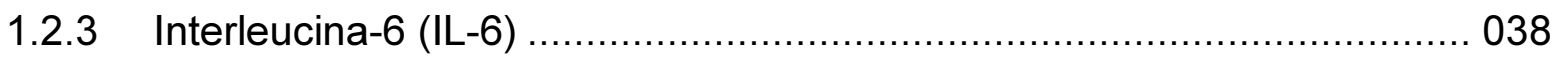

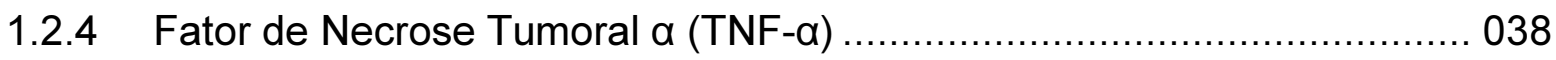

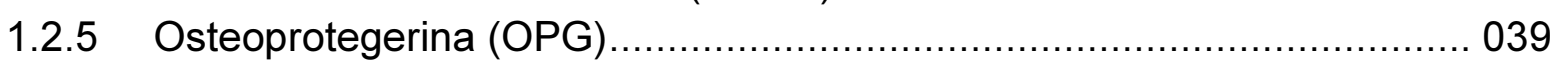

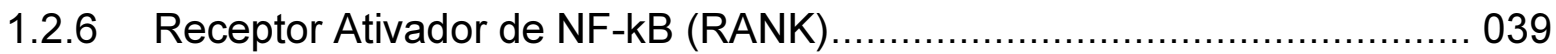

1.2.7 Ligante do Receptor Ativador de NF-k $\beta$ (RANKL) ............................... 039

1.2.8 Fator de Crescimento Vascular Endotelial (VEGF) ............................... 040

1.2.9 Receptor 1 e 2 do Fator de Crescimento Vascular Endotelial

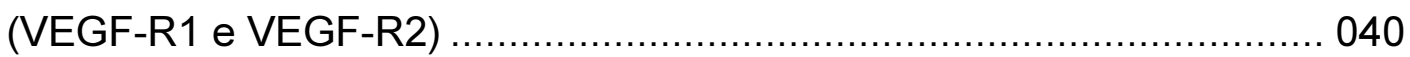

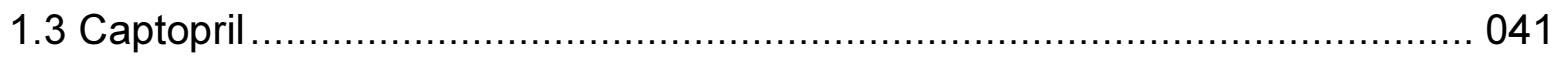

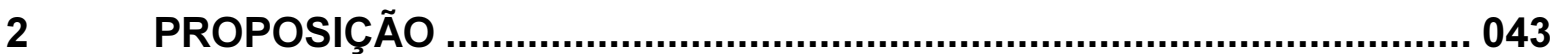

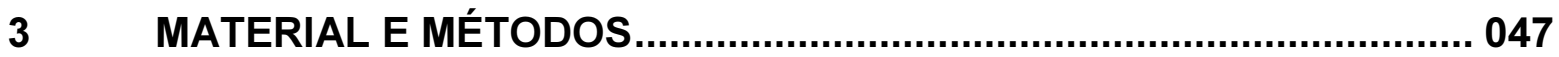

3.1 Indução experimental de doença periodontal (DP) por meio da

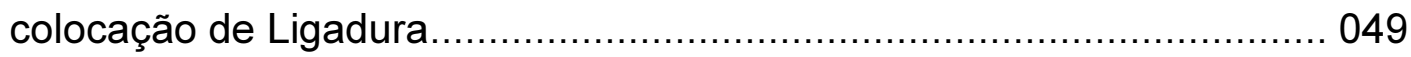

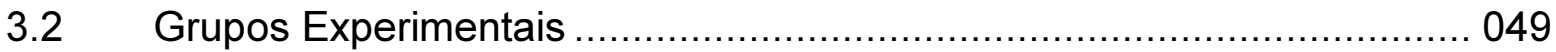

3.3 Obtenção de espécimes para os diferentes experimentos ..................... 054

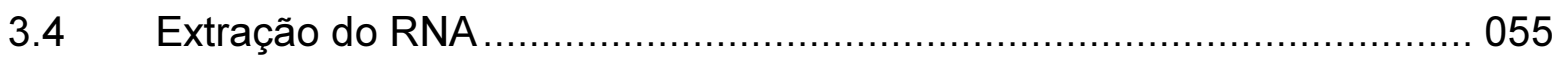

3.5 Análise da Quantidade e Qualidade do RNA total ................................ 056

3.6 Tratamento do RNA total com DNAse e transcrição reversa.................. 056

3.7 Reação em Cadeia da Polimerase (PCR) quantitativa (qPCR) .............. 057

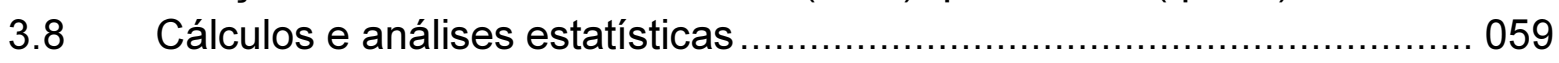



4.1 Progressão de peso (Média entre os grupos) ................................. 063

$4.2 \quad$ Análise de perda óssea alveolar ................................................ 064

4.3 ANÁLISE DA EXPRESSÃO DE RNAm NO TECIDO GENGIVAL...... 066

4.3.1 EXPRESSÃO DE RNAm PARA OS COMPONENTES DO SISTEMA RENINA-ANGIOTENSINA (RAS) ................................. 066

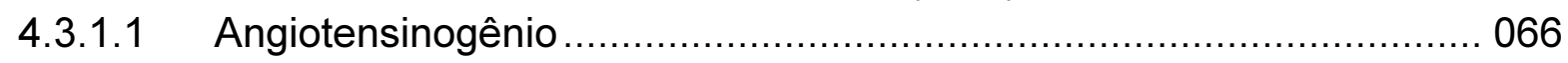

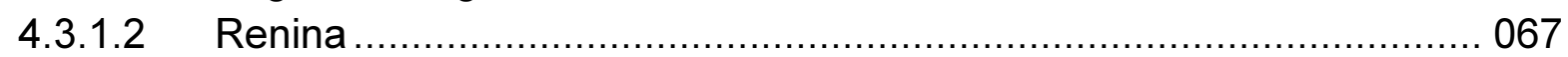

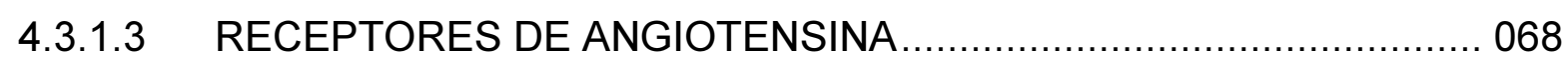

4.3.1.3.1 Receptor de Angiotensina Tipo 1a (AT1a) ........................................ 068

4.3.1.3.2 Receptor de Angiotensina Tipo $1 \mathrm{~b}$ (AT1b) ................................ 069

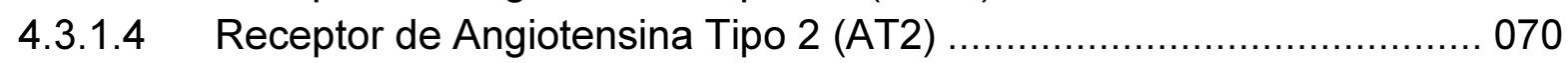

4.3.1.5 Enzima Conversora de Angiotensina (ECA) ................................. 072

4.3.1.6 Enzima Conversora de Angiotensina-2 (ECA-2) ......................... 074

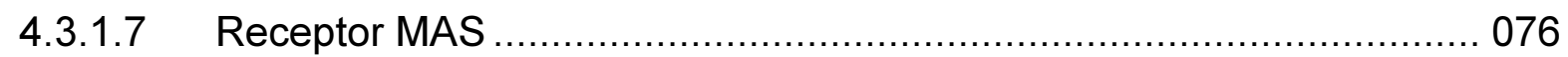

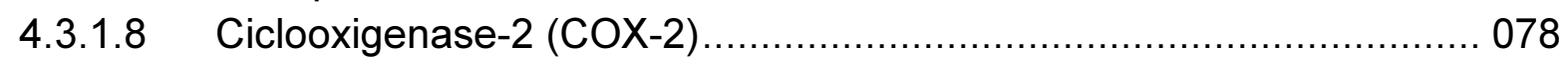

4.3.2 EXPRESSÃO DE RNAm PARA CITOCINAS .............................. 080

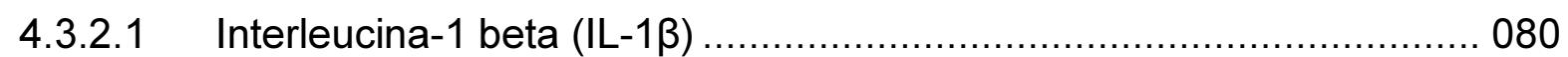

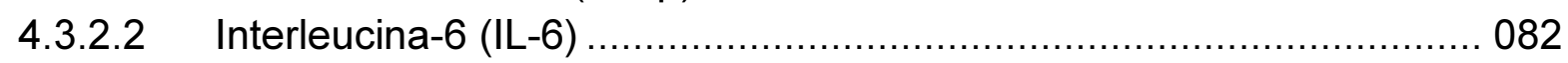

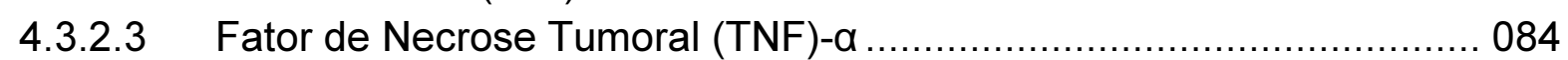

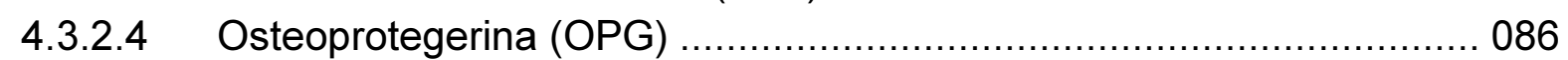

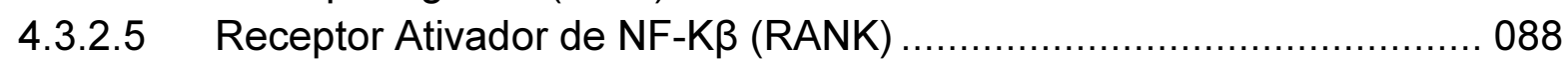

4.3.2.6 Ligante do Receptor Ativador de NF-KB (RANKL) ........................... 090

4.3.2.7 Fator de Crescimento Vascular Endotelial (VEGF) ......................... 092

4.3.2.8 Receptor 1 do Fator de Crescimento Vascular Endotelial

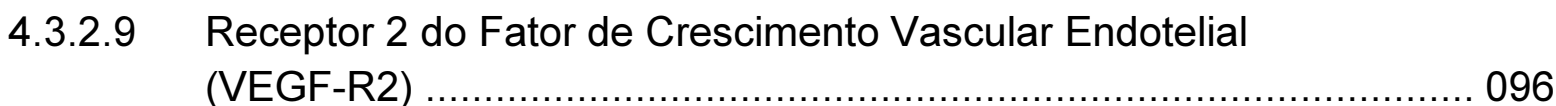

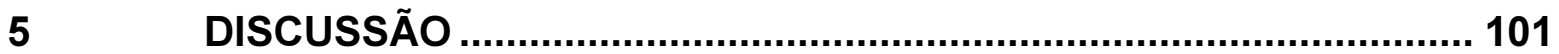

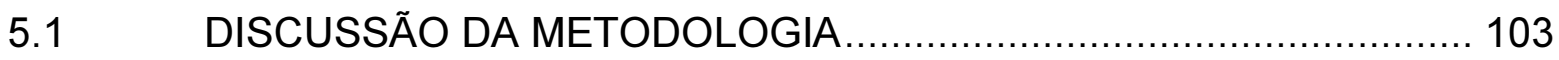

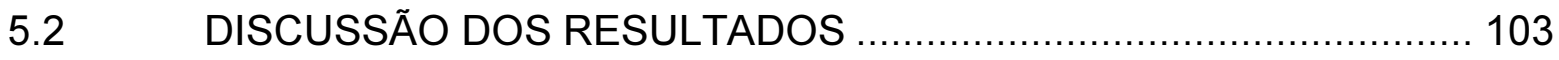

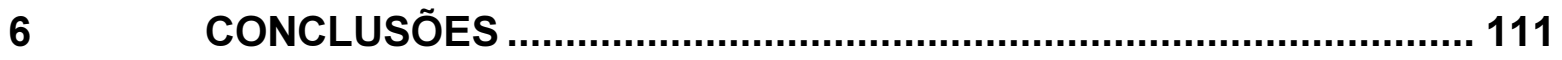

REFERÊNCIAS ...................................................................... 117 

17 utroducãa 



\section{INTRODUÇÃO E SÍNTESE BIBLIOGRÁFICA}

\subsection{Doença Periodontal (DP)}

A doença periodontal corresponde a um grupo de doenças inflamatórias que resultam na destruição das estruturas de suporte dental. São doenças infecciosas e possuem etiologia relacionada a microrganismos gram-negativos podendo manifestar-se de inúmeras maneiras. Estes possuem uma variedade de fatores que permitem $\mathrm{o}$ aumento de sua virulência e capacidade de se multiplicarem e persistirem no periodonto (VAN DYKE; SERHAN, 2003).

Um dos principais motivos dos processos inflamatórios que afetam 0 periodonto é a placa dentobacteriana que se acumula sobre a superfície dentária, o que pode ocasionar inflamação e fibrose gengival, levando à destruição do ligamento periodontal e perda do tecido ósseo alveolar. Conforme a doença progride, os tecidos moles separam-se do tecido ósseo, o que resulta na formação de lesão característica: a bolsa periodontal (WILSON, 1995; VAN DYKE; SERHAN, 2003).

\subsubsection{Sistema Renina-Angiotensina (SRA)}

O sistema renina-angiotensina (SRA) corresponde a um sistema biológico que está fortemente relacionado ao controle do volume de líquido extracelular e da pressão arterial. Composto por inúmeros peptídeos, este sistema está relacionado fortemente aos processos inflamatórios, pois atua de modo a reverter a tendência à hipotensão arterial por meio da indução de vasoconstricção arteriolar periférica (PAUL; MEHR; KREUTZ, 2006).

São conhecidos dois diferentes tipos de sistemas renina-angiotensina: o circulante que promove a liberação de angiotensina (Ang) II, a qual exerce seus efeitos pela interação com receptores específicos (PEACH, 1977; LEUNG, 2004; PAUL; MEHR; KREUTZ, 2006), descrito há bastante tempo, e o local, descrito mais 
recentemente e que parece desempenhar papel importante na homeostase circulatória (PAUL; MEHR; KREUTZ, 2006).

Um dos componentes do sistema a Ang II é gerada pela ação da renina, enzima produzida nos rins, sobre o angiotensinogênio plasmático, que é produzido no fígado, formando o decapeptídeo inativo Ang I, presente em abundância no endotélio pulmonar, liberando o octapeptídeo ativo Ang II.

A Figura 1 demonstra os componentes que atuam no sistema reninaangiotensina que foram descritos acima e outros que serão descritos a seguir.

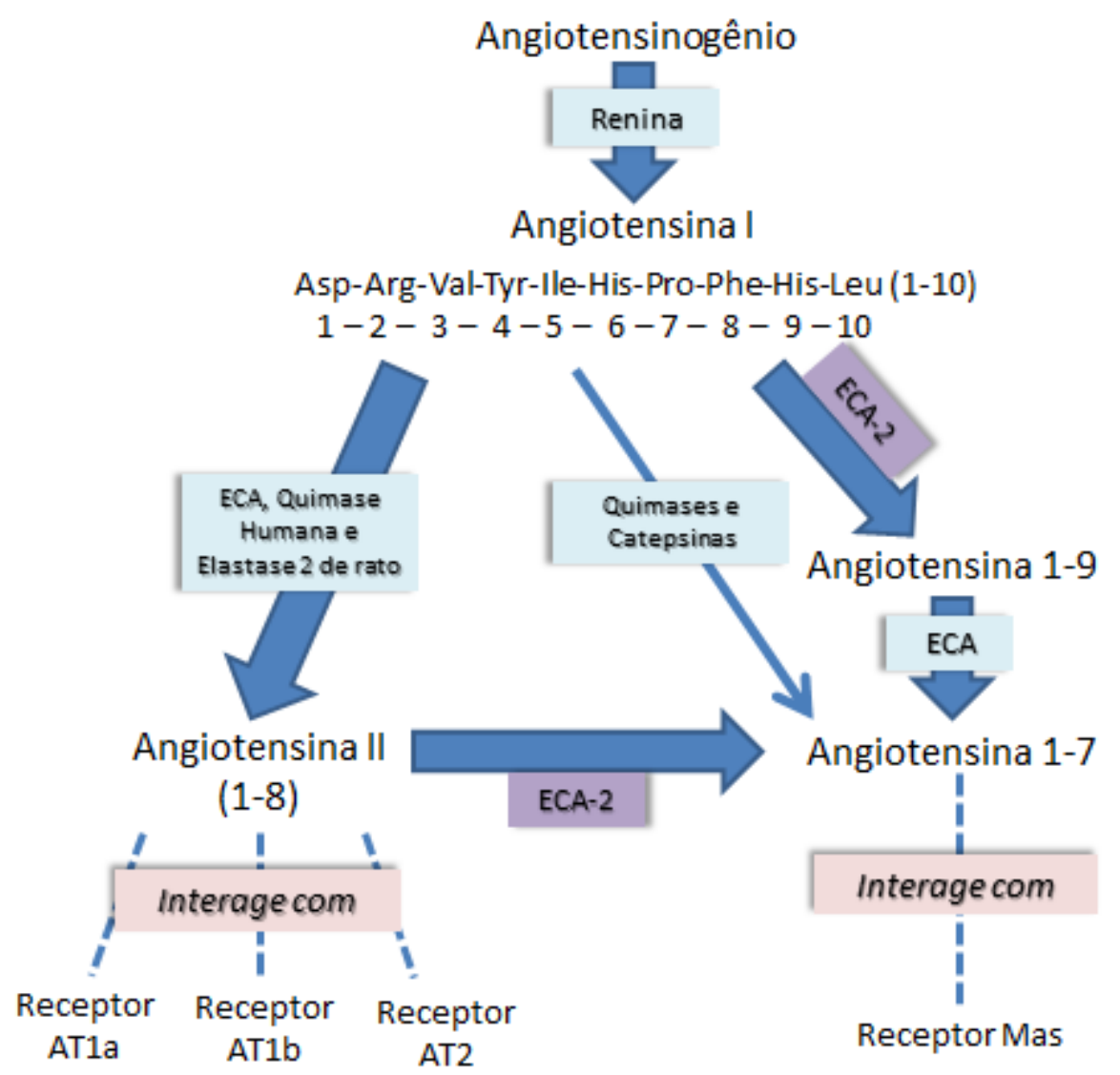

Figura 1 - Principais componentes do sistema renina-angiotensina. 


\subsubsection{Angiotensinogênio (AGT)}

O angiotensinogênio trata-se de uma proteína alfa 2 globulina de 452 aminoácidos que é sintetizado no fígado. O RNAm que codifica essa proteína é abundante principalmente no tecido adiposo, em algumas regiões do Sistema Nervoso Central (SNC) e nos rins (CAMPBELL; HABENER, 1986; CASSIS; SAVE; $\mathrm{PEACH}, 1988)$. Inúmeros hormônios e a própria Ang II estimulam a síntese de AGT (GARRISON, 1988).

\subsubsection{Renina}

A renina é uma glicoproteína, atua como enzima e possui 340 aminoácidos. Permanece armazenada sob a forma inativa (pró-renina) nas células justaglomerulares renais, localizadas nas paredes das arteríolas aferentes (OLIVEIRA et al. 1999). Atua clivando o AGT em Ang I (Figura 2).

A diminuição do fluxo sanguíneo relacionada a uma diminuição do sódio estimula a clivagem da pró-renina em renina.

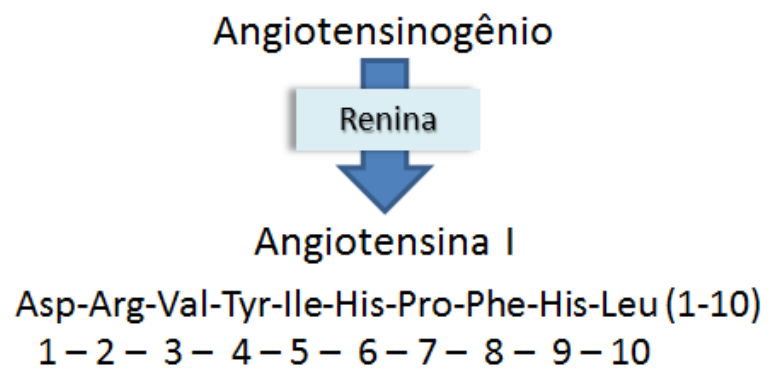

Figura 2 - Renina é uma glicoproteína que atua clivando o angiotensinogênio, transformando-o em um decapeptídeo, a angiotensina I. 


\subsubsection{Enzima Conversora de Angiotensina (ECA)}

A ECA é uma enzima que atua clivando Ang 1-9 em Ang 1-7 e Ang I em Ang II (Figura 3). É composta por 1.278 resíduos de aminoácidos e possui 2 domínios homólogos, cada um com um local catalítico e com uma região de ligação do zinco (SOUBRIER et al., 1988; BERNSTEIN et al., 1989).
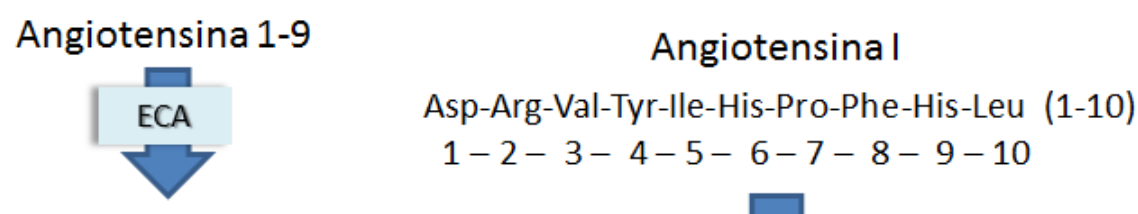

Angiotensina 1-7

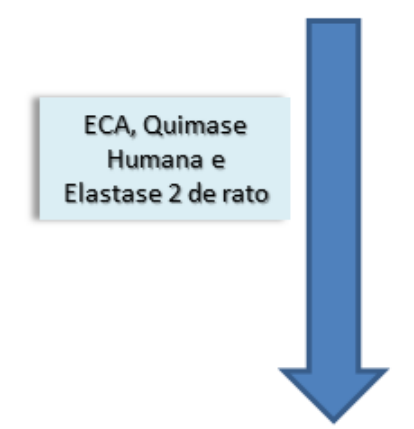

Angiotensina II

(1-8)

Figura 3 - O esquema mostra os locais de atuação da ECA no sistema reninaangiotensina.

\subsubsection{Enzima Conversora de Angiotensina 2 (ECA-2)}

Esta enzima consiste em uma metaloprotease dependente de zinco com atividade de carboxipeptidase. Possui importante papel na conversão de Ang II em Ang 1-7 e Ang I em Ang 1-9 e vem sendo sugerida como um importante regulador das funções cardíacas e do desenvolvimento celular (PAUL; MEHR; KREUTZ, 2006). 

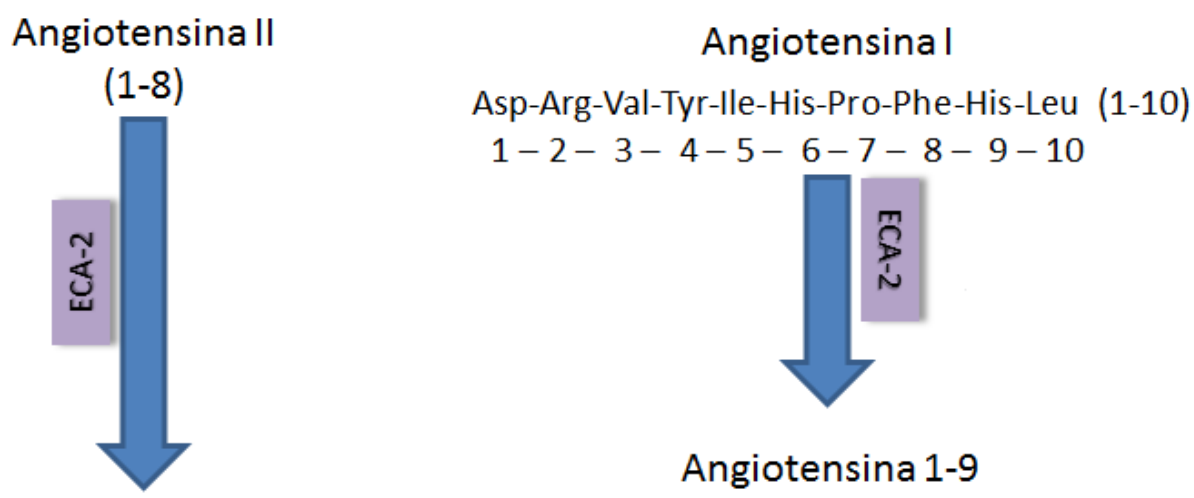

Angiotensina 1-7

Figura 4 - O esquema mostra os locais de atuação da ECA-2 no sistema renina-angiotensina.

\subsubsection{Angiotensina I}

Corresponde a um peptídeo de 10 aminoácidos (Asp-Arg-Val-Tyr-lle-His-ProPhe-His-Leu), porém diferente da Ang II não possui propriedades vasoconstritoras, ou seja, não produz alterações funcionais significativas na função circulatória, atuando, portanto, apenas como um substrato na formação da Ang II e Ang 1-9 (PAUL; MEHR; KREUTZ, 2006, KRAMKOWSKI; MOGIELNICKI; BUCZKO, 2006).

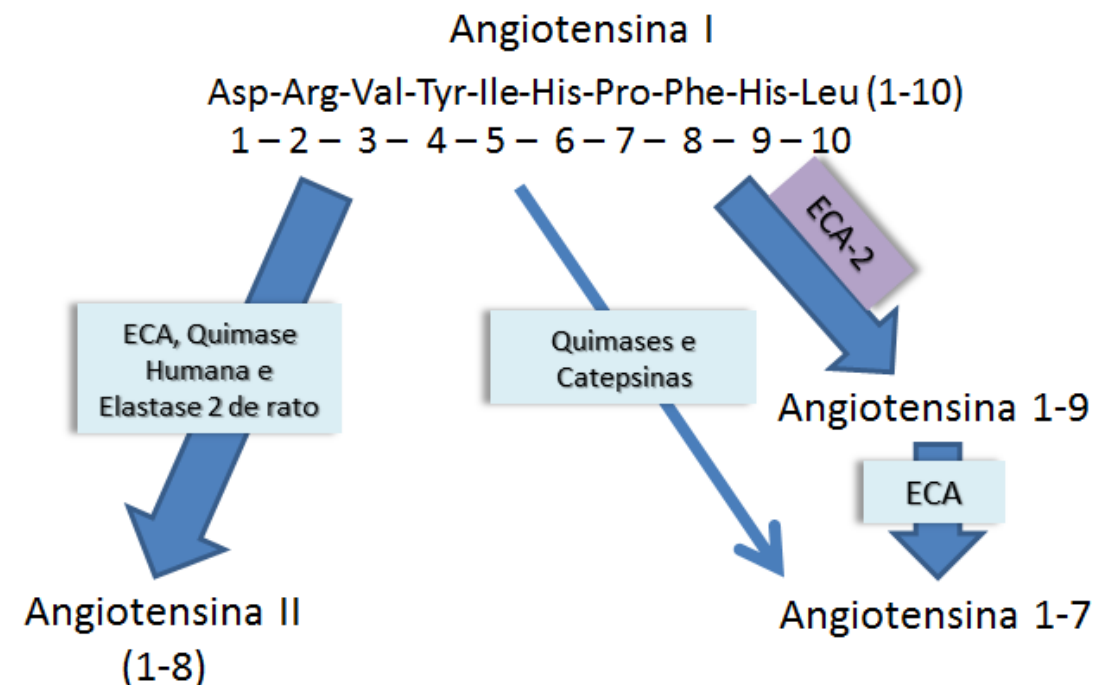

Figura 5 - Clivagem da Angiotensina I em outros peptídeos. 


\subsubsection{Angiotensina II}

A Ang II é o principal peptídeo do SRA (octapeptídeo: Asp-Arg-Val-Tyr-Ile-HisPro-Phe) formado após a clivagem da Ang I (Figura 6) e possui diversos efeitos, incluindo o controle da pressão arterial, homeostase hídrica e eletrolítica, além da regulação do crescimento celular (CASSIS et al, 1996, PAUL; MEHR; KREUTZ, 2006).

Possui importante papel na vasoconstrição e estimulação da secreção de aldosterona, e também ação inotrópica e cronotrópica positiva sobre o coração $(\mathrm{PEACH}, 1977)$. Está relacionada também à mitogênese de fibroblastos na pele, síntese de DNA por células do ligamento periodontal, regulação da formação de tecido ósseo, crescimento celular, secreção hormonal, ações pró-fibrogenéticas, tônus vascular e indução da liberação de prostaglandina $E_{2}\left(P E_{2}\right)$ em fibroblastos gengivais humanos (NICKENIG et al., 1997; LUNDERGAN et al., 1999; HIRUMA et al., 1997; HAGIWARA et al., 1998; LAMPARTER et al., 1998; LEUNG, 2004; SEGAWA et al., 2003; PAUL; MEHR; KREUTZ, 2006).

A Ang II é também um estimulador específico de células mesangiais renais, levando à proliferação e/ou apoptose das células (LODHA S, DANI D, MEHTA R et al., 2002; EFRATI S, BERMAN S, GOLDFINGER N et al., 2007).

Sabe-se que a Ang II pode ser formada a partir da ação da ECA, assim como por outras vias, tais como quimase humana (URATA et al., 1990b) e elastase-2 de rato (PAULA et al., 1998; SANTOS CF et al., 2002a; SANTOS CF et al., 2002b; SANTOS CF et al.; 2003; SANTOS CF et al., 2004), como ilustra figura a seguir. 


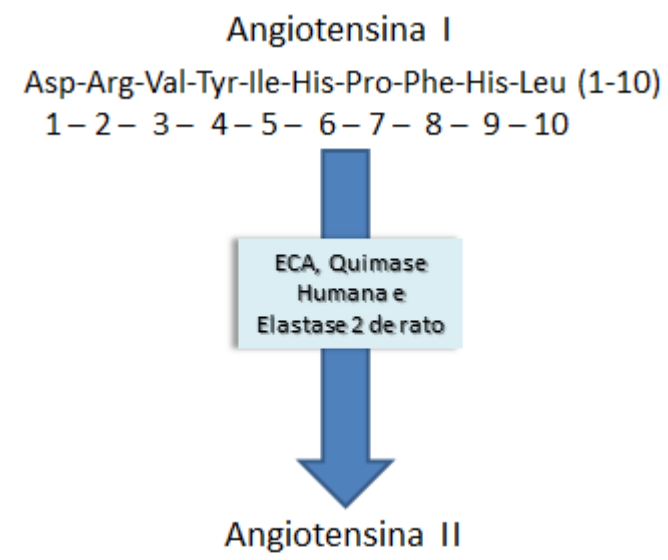

(1-8)

Figura 6 - Formação da Angiotensina II após clivagem da Angiotensina I.

As primeiras descrições de uma via alternativa de formação de Ang II foram relatadas por Boucher, Asselin e Genest (1974) nas glândulas submandibulares de rato, por Cornish, Joyner e Gilmore (1979) na bochecha de hamster e por Trachte e Lefer (1979) no músculo papilar cardíaco de gato. Cornish, Joyner e Gilmore (1979) também observaram a formação de Ang II de forma independente da ECA na artéria coronária de hamster. Okunishi, Miyazaki e Toda (1984) identificaram uma enzima geradora de Ang II sensível à quimostatina na artéria mesentérica de cão, a qual também é insensível a inibidores da ECA (como por exemplo o captopril). A atividade formadora de Ang II dependente da ação da ECA que é responsável somente por aproximadamente $11 \%$ da formação total de Ang II (URATA et al., 1990a). Esta serino-protease cardíaca foi posteriormente purificada e identificada como um novo membro da família quimase e, desde então, denominada de quimase do coração humano (URATA et al., 1990b).

\subsubsection{Angiotensina 1-7}

A Ang 1-7 corresponde a um componente bioativo do SRA. É um heptapeptídeo (Asp-Arg-Val-Tyr-Ile-His-Pro) formado a partir de Ang I (Figura 7) por ação de endopeptidases neutras, ou seja, por uma via independente da ECA (SANTOS et al., 1988; SANTOS; COMPAGNOLE-SANTOS, 1994). Pode ser formada também a partir da clivagem da Ang II pela ação da ECA-2 (RAIZADA; 
FERREIRA, 2007) ou da Ang 1-9 pela ação da ECA (CHEN et al., 2005). Possui ações opostas às da Ang II, como ações antiproliferativas e efeitos vasodilatadores. A Ang 1-7 pode regular a pressão sanguínea, a função cardíaca e o crescimento celular, podendo ser alvo importante no tratamento de doenças cardiovasculares, câncer e doença renal (TRASK; FERRARIO, 2007).

Angiotensinogênio

Renina

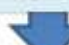

Angiotensina I

Asp-Arg-Val-Tyr-Ile-His-Pro-Phe-His-Leu (1-10)

$1-2-3-4-5-6-7-8-9-10$

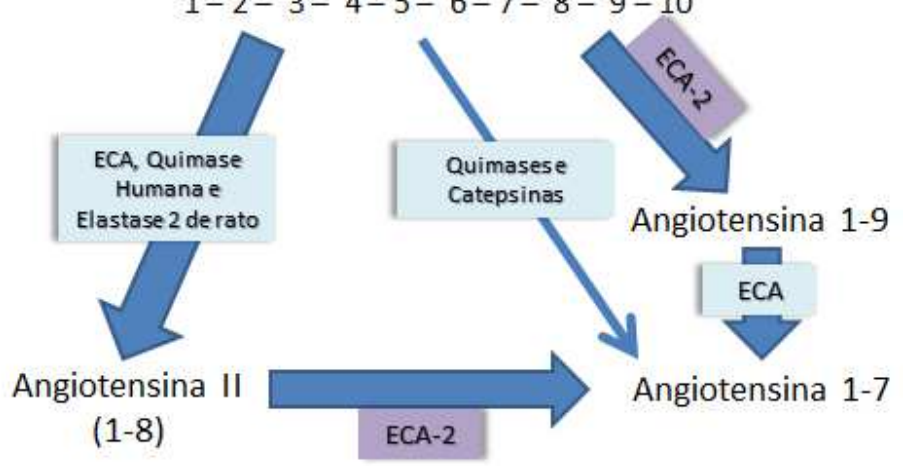

Figura 7- Formação da Angiotensina 1-7 a partir da clivagem da Angiotensina I, Angiotensina II ou Angiotensina 1-9.

\subsubsection{Angiotensina 1-9}

A Ang 1-9 (Asp-Arg-Val-Tyr-lle-His-Pro-Phe-His) é formada a partir da ação da ECA-2, que atua clivando a angiotensina I (Figura 8). Possui pouca atividade biológica (KRAMKOWISKI; MOGIELNICKI; BUCZKO, 2006). Quando clivada pela ECA libera Ang 1-7. Pode ser novamente clivada novamente, liberando o dipeptídeo C-terminal e formar a Ang 1-5 (Asp-Arg-Val-Tyr-Ile) (CHEN et al., 2005). Em altas concentrações, Ang 1-9 pode inibir a ECA (SNYDER; WINTROUB, 1986; MARCIC et al., 1999) e consequentemente potencializar a ação da bradicinina em seu receptor B2 (MARCIC et al., 1999). 


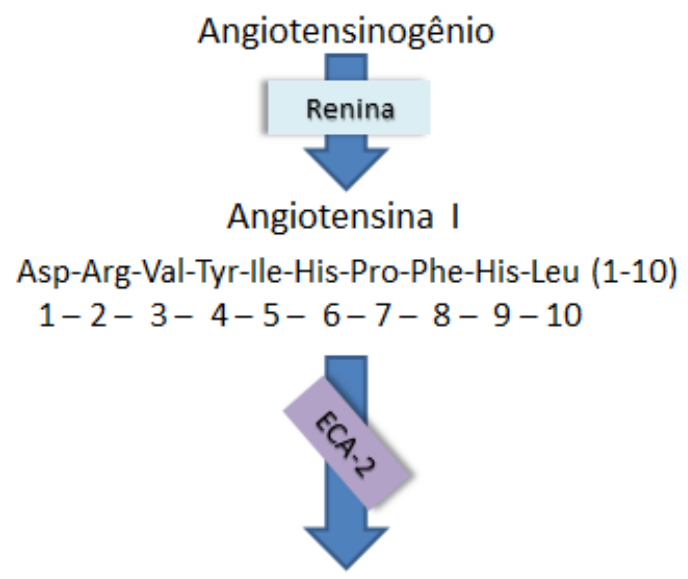

Angiotensina 1-9

Figura 8 - Formação da Angiotensina 1-9 a partir da ação da ECA-2, que atua clivando a Angiotensina I.

\subsubsection{Receptores da Angiotensina}

A ação da Ang II está relacionada ao receptor que irá se ligar. Existem quatro subtipos de receptores descritos, são eles: AT1, AT2, AT3 e AT4 (WRIGHT; HARDING, 1994), sendo que a Ang II liga-se preferencialmente aos receptores AT1 e AT2 (MALLOW, TRINDL e LOFFLER, 2000) (Figura 9). O receptor AT1 é um membro da família de receptores ligados à proteína $G$, possui 7 regiões transmembrânicas com 359 aminoácidos, é um mediador da angiogênese e possui propriedades vasoconstritoras. O receptor AT2 tem 363 aminoácidos e possui propriedade vasodilatadora, inibindo, assim, a angiogênese, portanto o receptor AT2 é caracterizado por apresentar efeitos contrários aos efeitos associados ao receptor AT1.

Têm sido demonstrados efeitos anti-inflamatório, antifibrose, antiapoptose e regeneração neuronal, associados aos receptores AT2, o que pode contrabalançar processos patológicos e permitir a recuperação de doenças (NAMSOLLECK P et al., 2014). 
Em tecidos saudáveis, o receptor AT2 é pouco expresso (NAMSOLLECK et al., 2014; STECKELINGS UM, ROMPE F, KASCHINA E, NAMSOLLECK P, GRZESIAK A, FUNKE-KAISER H, et al., 2010).

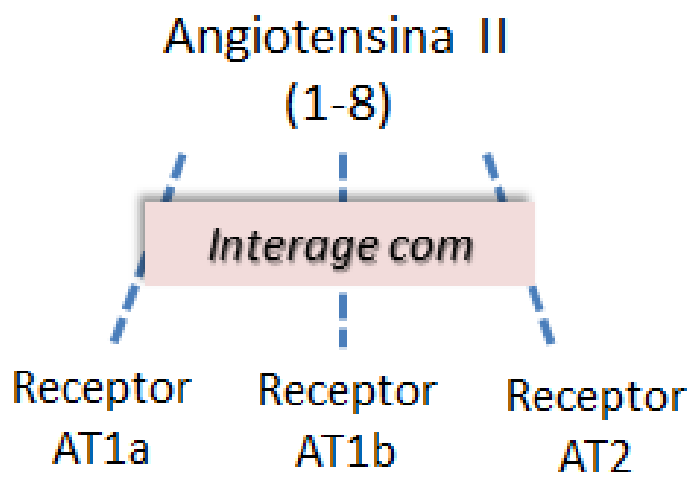

Figura 9 - Receptores que interagem com a Angiotensina II.

\subsubsection{Receptor MAS}

O receptor MAS interage com a Ang 1-7 (Figura 10) (PAUL; MEHR; KREUTZ, 2006), sendo caracterizado por apresentar efeitos semelhantes aos do receptor AT2, porém contrários aos efeitos associados ao receptor AT1. Tem sido demonstrado com relação aos receptores MAS, assim como os receptores AT2, efeitos antiinflamatório, antifibrose, antiapoptose e regeneração neuronal (NAMSOLLECK et al., 2014). É caracterizado como um receptor acoplado à proteína $G$, e originalmente foi descrito como um fator envolvido na tumorogênese (PAUL; MEHR; KREUTZ, 2006).

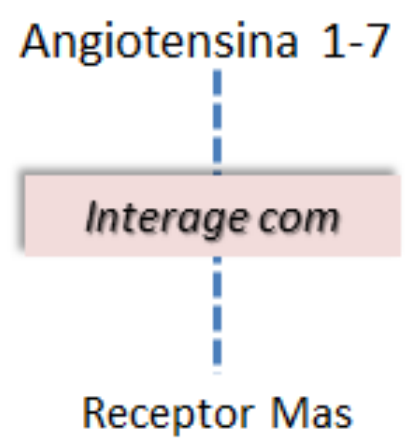

Figura 10 - Receptor MAS interage com a Angiotensina 1-7. 


\subsection{Outros alvos que atuam na inflamação}

\subsubsection{Ciclooxigenase 2}

A COX-2, que é uma enzima responsável pela formação de prostaglandina $E_{2}$ a partir do ácido araquidônico, regula a angiogênese, é expressa constitutivamente no corno dorsal do cordão espinhal e é mais expressa no processo inflamatório. Evidências sugerem que a expressão da COX-2 pode facilitar a transmissão de impulsos nociceptivos (RAMER; BRUNE, 2001).

Evidências mostraram que a COX-2 pode ter um papel fisiológico nas funções renais. A COX-2 constitutiva foi mostrada em rins de ratos, particularmente na mácula densa e tornou-se aumentada em ratos com dietas com restrição de sódio. $A$ COX-2 endotelial confere vasoproteção e ação antiaterogênica graças a seu maior produto, a prostaciclina $\left(\mathrm{PGI}_{2}\right)$, que é um potente vasodilatador e inibidor da agregação plaquetária (RAMER; BRUNE, 2001).

\subsubsection{Interleucina-1 beta (IL-1 $\beta$ )}

A IL-1 é uma das formas moleculares de IL-1, produzida por praticamente todos os tipos celulares nucleados, principalmente monócitos, macrófagos e células dendríticas, e está entre os mais importantes marcadores de indução da resposta inflamatória (FERRERO-MILIANI et al., 2006). Estudos têm demonstrado que monócitos e macrófagos são ativados como resposta a um processo inflamatório e com isso liberam várias citocinas pró-inflamatórias, incluindo a IL-1 1 , e também 0 fator de necrose tumoral TNF- $\alpha$, que por sua vez, irão atuar em novos processos destrutivos diretos (GIANNOBILE, 2008).

As funções biológicas da IL-1 $\beta$ são muito similares às do TNF- $\alpha$. A IL-1 $\beta$ induz a liberação de mediadores secundários, do mesmo modo que um número de citocinas inflamatórias, metabólitos do ácido araquidônico e óxido nítrico (MONTÓN et al., 1998). 


\subsubsection{Interleucina-6 (IL-6)}

A IL-6 é uma citocina pleiotrópica, que regula as respostas imunes e inflamatórias. Embora a IL-6 tem sido relatada como sendo um regulador principal de proteínas de fase aguda da inflamação (MACKIEWICZ, 1997; KWAN et al., 2004), outras citocinas, tais como IL-1 e TNF-a também participam da indução de um largo subconjunto de proteínas durante o processo inflamatório (MACKIEWICZ, 1997). Além disso, a IL-6 pode promover indiretamente a osteoclastogênese, por meio do aumento da liberação de RANKL derivada de osteoblastos e de células sinoviais (TAGA; KISHIMOTO, 1997). A partir de estudos extensivos, tanto sobre IL1 como IL-6, durante as últimas duas décadas, sugere-se uma participação destas citocinas em lesões inflamatórias, especialmente a periodontite (SIPE, 1995; MACKIEWICZ, 1997; TAGA; KISHIMOTO, 1997; KWAN et al., 2004; BARKSBY et al., 2007).

\subsubsection{Fator de Necrose Tumoral $\alpha$ (TNF- $\alpha)$}

O TNF- $\alpha$ é uma citocina, que atua na necrose hemorrágica do tecido e possui efeito antitumoral. É considerada uma das principais citocinas envolvidas na progressão da inflamação na doença periodontal, auxilia na destruição do tecido e na perda óssea decorrente da doença (BOSTRÖM; LINDER; BERGSTRÖM, 1998). É produzida por monócitos e macrófagos em resposta a componentes bacterianos orais, tais como lipopolissacarídeos (LPS) (BROOK, 2006; KURIYAMA et al., 2006). Quando os níveis de TNF- $\alpha$ aumentam no tecido, pode ocorrer a liberação da colagenase de fibroblastos gengivais humanos (OKADA; MURAKAMI, 1998), levando à destruição de colágeno e reabsorção óssea (BOSTRÖM; LINDER; BERGSTRÖM, 1998). 


\subsubsection{Osteoprotegerina (OPG)}

OPG é um antagonista dos efeitos de RANKL, atuando, portanto, na preservação da integridade óssea. Sendo assim, a expressão de RANKL e OPG é determinante para regular a atividade osteoclástica e reabsorção óssea (UDAGAWA, 1999; SUDA, 1999). Também tem sido sugerido que as citocinas e hormônios relacionados ao processo de reabsorção óssea e antirreabsorção convergem no sistema RANKL-OPG. RANKL e OPG, então, atuam como um sistema efetor para regulação da formação osteoclástica. OPG protege o esqueleto da reabsorção óssea excessiva (UDAGAWA, 1999; SUDA, 1999).

\subsubsection{Receptor Ativador de NF-kB (RANK)}

RANK é uma proteína de membrana do tipo I que se expressa na superfície de osteoclastos e em células dendríticas facilitando a sinalização imunológica, associado ao processo de reabsorção óssea. RANK e OPG são as moléculas-chave na regulação da diferenciação dos osteoclastos (BAUD'HUIN et al., 2007; KIM et al., 2007; NARDUCCli et al., 2009; DUARTE et al., 2009; ARIKAN et al., 2009). Quando RANKL liga-se ao RANK, induz diferenciação das células precursoras de osteoclastos (LACEY et al., 1998) e reabsorção óssea periodontal.

\subsubsection{Ligante do Receptor Ativador de NF-k $\beta$ (RANKL)}

RANKL é expresso na membrana de células do estroma da medula óssea (osteoblastos imaturos), sua principal função é estimular a diferenciação dos osteoclastos e inibir a apoptose dos mesmos. Pode ser libertado da superfície celular por clivagem proteolítica e ligar-se ao RANK ou à OPG. A OPG, por sua vez, é formada pelos osteoblastos quando estes reagem com citocinas (ANDERSON et al., 1997; WONG et al., 1997; YASUDA et al., 1998; IKEDA et al., 2004; VALLÉS et al., 2008). 
A razão existente entre RANKL e OPG, é considerado um parâmetro importante para o controle da reabsorção óssea. A razão da expressão de RANKL e OPG tem um papel importante no controle dos graus de reabsorção ou densidade óssea uma vez que a OPG bloqueia a interação entre RANK e RANKL. O RANKL é considerado um estimulador poderoso da reabsorção óssea ao ligar-se ao RANK, tendo um papel oposto quando liga-se à OPG (MONOV et al., 2006; BAUD'HUIN et al., 2007; KIM et al., 2007; NARDUCCI; NICOLIN 2009; DUARTE et al., 2009; ARIKAN et al., 2009; MINE et al., 2010).

\subsubsection{Fator de Crescimento Vascular Endotelial (VEGF)}

VEGF é uma macromolécula de importância na inflamação por atuar na angiogênese e tem sido implicada na progressão da periodontite (FERRARA; GERBER; LECOURTER, 2003). É uma das substâncias mais potentes para induzir o crescimento de células endoteliais e aumenta a permeabilidade vascular (FERRARA, 1999; FERRARA, 2005). VEGF induz a proliferação de células endoteliais, promove a migração de células e inibe a apoptose, bem como a permeabilidade dos vasos sanguíneos, desempenhando, assim, um papel central na regulação da angiogênese (FERRARA; GERBER; LECOURTER, 2003). A expressão do VEGF é desencadeada em resposta à hipóxia e por uma variedade de citocinas. A expressão do VEGF desregulada contribui para a etiologia de várias doenças que são caracterizadas por angiogênese anormal. (OLIVEIRA et al., 2008).

\subsubsection{Receptor 1 e 2 do Fator de Crescimento Vascular Endotelial (VEGF-R1 e VEGF-R2)}

Tanto o VEGF quanto seus receptores (VEGF-R1 e VEGF-R2) são peçaschave na angiogênese e também estão envolvidos em certos processo patológicos, tais como a periodontite e a perda óssea proporcionada por estas. A angiogênese é crítica para a progressão da doença periodontal e a reabsorção óssea é uma característica da periodontite. No entanto, a sua localização (VEGF e VEGF-R), suas vias de sinalização em periodontite apical humana ainda não foram totalmente elucidadas (VIRTEJ et al., 2013). 


\subsection{Captopril}

O captopril é inibidor da ECA. Sua principal indicação é para tratamento de hipertensão arterial e alguns casos de insuficiência cardíaca. Porém, há evidências na literatura que demonstram que o captopril possui um efeito antiinflamatório e é, portanto, capaz de reduzir a progressão de doenças inflamatórias. llieva et al. (2006) testaram o captopril em ratos com uveíte induzida por endotoxina e nesse modelo experimental o captopril diminuiu a progressão da inflamação. Além do captopril, outros inibidores da ECA têm provado ser benéficos em encefalomielite autoimune induzida experimentalmente (CONSTANTINESCU et al. de 1995), miocardite (GODSEL et al., 2003), artrite adjuvante de Freund (AGHA; MANSOUR, 2000) e colite experimental (JAHOVICH et al., 2005). Além de efeitos antiinflamatórios, efeitos antitumoral, antifibrótico e citoprotetor do captopril também têm sido demonstrados (WILLIAMS et al, 2005.; REGAN et al, 1996.; MURLEY et al., 2004). Portanto, em trabalhos prévios ficou demonstrado claramente que o captopril foi capaz de atuar como regulador imunológico e anti-inflamatório.

Há amplas evidências que sugerem que a supressão dos componentes do SRA melhora o funcionamento renal, via redução da pressão intraglomerular, diminuição da proteinúria, e também inibe a inflamação intersticial e os efeitos fibróticos (EFRATI et al., 2012). 

2 Propasicãa 



\section{PROPOSIÇÃO}

O trabalho se propõe a investigar se $\mathrm{o}$ tratamento com captopril previamente $\mathrm{e}$ posteriormente à indução da doença periodontal é capaz de amenizar a progressão da perda óssea alveolar.

$\mathrm{Na}$ tentativa de explicar molecularmente os resultados obtidos, será investigada a expressão de RNAm para os componentes do SRA e proteínas inflamatórias. 

3 Material e Métodos 



\section{MATERIAL E MÉTODOS}

\subsection{Indução experimental de doença periodontal (DP) por meio da colocação de ligadura}

Para que ocorresse a manipulação dos animais desse trabalho, foi seguida a aprovação pelo Comitê de Ética em Pesquisa em Animais da FOB/USP (Processo $\mathrm{n}^{\circ}$ 014/2013).

Os animais foram provenientes do Biotério Central da Faculdade de Odontologia de Bauru (FOB/USP), local onde foram mantidos durante todo 0 protocolo experimental.

Todos os animais foram anestesiados utilizando Cloridrato de Ketamina e Cloridrato de Xilazina (Dopalen - $50 \mathrm{mg} / \mathrm{Kg}$ e Anasedan - 10 mg/kg, via intramuscular (ALMEIDA et al., 2007).

Após a anestesia, foi iniciado o processo de colocação de ligadura utilizando um fio de seda preta 3.0 (Ethicon), o qual foi colocado na região cervical do primeiro molar inferior direito, tomando-se o cuidado de penetrar o fio no sulco gengival. $\mathrm{O}$ fio foi colocado próximo aos tecidos gengivais e o nó posicionado na região mesial (GYÖRFI et al., 1994; LOHINAl et al., 1998).

Após o processo de indução, todos os ratos foram mantidos no biotério central da FOB/USP e alimentados com ração normal e água ad libitum.

As doses da droga foram ajustadas de acordo com a pesagem semanal dos animais, a fim de assegurar a dosagem correta, de acordo com a massa, para cada grupo experimental.

\subsection{Grupos Experimentais}

Neste trabalho, foram utilizados para a composição da amostra 90 ratos (Rattus norvegicus) Wistar, machos, com massa inicial de aproximadamente 250 gramas. Foram escolhidos ratos devido à facilidade de manuseio e o ciclo de vida relativamente curto. Portanto, com a idade aproximada de 60 dias, ratos já estão na 
fase adulta, e já possuem o ponto de contato entre molares bem estabelecido. Durante o crescimento deste animal ocorre naturalmente a remodelação óssea, um processo fisiológico e natural (WEINBERG, 1999), por isso o presente trabalho consistiu na análise comparativa principalmente da perda óssea alveolar, dados estes obtidos para animais tratados com veículo ou captopril com os animais não submetidos a nenhum tipo de tratamento e com a indução experimental da doença periodontal por meio de colocação de ligadura ao redor do primeiro molar inferior. Segue a descrição de cada um dos grupos.

GRUPO 1: 20 animais foram submetidos ao procedimento de indução de doença periodontal por ligadura com fio de sutura 3.0 (Ethicon) ao redor do primeiro molar inferior durante 14 dias. Durante esse período, 10 animais foram submetidos ao tratamento diário com $30 \mathrm{mg} / \mathrm{kg} / \mathrm{dia}$ de captopril via gavagem, enquanto 10 animais foram submetidos ao tratamento com volume correspondente de água (veículo). No décimo quinto dia todos foram eutanasiados.

\section{4 dias}

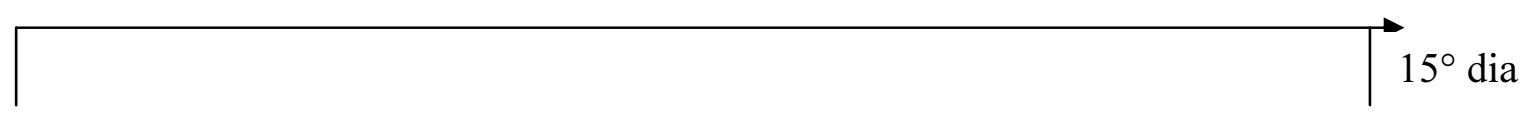

Indução da Doença

Periodontal

Eutanásia

GRUPO 2: 20 animais foram submetidos ao procedimento de indução de doença periodontal por ligadura com fio de sutura 3.0 (Ethicon) ao redor do primeiro molar inferior durante 21 dias. Durante esse período, 10 animais foram submetidos ao tratamento diário com $30 \mathrm{mg} / \mathrm{kg} / \mathrm{dia}$ de captopril via gavagem, enquanto 10 animais foram submetidos ao tratamento com volume correspondente de água (veículo). No vigésimo segundo dia todos foram eutanasiados.

21 dias

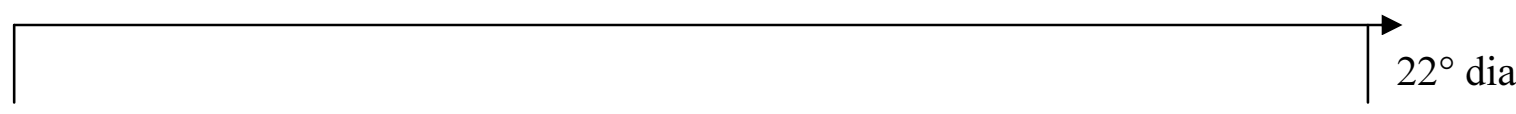

Indução da Doença

Eutanásia

Periodontal 
GRUPO 3: 10 animais foram submetidos ao pré-tratamento diário com $30 \mathrm{mg} / \mathrm{kg} / \mathrm{dia}$ de captopril via gavagem por 7 dias. No oitavo dia foram submetidos ao procedimento de indução de doença periodontal por ligadura com fio de sutura 3.0 (Ethicon), ao redor do primeiro molar inferior durante 14 dias e continuaram o tratamento com captopril. No décimo quinto dia após a indução da doença periodontal todos foram eutanasiados.

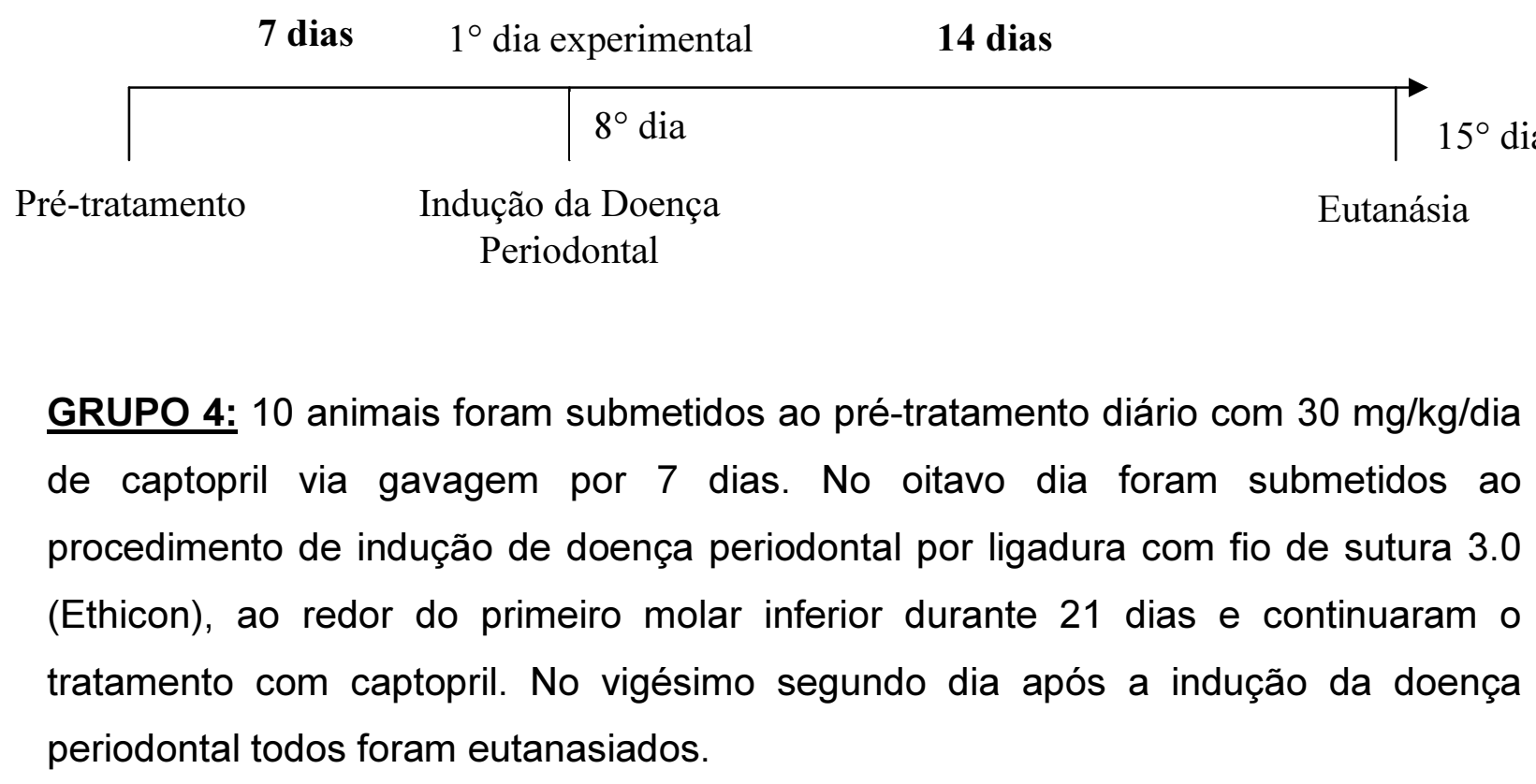

7 dias $\quad 1^{\circ}$ dia experimental $\quad 21$ dias

\begin{tabular}{l|l|l}
\hline & $8^{\circ}$ dia & dia
\end{tabular}

Pré-tratamento Indução da Doença

Periodontal

Eutanásia 
GRUPO 5: 10 animais foram submetidos ao pré-tratamento diário com $30 \mathrm{mg} / \mathrm{kg} / \mathrm{dia}$ de captopril via gavagem por 14 dias. No décimo quinto dia foram submetidos ao procedimento de indução de doença periodontal por ligadura com fio de sutura 3.0 (Ethicon), ao redor do primeiro molar inferior durante 14 dias e continuaram 0 tratamento com captopril. No décimo quinto dia após a indução da doença periodontal todos foram eutanasiados.

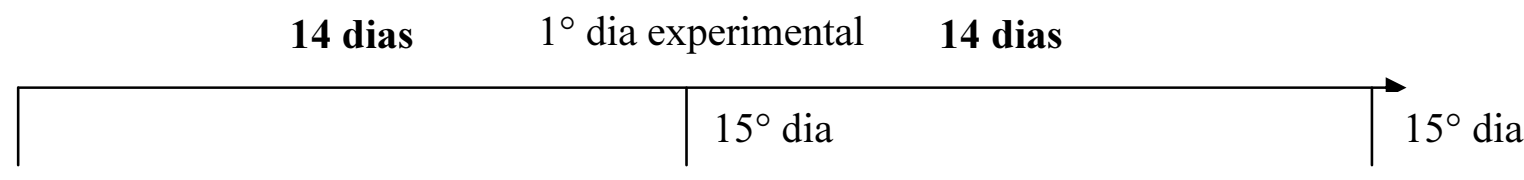

Pré-tratamento

Indução da Doença

Eutanásia

Periodontal

GRUPO 6: 10 animais foram submetidos ao pré-tratamento diário com $30 \mathrm{mg} / \mathrm{kg} / \mathrm{dia}$ de captopril via gavagem por 14 dias. No décimo quinto dia foram submetidos ao procedimento de indução de doença periodontal por ligadura com fio de sutura 3.0 (Ethicon), ao redor do primeiro molar inferior durante 21 dias e continuaram 0 tratamento com captopril. No vigésimo segundo dia após a indução da doença periodontal todos foram eutanasiados.

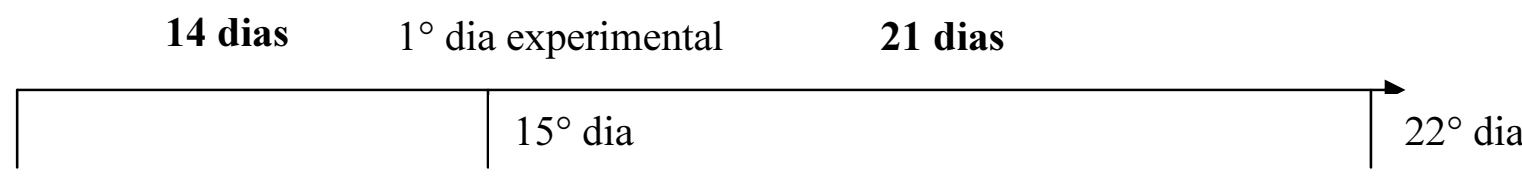

Pré-tratamento Indução da Doença

Eutanásia

Periodontal 
GRUPO 7: Grupo controle, no qual 10 animais foram submetidos à indução da doença periodontal fictícia (Grupo Sham). Durante este processo os animais foram anestesiados, submetidos a mesma situação de estresse que os animais que de fato foram induzidos, e um fio de sutura apenas foi passado ao redor do seu primeiro molar e em seguida retirado. Após, 5 animais foram eutanasiados após 14 dias e 5 após 21 dias de tratamento com veículo.

\section{4 dias}

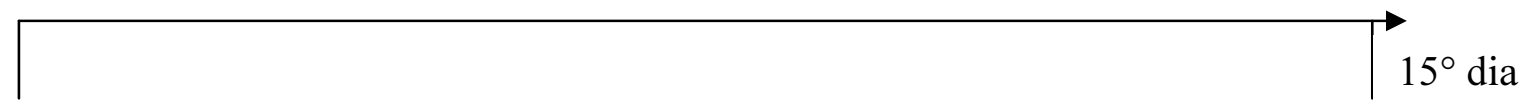

Indução da Doença

Eutanásia

Periodontal Fictícia

21 dias

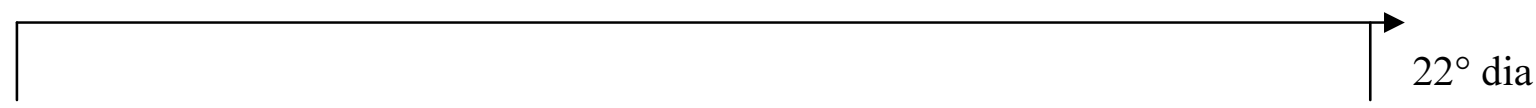

Indução da Doença

Eutanásia

Periodontal Fictícia 


\subsection{Obtenção de espécimes para os diferentes experimentos}

Os animais que foram tratados com captopril, com o veículo e os do grupo SHAM foram eutanasiados com dose excessiva de anestésico aplicado na veia peniana, esta foi escolhida por ser de fácil acesso e com rápida eficácia no procedimento de eutanásia (Figura 11).

Após a eutanásia, as hemimandíbulas foram removidas (Figura 12) e o material destinado à análise de perda óssea teve o tecido mole (gengiva) descolado e armazenado em solução de RNAlater $(A m b i o n \AA, C A$, Estados Unidos) e congelado a $-80^{\circ} \mathrm{C}$ para análises de expressão gênica por PCR.

As hemimandíbulas sem o tecido gengival foram devidamente higienizadas com auxílio de água oxigenada 10 volumes e em seguida coradas com azul de metileno 0,1\% (LIMA, 2011; MACIEL, 2013). Feito isso, as hemimandíbulas foram fotografadas e a área de perda óssea foi analisada com o uso do software DinoCapture 2.0 versão 1.4.5.B, criado pela Anmo Electronics Corporation (Taipei City, Taiwan, China). (Figura 13)

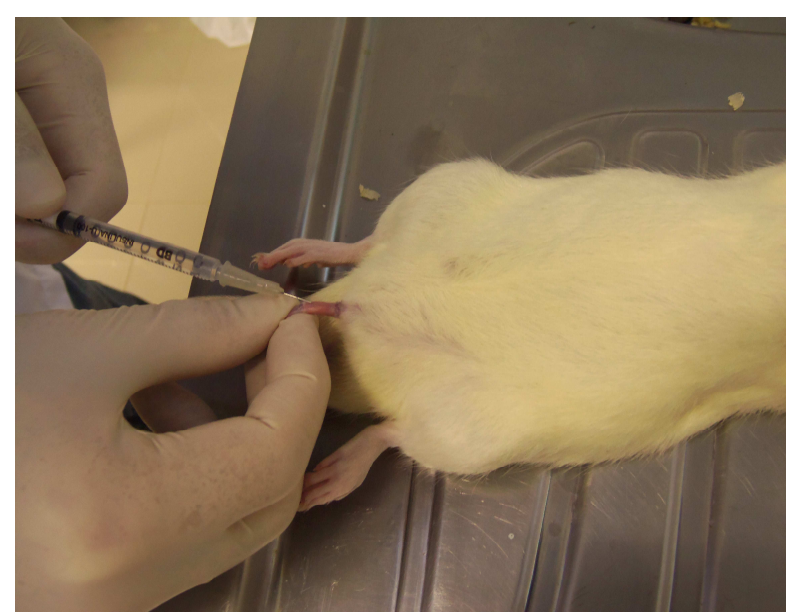

Figura 11 - Aplicação de anestésico na veia peniana (eutanásia).

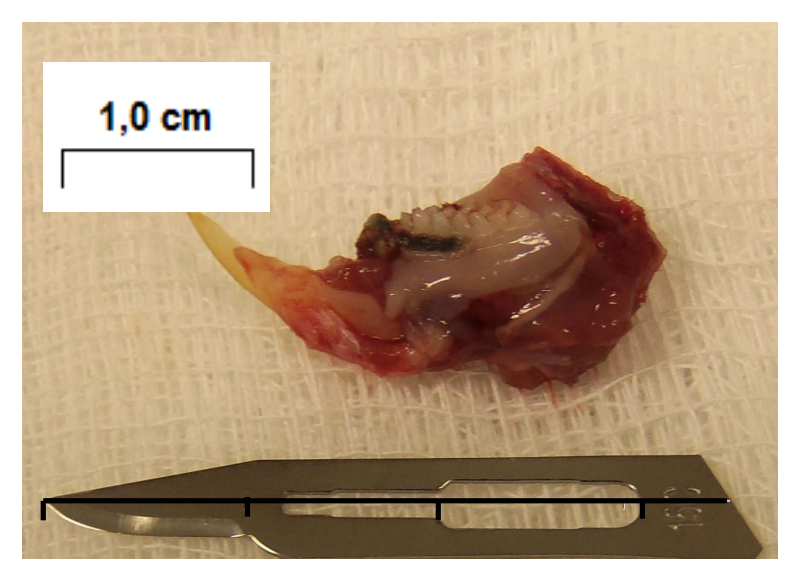

Figura 12 - Hemimandíbula de um dos animais, comparada ao tamanho da lâmina do bisturi. 


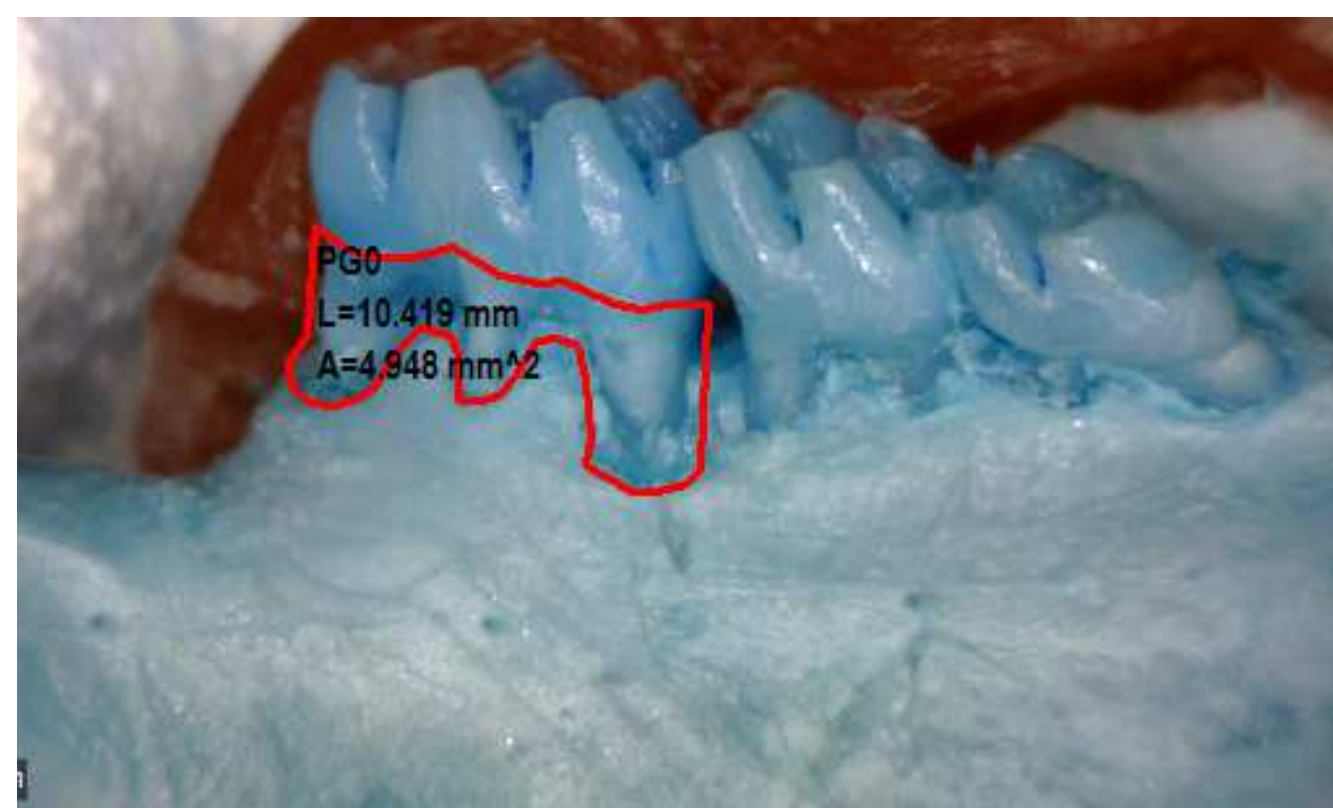

Figura 13 - Demonstração da área de perda óssea demarcada em uma hemimandíbula de rato tratado com captopril. Imagem analisada no software DinoCapture 2.0 versão 1.4.5.B. A área total $A$, refere-se a quantidade de osso perdido, a análise foi realizada na face lingual do animal.

Quando os animais foram eutanasiados foram removidas as hemimandíbulas e separadas da seguinte forma: hemimandíbulas preservadas (tecido ósseo com gengiva), hemimandíbulas onde foi separada o tecido ósseo da gengiva (a gengiva foi armazenada em um tubo Eppendorf e o tecido ósseo em um tubo Falcon).

As hemimandíbulas preservadas foram utilizadas na confecção de lâminas para a análise histológica, o tecido mole foi submetido a extração de RNA e o tecido ósseo a análise de perda óssea.

O procedimento de análise de área de perda óssea foi realizado por 4 examinadores, reduzindo ao máximo o erro entre estes através da média das áreas obtidas dentre os analisadores. Foi utilizada a análise de perda óssea por área, pois em trabalhos prévios onde foi utilizada a análise por volume, observou-se uma maior chance de erro entre os examinadores, sendo a análise por área mais precisa.

Dos animais eutanasiados, foi removida apenas a hemimandíbula do lado que foi induzido, o outro lado foi descartado. Em estudos posteriores esta hemimandíbula do lado não induzido que foi descartada pode ser utilizado em via de comparação entre a hemimandíbula induzida e o lado com a hemimandíbula não 
induzida, para que se possa verificar as possíveis diferenças dentre as duas hemimandíbulas (com e sem o fio de sutura).

\subsection{Extração do RNA}

O isolamento do RNA total foi feito com o kit comercial RNAeasy Mini Kit (Qiagen巴, Alemanha) de acordo com as instruções do fabricante. Descrevendo brevemente, as amostras de gengiva foram descongeladas e transferidas para um tubo de microcentrífuga contendo a solução de lise do kit. Em seguida essas amostras foram homogeneizadas com o uso de um rotor e centrifugadas por 3 minutos em velocidade máxima, sendo o sobrenadante coletado e misturado com $350 \mu \mathrm{l}$ de álcool 70\%. Esta mistura foi então transferida para as colunas de sílica e novamente centrifugada por 15 segundos em velocidade máxima.

Os procedimentos supracitados permitiram que o RNA ficasse aderido a esta coluna de sílica, a qual foi lavada com três soluções distintas pertencentes ao kit para a remoção dos possíveis inibidores da reação de PCR. Ao final do protocolo, água livre de DNAse e RNAse foi adicionada à coluna para a eluição e recuperação do RNA purificado.

As amostras foram armazenadas em freezer $-80^{\circ} \mathrm{C}$ até o momento da transcrição reversa.

\subsection{Análise da Quantidade e Qualidade do RNA total}

Essa etapa teve por objetivo quantificar e verificar a qualidade do RNA extraído. O aparelho utilizado foi o espectrofotômetro Nanodrop 1000 (Thermo Scientific ${ }^{\circledR}$, Estados Unidos), o qual fornece os dados de absorbância em 230, 260 e 280 nanômetros após o carregamento de $2 \mu \mathrm{L}$ de amostra sem diluição. Este aparelho emite luz nos comprimentos de onda citados acima, e ao mesmo tempo detecta quanto dessa luz foi absorvida pela amostra. No caso do RNA, há a 
absorção da luz no comprimento de $260 \mathrm{~nm}$ e o cálculo utilizado para a quantificação desse DNA é:

[DNA] = Absorbância em 260 nm x fator de diluição x 40 (constante para o RNA).

De posse desses dados, o mesmo aparelho, indicou a quantidade e a qualidade do RNA, o qual foi usado no estudo. A qualidade é expressa de acordo com a razão entre as absorbâncias em 260 nm e 280 nm (A260/A280) e 260 nm e $230 \mathrm{~nm}(\mathrm{~A} 260 / \mathrm{A} 230)$ as quais devem estar entre 1,9 e 2,1.

\subsection{Tratamento do RNA total com DNAse e transcrição reversa}

Para evitar a possibilidade de contaminação por DNA genômico do RNA total extraído de diferentes tecidos e células, procedeu-se o tratamento de todas as amostras com DNAse (gDNA wipeout - Qiagen, Alemanha) durante 2 minutos a $42^{\circ} \mathrm{C}$ sendo este procedimento realizado segundo as orientações do fabricante. As amostras com $1 \mu \mathrm{g}$ de RNA total cada foram tratadas com DNAse e imediatamente submetidas ao processo de transcrição reversa com o kit Quantitect $囚$ Reverse Transcription (Qiagen).

Neste RNA tratado com DNAse foi adicionado uma mistura de $1 \mu \mathrm{L}$ dos primers randômicos e oligo dT, $1 \mu \mathrm{L}$ da transcriptase reversa e $4 \mu \mathrm{L}$ do tampão Quantscript RT. Esta mistura foi incubada a $42^{\circ} \mathrm{C}$ por $30 \mathrm{~min}$, seguido de outra incubação a $95^{\circ} \mathrm{C}$ por 3 min.

\subsection{Reação em Cadeia da Polimerase (PCR) quantitativa (qPCR)}

O protocolo qPCR foi realizado conforme padronização estabelecida por trabalhos prévios (MORANDINI et al., 2013; SIPERT et al., 2014). A expressão quantitativa dos componentes do SRA foi analisada por meio de reações de PCR em tempo real, utilizando-se o sistema Taqman (Applied Biosystems, Foster City, USA) em um aparelho Viia 7 (Applied Biosystems, Foster City, Estados Unidos da 
América). Os primers utilizados (Applied Biosystems) para tais reações são apresentados na Tabela 1. Esse sistema realiza as reações de amplificação e deteç̧ão e quantifica as amostras (Viia 7 Software versão 1.1) por meio de nucleases fluorogênicas utilizadas na reação, sendo tal expressão normalizada com base em controles. A expressão foi normalizada pelo RNAm de $\beta$-actina. O DNA complementar sintetizado a partir do RNA mensageiro foi utilizado juntamente com reagentes Taqman, como determinado pelo fabricante. A reação compreende 2 min a $50^{\circ} \mathrm{C}, 10 \mathrm{~min}$ a $95^{\circ} \mathrm{C}, 50$ ciclos de $15 \mathrm{~s}$ a $95^{\circ} \mathrm{C}$ e $1 \mathrm{~min}$ a $60^{\circ} \mathrm{C}$. 
Tabela 1 - Número de catálogo dos kits de PCR inventoriados (Applied Biosystems) utilizados nesta pesquisa.

\begin{tabular}{cc}
\hline Alvo & Número de Catálogo \\
\hline B-Actina & Rn00667869_m1 \\
AGT & Rn00593114_m1 \\
Renina & Rn00561847_m1 \\
AT1a & Rn02758772_s1 \\
AT1b & Rn02132799_s1 \\
AT2 & Rn00560677_s1 \\
ECA & Rn00561094_m1 \\
ECA-2 & Rn01416289_m1 \\
\hline Receptor MAS & Rn00562673_s1 \\
COX-2 & Rn01483828_m1 \\
IL-1 $\beta$ & Rn00580432_m1 \\
IL-6 & Rn01410330_m1 \\
TNF & Rn01525859_g1 \\
OPG & Rn00563499_m1 \\
RANK & Rn01426423_m1 \\
RANKL & Rn00589289_m1 \\
VEGF & Rn01511601_m1 \\
VEGF-R1 (Flt) & Rn00570815_m1 \\
VEGF-R2 (kdr) & Rn00564986_m1 \\
\hline
\end{tabular}

\subsection{Cálculos e análises estatísticas}

O programa estatístico GraphPad Prism 5, criado por GraphPad Software, Inc (Califórnia, Estados Unidos) foi utilizado para analisar os dados. Todos os resultados foram submetidos a uma análise unidirecional de variância (ANOVA) e representam médias de cinco animais por grupo experimental. Diferenças nos valores médios entre os grupos foram avaliadas considerando um $p<0,05$. Os resultados foram apresentados como média \pm desvio-padrão da média. 

4 Resultados 



\section{REULTADOS}

\subsection{Progressão da massa (Média entre os grupos)}

Durante o tratamento os ratos foram pesados semanalmente, para que as doses fossem ajustadas de acordo com o ganho de peso. Como demonstrado na figura 15. Não foi observada diferença estatisticamente significativa na evolução da massa corpórea entre os animais tratados e não tratados.

\section{Progressão da Massa dos Animais}

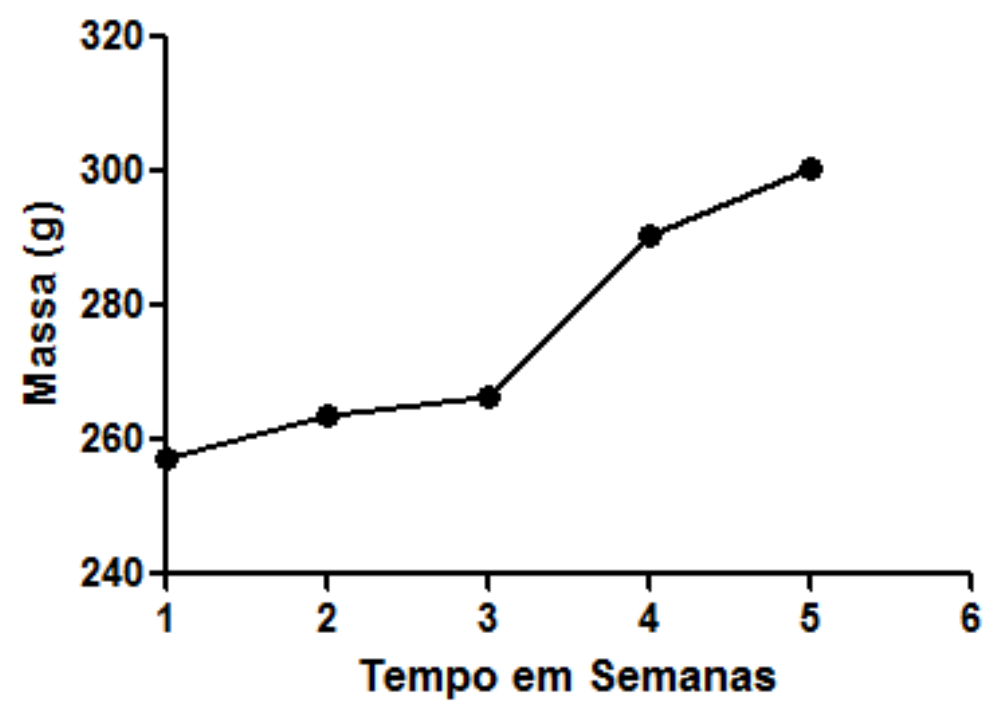

Figura 14 - Evolução da massa corporal dos animais ao longo das 6 semanas do período experimental. 


\subsection{Análise de perda óssea alveolar}

A perda óssea entre os animais com DP tratados com veículo e com captopril não apresentou diferença estatisticamente significativa. Porém, quando comparados aos animais Sham, todos os grupos apresentaram aumento de perda óssea.

Assim, quando comparados os grupos 1 a 6 tratados com captopril, a duração do tratamento não interferiu na progressão da perda óssea, sugerindo que a droga não foi capaz de diminuir a progressão da perda de volume ósseo alveolar nos animais com DP.

Entretanto, se comparados os grupos 1 a 6 , com o grupo 7 (SHAM), é possível constatar que a doença periodontal foi efetivamente instalada, ao passo que foi encontrada diferença estatisticamente significativa entre os animais tratados com captopril ou veículo (grupos 1 a 6) com o grupo submetido à indução fictícia (grupo 7). Sendo assim, tratamento com captopril não foi efetivo (Figuras 15 e 16).

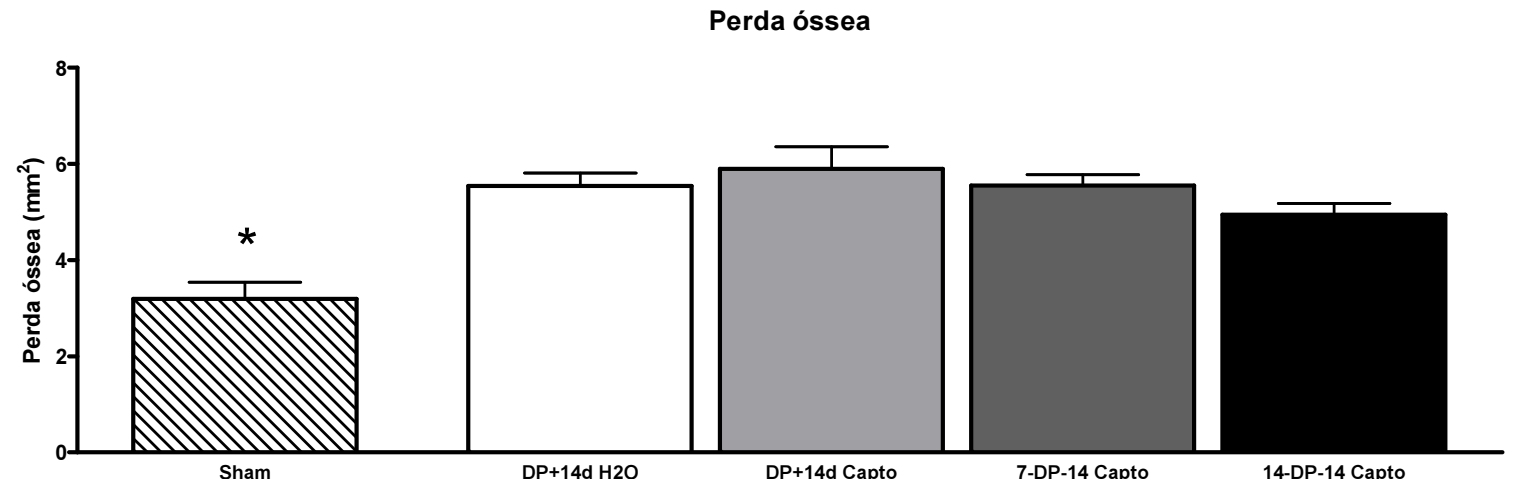

Figura 15 - Perdas ósseas em $\mathrm{mm}^{2}$ dos animais do grupo Sham $(\mathrm{n}=5$, submetidos à indução fictícia), do grupo DP-14 $\mathrm{H}_{2} \mathrm{O}$ ( $\mathrm{n}=5$, Tratados com veículo durante 14 dias após a indução), do grupo DP-14 Capto ( $n=5$, Tratados com captopril durante 14 dias após a indução), do grupo 7-DP-14 Capto ( $n=5$, tratados com captopril 7 dias antes da indução e 14 dias após a indução), do grupo 14-DP-14 Capto $(n=5$, tratados com captopril 14 dias antes da indução e 14 dias após a indução). * $p<0,05$ em relação a todos os demais grupos. 
Perda óssea

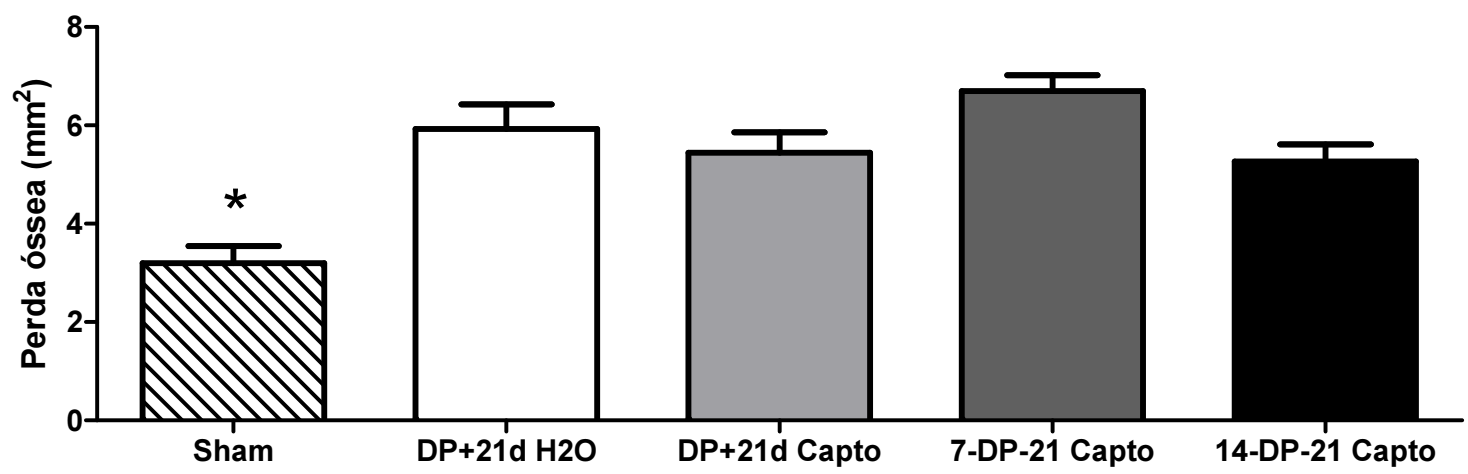

Figura 16 - Perdas ósseas em $\mathrm{mm}^{2}$ dos animais do grupo Sham $(\mathrm{n}=5$, submetidos à indução fictícia), do grupo DP-21 $\mathrm{H}_{2} \mathrm{O}(\mathrm{n}=5$, tratados com veículo 21 dias após a indução), do grupo DP-21 Capto ( $n=5$, tratados com captopril 21 dias após a indução), do grupo 7-DP-21 Capto ( $n=5$, tratados com captopril 7 dias antes da indução e 21 dias após a indução) e do grupo 14-DP-21 Capto ( $n=5$, tratados com captopril 14 dias antes da indução e 21 dias após a indução). * $p<0,05$ em relação a todos os demais grupos. 


\subsection{ANÁLISE DA EXPRESSÃO DE RNAm NO TECIDO GENGIVAL}

\subsubsection{EXPRESSÃO DE RNAm PARA OS COMPONENTES DO SISTEMA RENINA-} ANGIOTENSINA (RAS)

\subsubsection{Angiotensinogênio}

Com relação à expressão de RNAm para AGT não foi possível detectar nenhuma diferença significativa entre todos os grupos avaliados (Figuras 17 e 18).

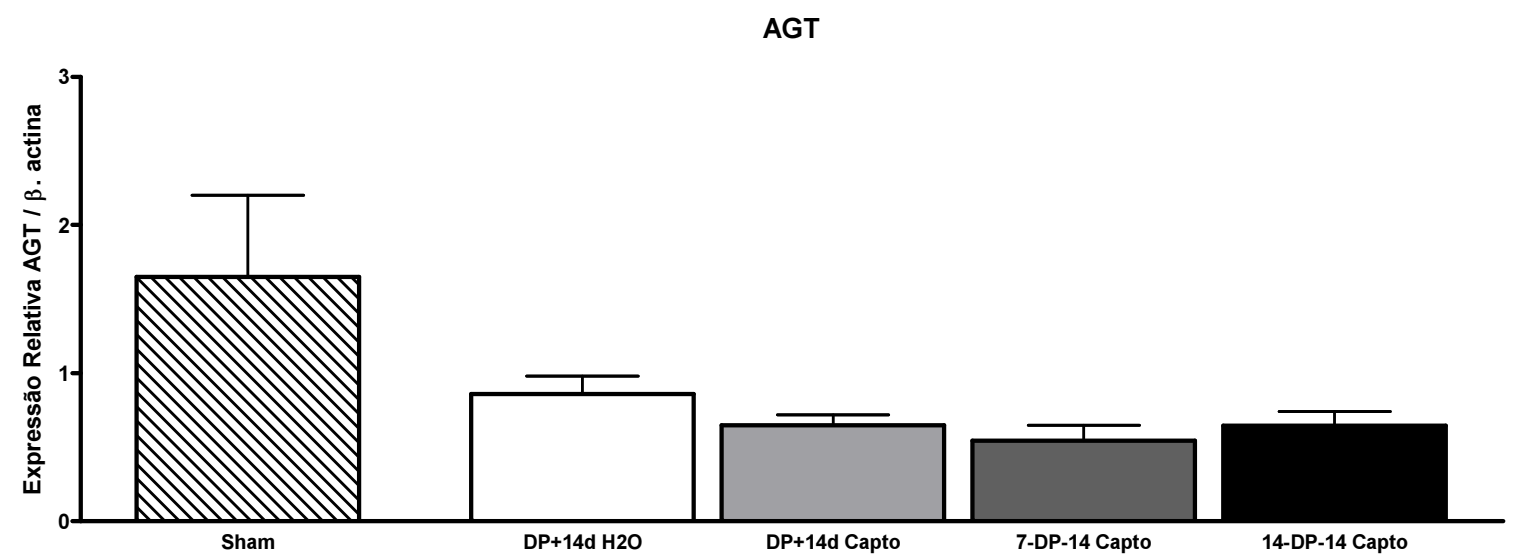

Figura 17 - Expressão de RNAm para angiotensinogênio relativa à expressão de $\beta$ actina nos animais do grupo Sham $(n=5$, submetidos à indução fictícia), do grupo DP-14 $\mathrm{H}_{2} \mathrm{O}(\mathrm{n}=5$, Tratados com veículo durante 14 dias após a indução), do grupo DP-14 Capto ( $n=5$, Tratados com captopril durante 14 dias após a indução) do grupo 7-DP-14 Capto ( $n=5$, tratados com captopril 7 dias antes da indução e 14 dias após a indução), do grupo 14-DP-14 Capto ( $n=5$, tratados com captopril 14 dias antes da indução e 14 dias após a indução). 


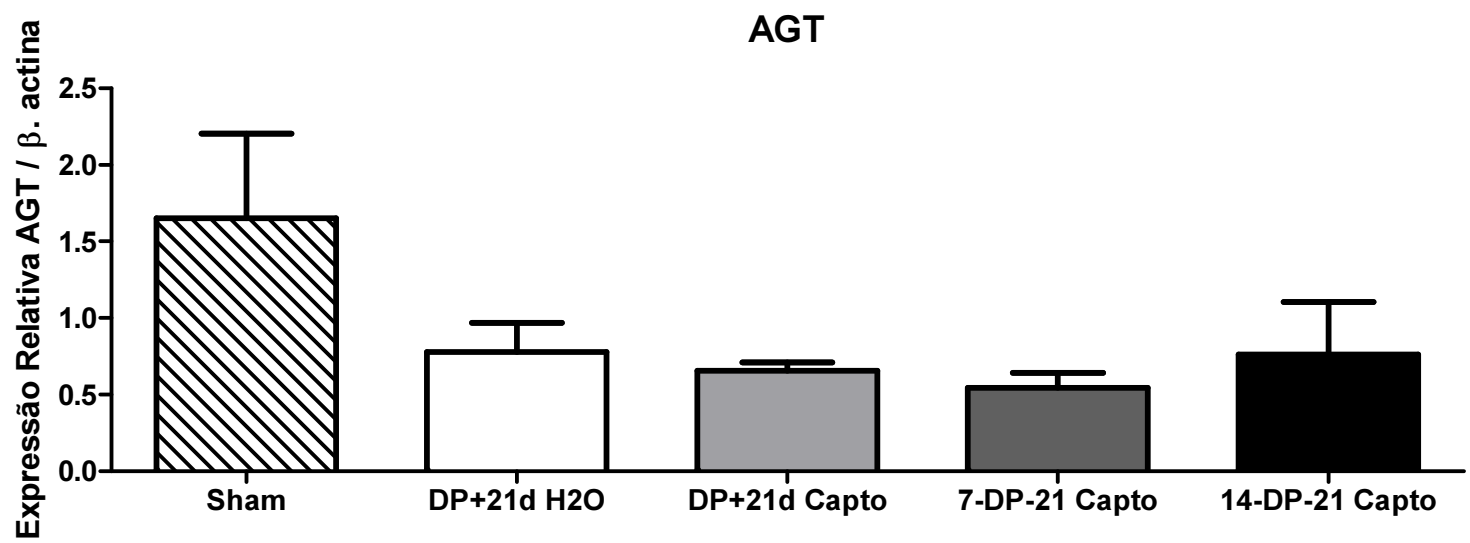

Figura 18 - Expressão de RNAm para angiotensinogênio relativa à expressão de $\beta$ actina nos animais do grupo Sham $(n=5$, submetidos à indução fictícia), do grupo DP-21 $\mathrm{H}_{2} \mathrm{O}$ ( $\mathrm{n}=5$, tratados com veículo 21 dias após a indução), do grupo DP-21 Capto ( $n=5$, tratados com captopril 21 dias após a indução), do grupo 7-DP-21 Capto $(n=5$, tratados com captopril 7 dias antes da indução e 21 dias após a indução) e do grupo 14-DP-21 Capto ( $n=5$, tratados com captopril 14 dias antes da indução e 21 dias após a indução).

\subsubsection{Renina}

A expressão de RNAm para Renina foi detectada em todos os grupos avaliados. Porém os resultados foram inconsistentes não sendo possível análise estatística e confecção de gráfico. 


\subsubsection{RECEPTORES DE ANGIOTENSINA}

\subsection{Receptor de Angiotensina Tipo 1a (AT1a)}

A expressão de RNAm para AT1a no grupo 14-DP-21 Capto apresentou um aumento significativo comparado ao grupo DP-21 $\mathrm{H}_{2} \mathrm{O}$. Para as demais comparações possíveis não foi possível detectar diferenças significativas (Figuras 19 e 20).

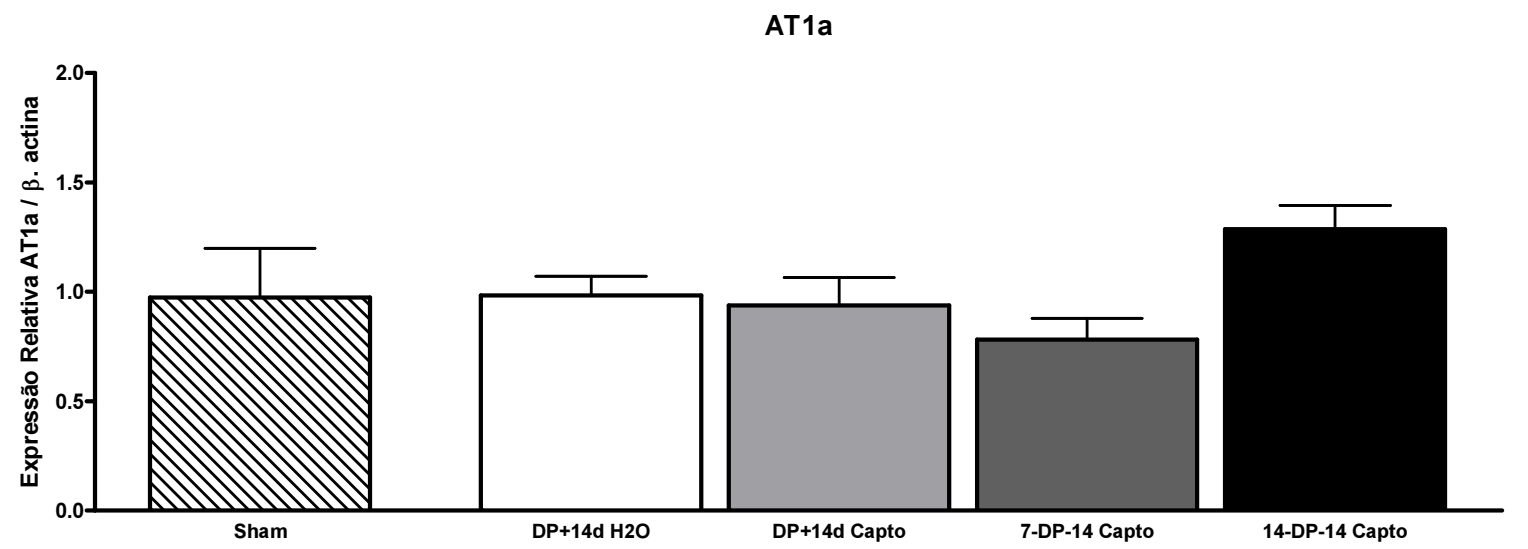

Figura 19 - Expressão de RNAm para o receptor AT1a relativa à expressão de $\beta$ actina nos animais do grupo Sham ( $n=5$, submetidos a indução fictícia), do grupo DP-14 $\mathrm{H}_{2} \mathrm{O}(\mathrm{n}=5$, Tratados com veículo durante 14 dias após a indução), do grupo DP-14 Capto ( $n=5$, Tratados com captopril durante 14 dias após a indução), do grupo 7-DP-14 Capto ( $n=5$, tratados com captopril 7 dias antes da indução e 14 dias após a indução), do grupo 14-DP-14 Capto ( $n=5$, tratados com captopril 14 dias antes da indução e 14 dias após a indução). 


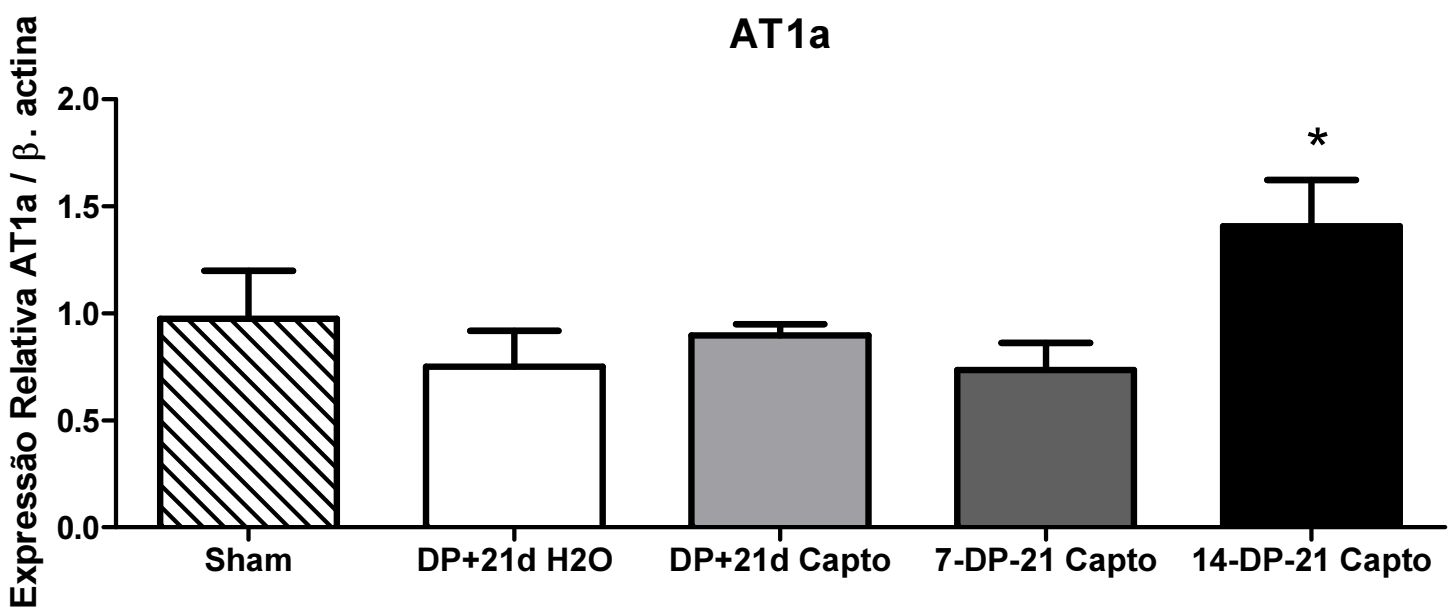

Figura 20 - Expressão de RNAm para o receptor AT1a relativa à expressão de $\beta$ actina nos animais do grupo Sham ( $n=5$, submetidos a indução fictícia), do grupo DP-21 $\mathrm{H}_{2} \mathrm{O}(\mathrm{n}=5$, tratados com veículo 21 dias após a indução), do grupo DP-21 Capto ( $n=5$, tratados com captopril 21 dias após a indução), do grupo 7-DP-21 Capto $(n=5$, tratados com captopril 7 dias antes da indução e 21 dias após a indução) e do grupo 14-DP-21 Capto ( $n=5$, tratados com captopril 14 dias antes da indução e 21 dias após a indução). * vs DP-21 $\mathrm{H}_{2} \mathrm{O}$

\subsection{Receptor de Angiotensina Tipo 1 b (AT1b)}

A expressão de RNAm para At1b foi detectada em todos os grupos avaliados. Porém os resultados foram inconsistentes não sendo possível análise estatística e confecção de gráfico. 


\subsubsection{Receptor de Angiotensina Tipo 2 (AT2)}

Com relação a expressão de RNAm para AT2 não foi possível detectar nenhuma diferença significativa entre todos os grupos avaliados (Figuras 21 e 22).

AT2

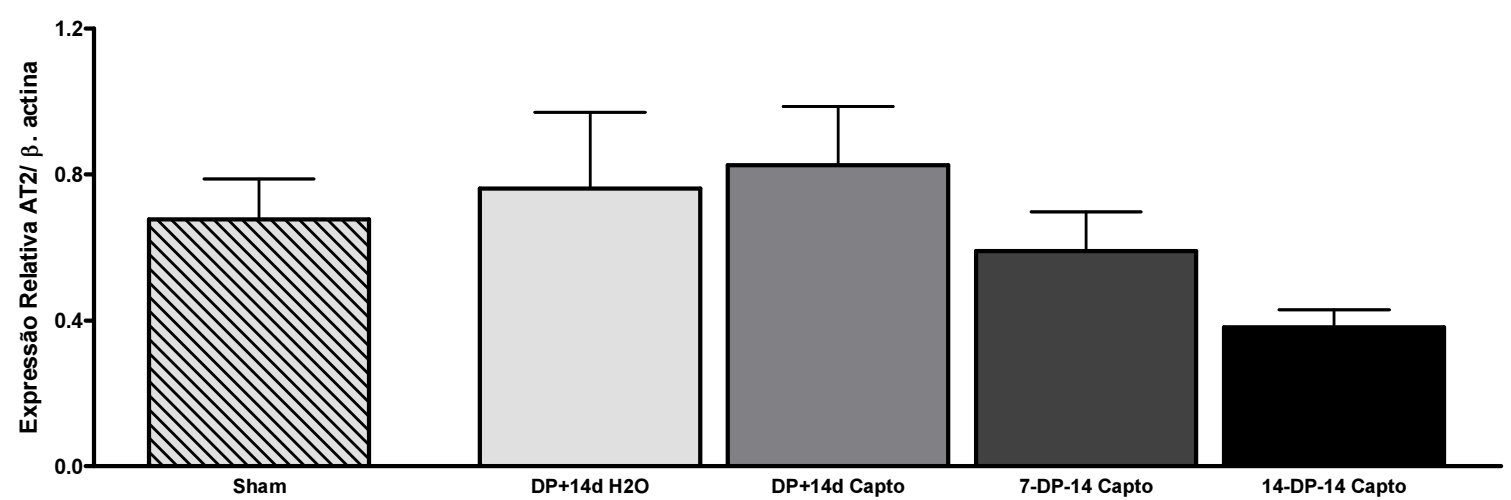

Figura 21 - Expressão de RNAm para o receptor AT2 relativa à expressão de $\beta$ actina nos animais do grupo Sham ( $n=5$, submetidos a indução fictícia), do grupo DP$14 \mathrm{H}_{2} \mathrm{O}$ ( $n=5$, Tratados com veículo durante 14 dias após a indução), do grupo DP-14 Capto ( $n=5$, Tratados com captopril durante 14 dias após a indução), do grupo 7-DP14 Capto $(n=5$, tratados com captopril 7 dias antes da indução e 14 dias após a indução), do grupo 14-DP-14 Capto ( $n=5$, tratados com captopril 14 dias antes da indução e 14 dias após a indução). 


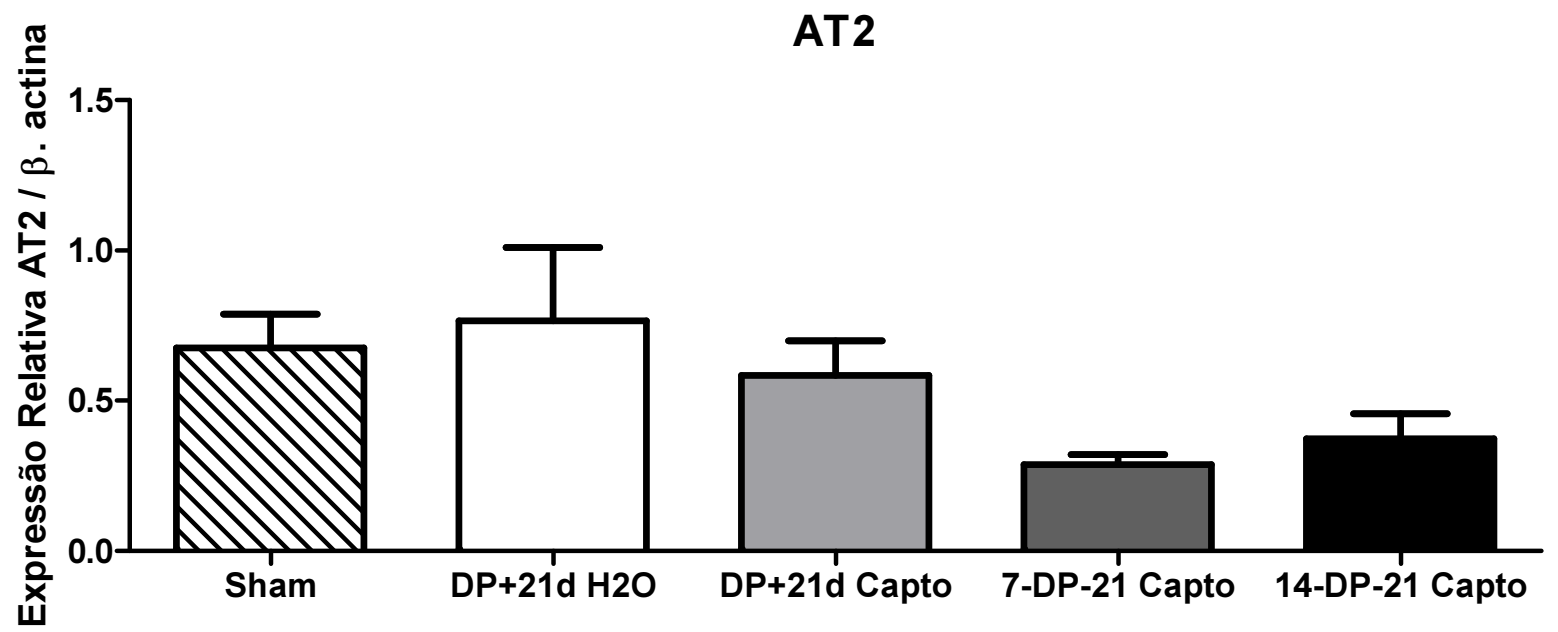

Figura 22 - Expressão de RNAm para o receptor AT2 relativa à expressão de $\beta$ actina nos animais do grupo Sham $(n=5$, submetidos a indução fictícia), do grupo DP-21 $\mathrm{H}_{2} \mathrm{O}(\mathrm{n}=5$, tratados com veículo 21 dias após a indução), do grupo DP-21 Capto ( $n=5$, tratados com captopril 21 dias após a indução), do grupo 7-DP-21 Capto ( $n=5$, tratados com captopril 7 dias antes da indução e 21 dias após a indução) e do grupo 14-DP-21 Capto ( $n=5$, tratados com captopril 14 dias antes da indução e 21 dias após a indução). 


\subsubsection{Enzima Conversora de Angiotensina (ECA)}

A expressão de RNAm para a enzima conversora de angiotensina permaneceu sem diferenças estatisticamente significativas entre os animais com DP submetidos ao tratamento com veículo e os animais com DP submetidos ao tratamento com captopril (Figuras 23 e 24).

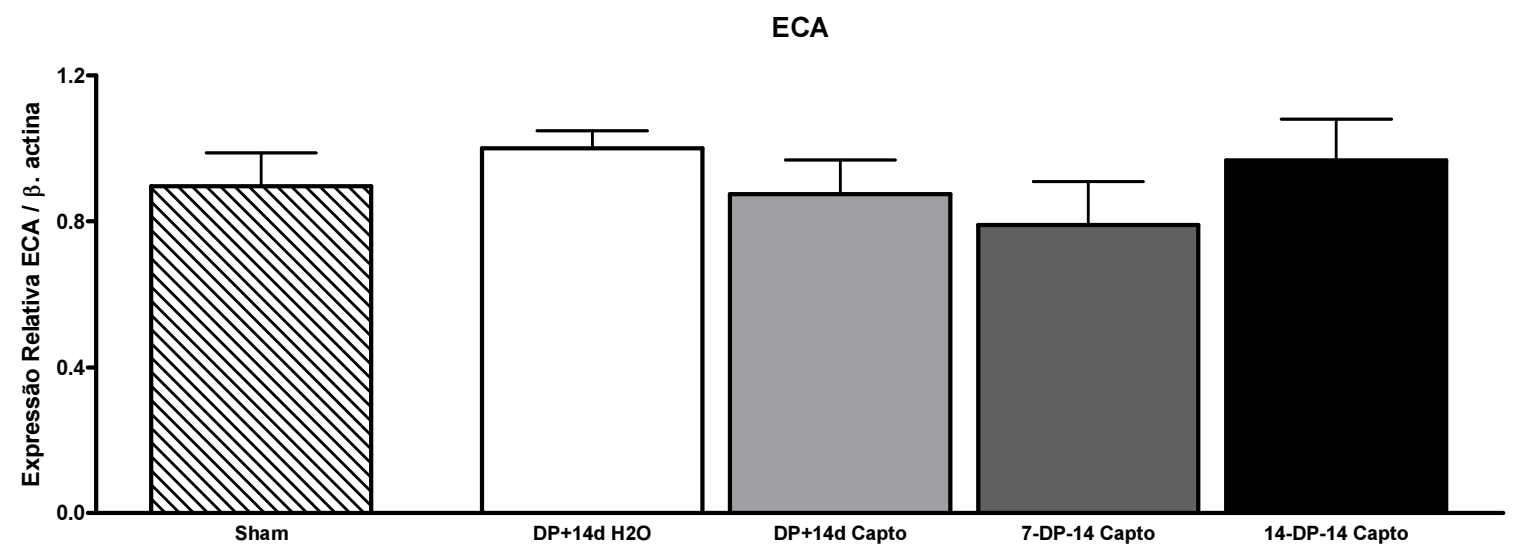

Figura 23 - Expressão de RNAm para ECA relativa à expressão de $\beta$-actina nos animais do grupo Sham ( $n=5$, submetidos a indução fictícia), do grupo DP-14 $\mathrm{H}_{2} \mathrm{O}$ $(n=5$, Tratados com veículo durante 14 dias após a indução), do grupo DP-14 Capto $(n=5$, Tratados com captopril durante 14 dias após a indução), do grupo 7-DP-14 Capto $(n=5$, tratados com captopril 7 dias antes da indução e 14 dias após a indução), do grupo 14-DP-14 Capto ( $n=5$, tratados com captopril 14 dias antes da indução e 14 dias após a indução). 


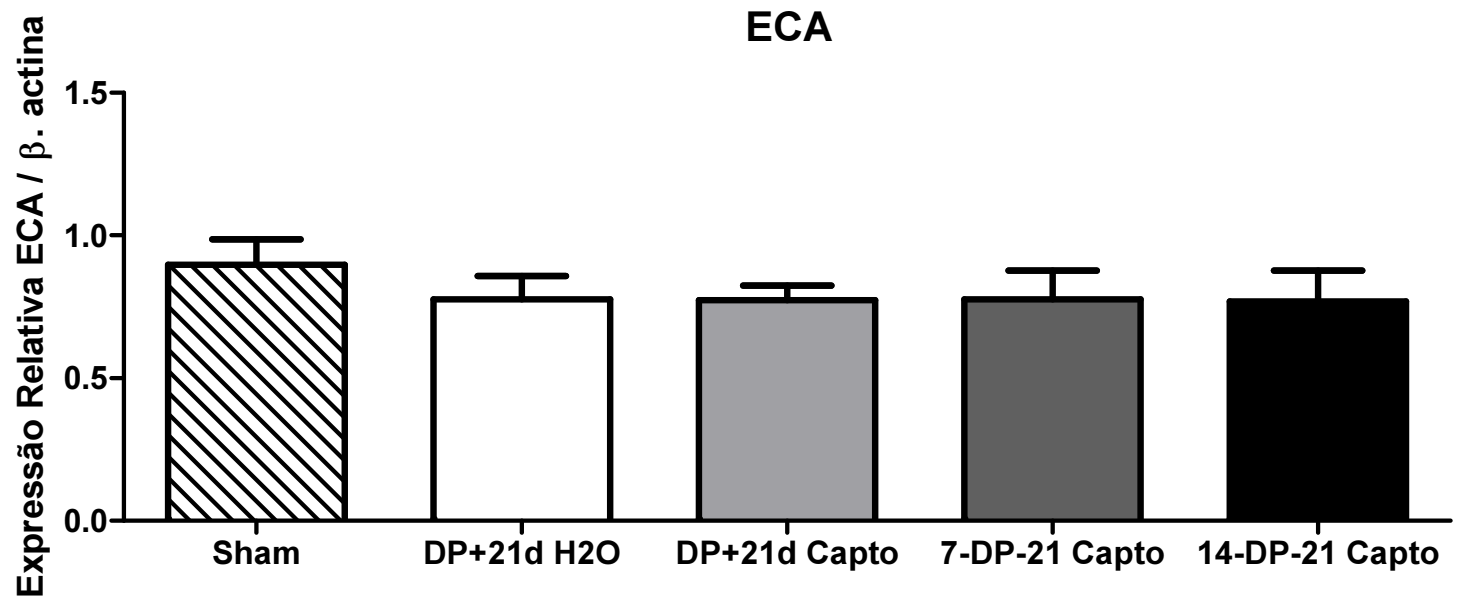

Figura 24 - Expressão de RNAm para ECA relativa à expressão de $\beta$-actina nos animais do grupo Sham ( $n=5$, submetidos a indução fictícia), do grupo DP-21 $\mathrm{H}_{2} \mathrm{O}$ ( $n=5$, tratados com veículo 21 dias após a indução), do grupo DP-21 Capto $(n=5$, tratados com captopril 21 dias após a indução), do grupo 7-DP-21 Capto $(n=5$, tratados com captopril 7 dias antes da indução e 21 dias após a indução) e do grupo 14-DP-21 Capto ( $n=5$, tratados com captopril 14 dias antes da indução e 21 dias após a indução). 


\subsubsection{Enzima Conversora de Angiotensina-2 (ECA-2)}

A expressão de RNAm para a enzima conversora de angiotensina-2 permaneceu sem diferenças estatisticamente significativas entre os animais com DP submetidos ao tratamento com veículo e os animais com DP submetidos ao tratamento com captopril.

Os animais tratados com o veículo após a indução da DP apresentaram uma maior expressão de RNAm para ECA-2 quando comparados aos animais do grupo Sham. Da mesma forma os animais dos grupos DP-14 Capto e 14-DP-21 Capto apresentaram uma maior e significativa expressão de RNAm para ECA-2 comparados ao grupo Sham (Figuras 25 e 26).

ECA-2

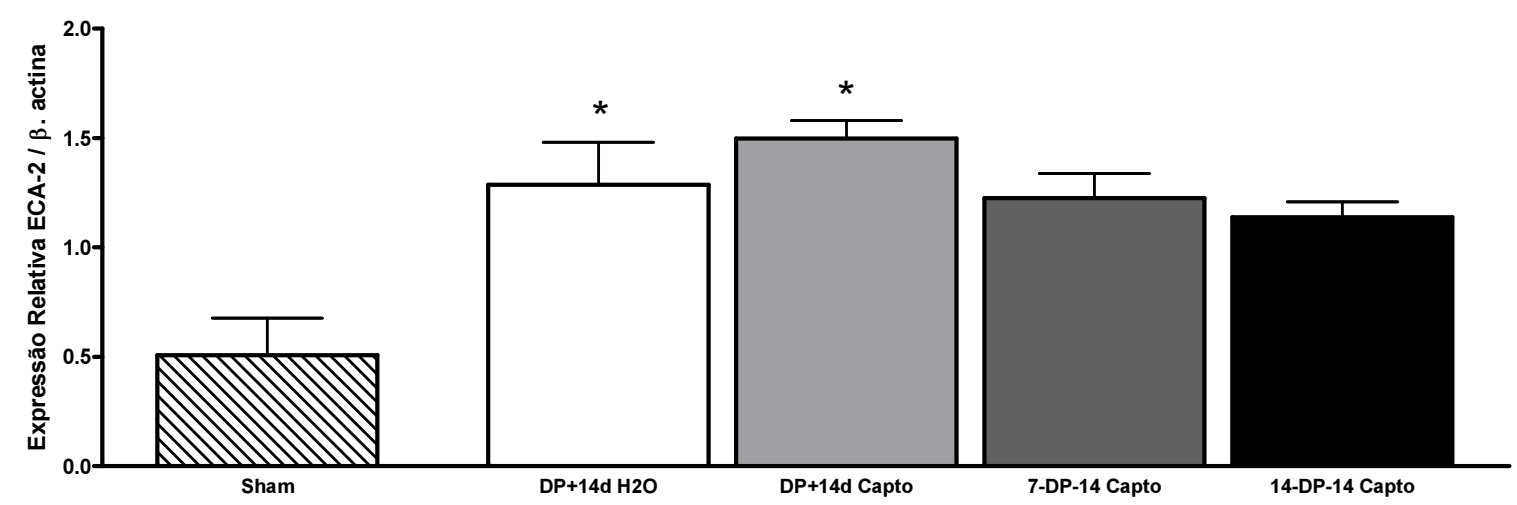

Figura 25 - Expressão de RNAm para ECA-2 relativa à expressão de $\beta$-actina nos animais do grupo Sham ( $n=5$, submetidos a indução fictícia), do grupo DP-14 $\mathrm{H}_{2} \mathrm{O}$ $(n=5$, Tratados com veículo durante 14 dias após a indução), do grupo DP-14 Capto $(n=5$, Tratados com captopril durante 14 dias após a indução), do grupo 7-DP-14 Capto $(n=5$, tratados com captopril 7 dias antes da indução e 14 dias após a indução), do grupo 14-DP-14 Capto ( $\mathrm{n}=5$, tratados com captopril 14 dias antes da indução e 14 dias após a indução). * vs Sham. 


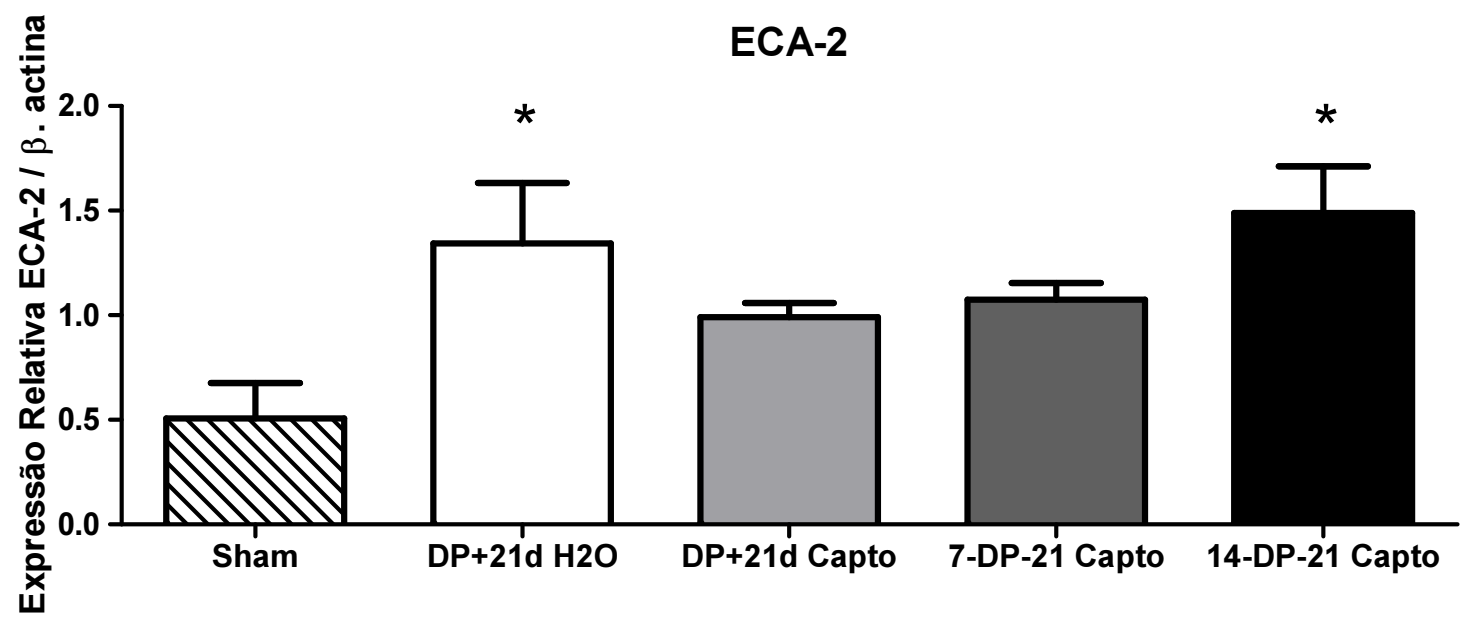

Figura 26 - Expressão de RNAm para ECA-2 relativa à expressão de $\beta$-actina nos animais do grupo Sham ( $n=5$, submetidos a indução fictícia), do grupo DP-21 $\mathrm{H}_{2} \mathrm{O}$ ( $n=5$, tratados com veículo 21 dias após a indução), do grupo DP-21 Capto $(n=5$, tratados com captopril 21 dias após a indução), do grupo 7-DP-21 Capto $(n=5$, tratados com captopril 7 dias antes da indução e 21 dias após a indução) e do grupo 14-DP-21 Capto ( $n=5$, tratados com captopril 14 dias antes da indução e 21 dias após a indução). * vs Sham. 


\subsubsection{Receptor MAS}

Com relação à expressão de RNAm para os receptores do tipo MAS não foi possível detectar nenhuma diferença significativas entre todos os grupos avaliados (Figuras 27 e 28).

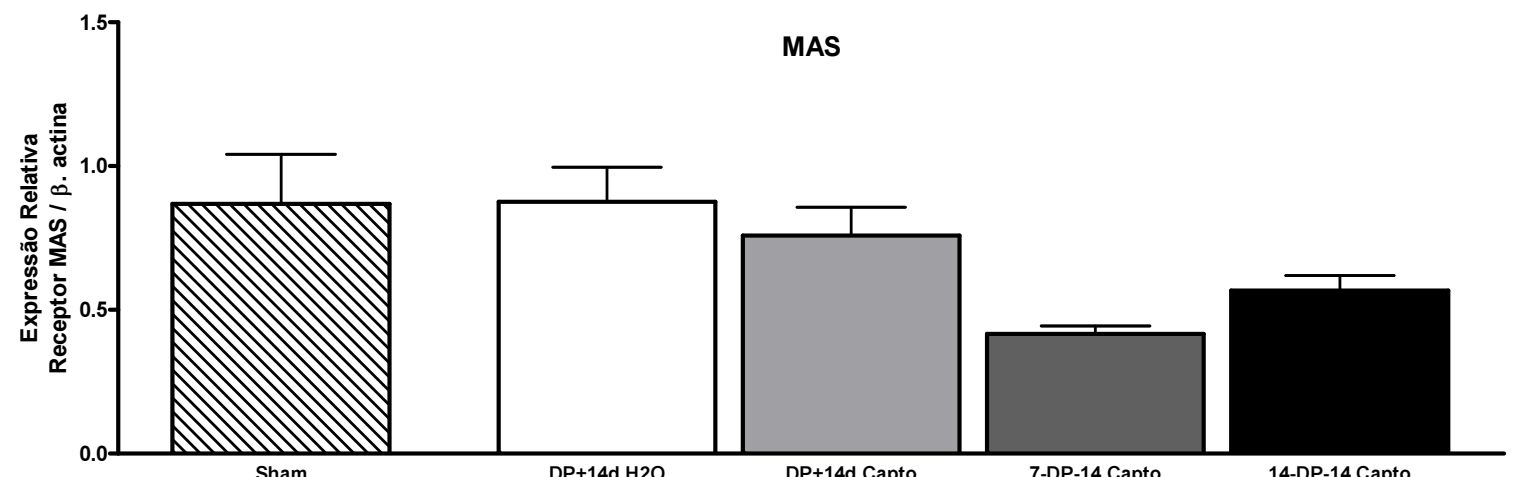

Figura 27 - Expressão de RNAm para receptor MAS relativa à expressão de $\beta$-actina nos animais do grupo Sham ( $n=5$, submetidos a indução fictícia), do grupo DP-14 $\mathrm{H}_{2} \mathrm{O}$ ( $\mathrm{n}=5$, Tratados com veículo durante 14 dias após a indução), do grupo DP-14 Capto ( $n=5$, Tratados com captopril durante 14 dias após a indução), do grupo 7-DP14 Capto $(n=5$, tratados com captopril 7 dias antes da indução e 14 dias após a indução), do grupo 14-DP-14 Capto ( $n=5$, tratados com captopril 14 dias antes da indução e 14 dias após a indução). 


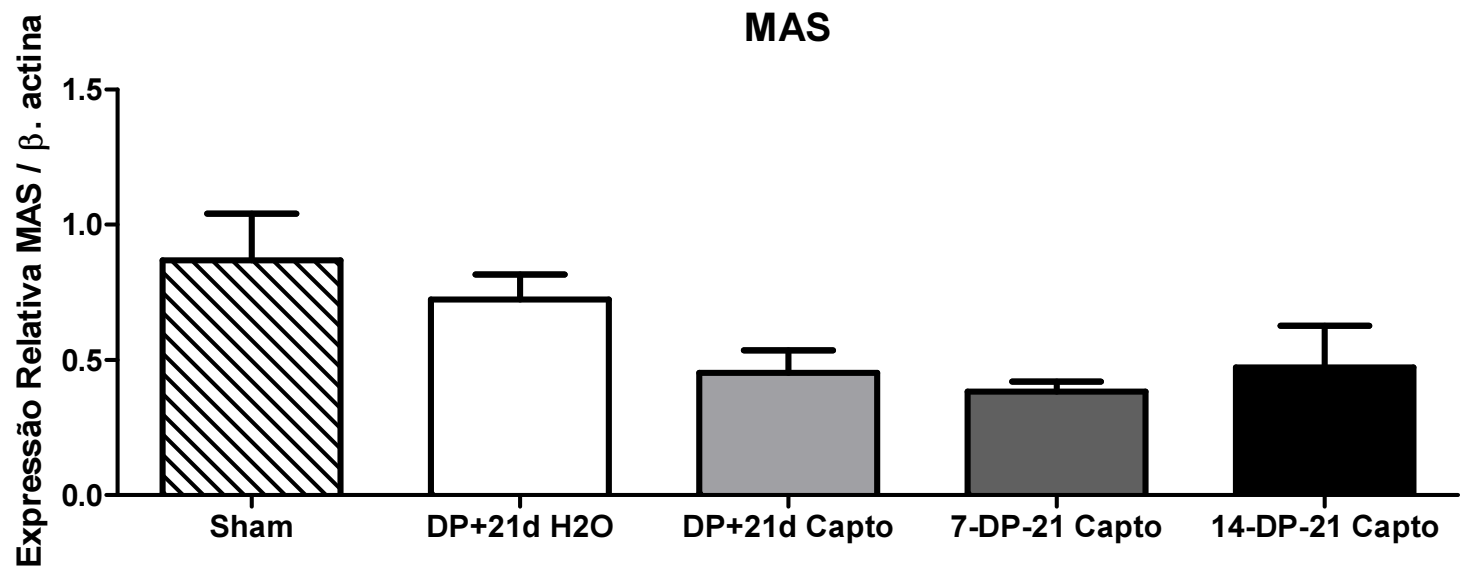

Figura 28 - Expressão de RNAm para receptor MAS relativa à expressão de $\beta$-actina nos animais do grupo Sham ( $n=5$, submetidos a indução fictícia), do grupo DP-21 $\mathrm{H}_{2} \mathrm{O}$ ( $\mathrm{n}=5$, tratados com veículo 21 dias após a indução), do grupo DP-21 Capto ( $n=5$, tratados com captopril 21 dias após a indução), do grupo 7-DP-21 Capto $(n=5$, tratados com captopril 7 dias antes da indução e 21 dias após a indução) e do grupo 14-DP-21 Capto ( $n=5$, tratados com captopril 14 dias antes da indução e 21 dias após a indução). 


\subsubsection{Ciclooxigenase-2 (COX-2)}

A expressão de RNAm para COX-2 foi significativamente maior nos grupos submetidos ao tratamento com captopril DP-14 Capto comparado aos animais do grupo Sham.

Quando comparamos o grupo DP-14 Capto ao grupo DP-14 H2O constatouse uma expressão de RNAm maior e significativa no grupo DP-14 Capto (Figuras 29 e 30).

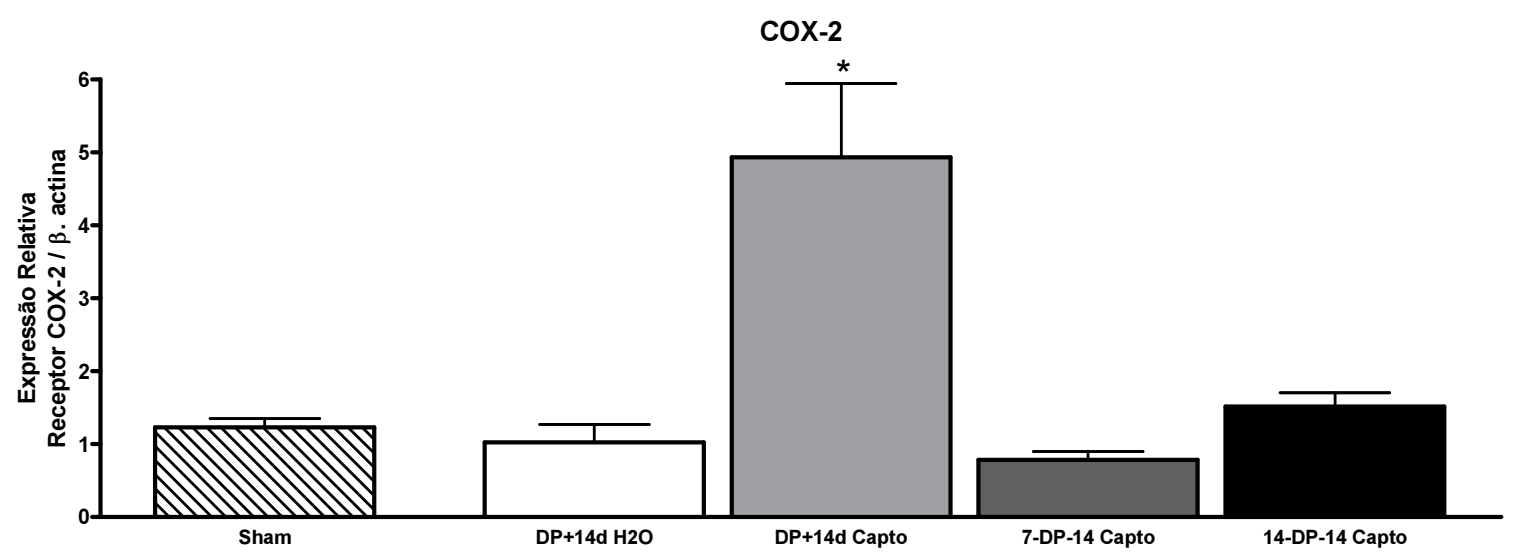

Figura 29 - Expressão de RNAm para COX-2 relativa à expressão de $\beta$-actina nos animais do grupo Sham ( $n=5$, submetidos a indução fictícia), do grupo DP-14 $\mathrm{H}_{2} \mathrm{O}$ $(n=5$, Tratados com veículo durante 14 dias após a indução), do grupo DP-14 Capto ( $n=5$, Tratados com captopril durante 14 dias após a indução), do grupo 7-DP-14 Capto ( $n=5$, tratados com captopril 7 dias antes da indução e 14 dias após a indução), do grupo 14-DP-14 Capto ( $n=5$, tratados com captopril 14 dias antes da indução e 14 dias após a indução). * vs Sham e Dp-14 $\mathrm{H}_{2} \mathrm{O}$. 


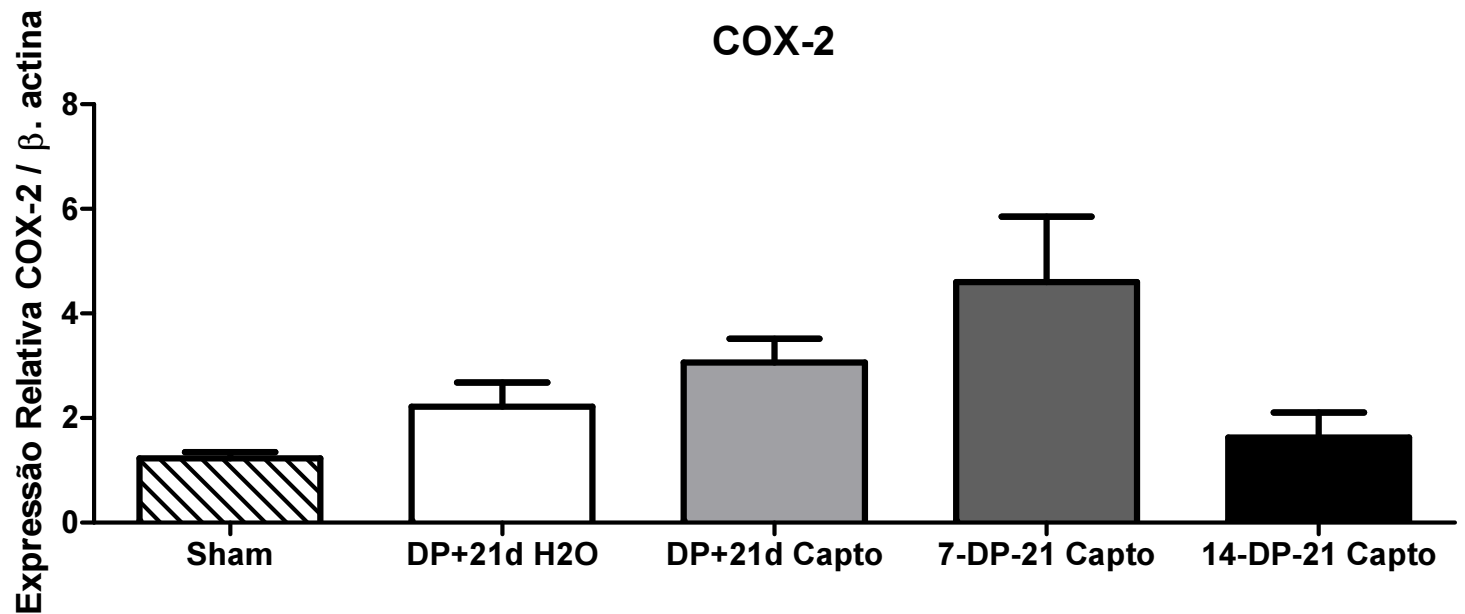

Figura 30 - Expressão de RNAm para COX-2 relativa à expressão de $\beta$-actina nos animais do grupo Sham ( $n=5$, submetidos a indução fictícia), do grupo DP-21 $\mathrm{H}_{2} \mathrm{O}$ ( $n=5$, tratados com veículo 21 dias após a indução), do grupo DP-21 Capto $(n=5$, tratados com captopril 21 dias após a indução), do grupo 7-DP-21 Capto $(n=5$, tratados com captopril 7 dias antes da indução e 21 dias após a indução) e do grupo 14-DP-21 Capto ( $n=5$, tratados com captopril 14 dias antes da indução e 21 dias após a indução). 


\subsubsection{EXPRESSÃO DE RNAm PARA CITOCINAS}

\subsubsection{Interleucina-1 beta (IL-1 $\beta$ )}

Com relação à expressão de RNAm para IL-1ß não foi possível detectar nenhuma diferença significativa entre todos os grupos avaliados (Figuras 31 e 32).

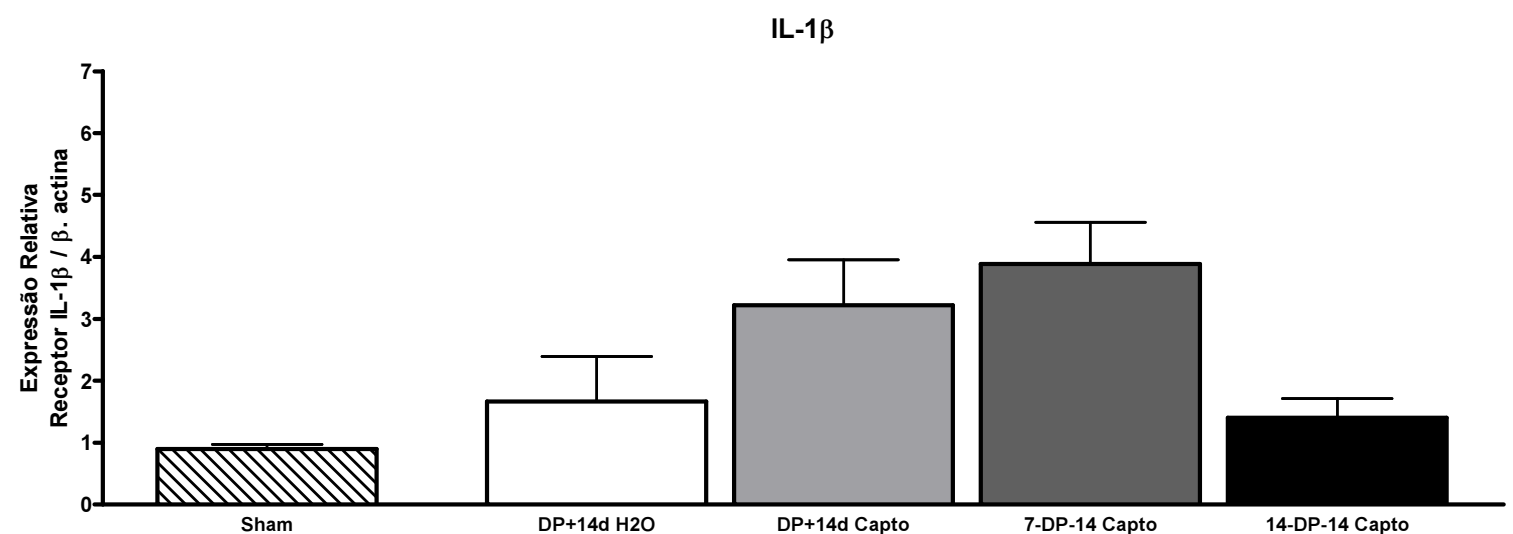

Figura 31 - Expressão de RNAm para IL-1 $\beta$ relativa à expressão de $\beta$-actina nos animais do grupo Sham ( $n=5$, submetidos a indução fictícia), do grupo DP-14 $\mathrm{H}_{2} \mathrm{O}$ ( $n=5$, Tratados com veículo durante 14 dias após a indução), do grupo DP-14 Capto ( $n=5$, Tratados com captopril durante 14 dias após a indução), do grupo 7-DP-14 Capto ( $n=5$, tratados com captopril 7 dias antes da indução e 14 dias após a indução), do grupo 14-DP-14 Capto ( $n=5$, tratados com captopril 14 dias antes da indução e 14 dias após a indução). 


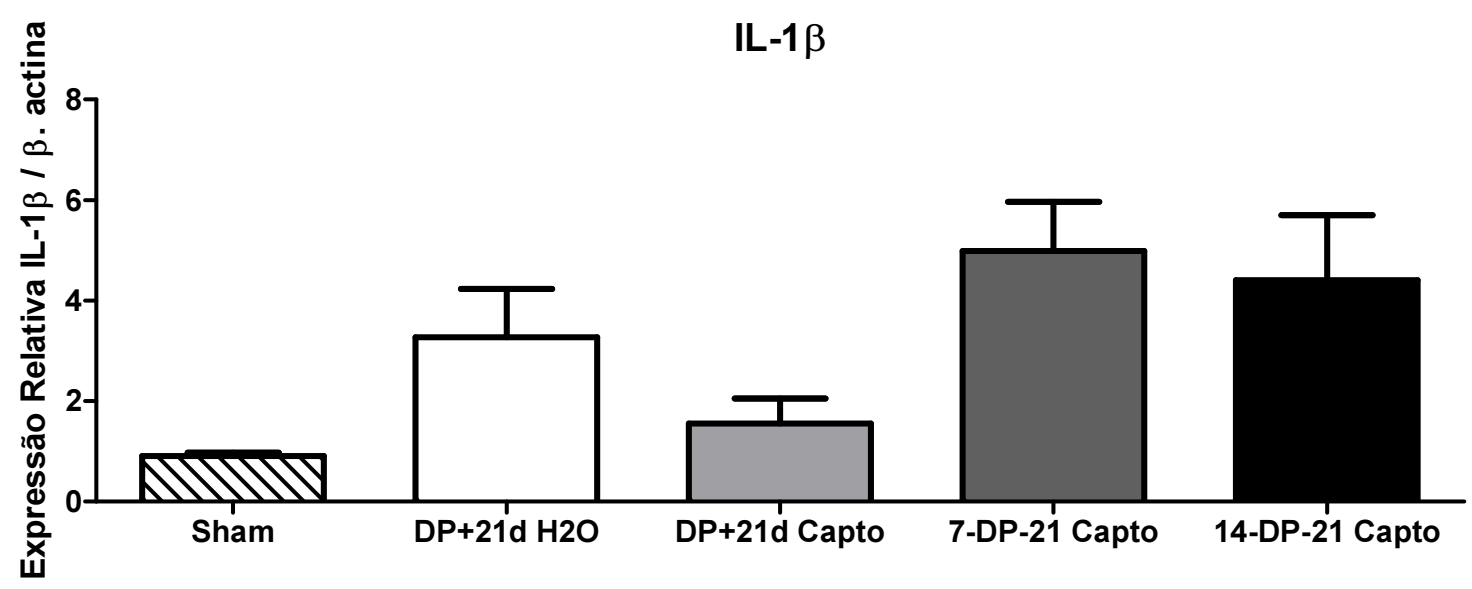

Figura 32 - Expressão de RNAm para IL-1 $\beta$ relativa à expressão de $\beta$-actina nos animais do grupo Sham ( $n=5$, submetidos a indução fictícia), do grupo DP-21 $\mathrm{H}_{2} \mathrm{O}$ ( $n=5$, tratados com veículo 21 dias após a indução), do grupo DP-21 Capto $(n=5$, tratados com captopril 21 dias após a indução), do grupo 7-DP-21 Capto $(n=5$, tratados com captopril 7 dias antes da indução e 21 dias após a indução) e do grupo 14-DP-21 Capto ( $n=5$, tratados com captopril 14 dias antes da indução e 21 dias após a indução). 


\subsubsection{Interleucina-6 (IL-6)}

No grupo 14-DP-21 tratado com captopril foi observada uma aumento na expressão de RNAm para IL-6 comparado ao grupo DP-21 H2O. Entre os outros grupos não foram encontradas diferenças estatisticamente significativas (Figuras 33 e 34).

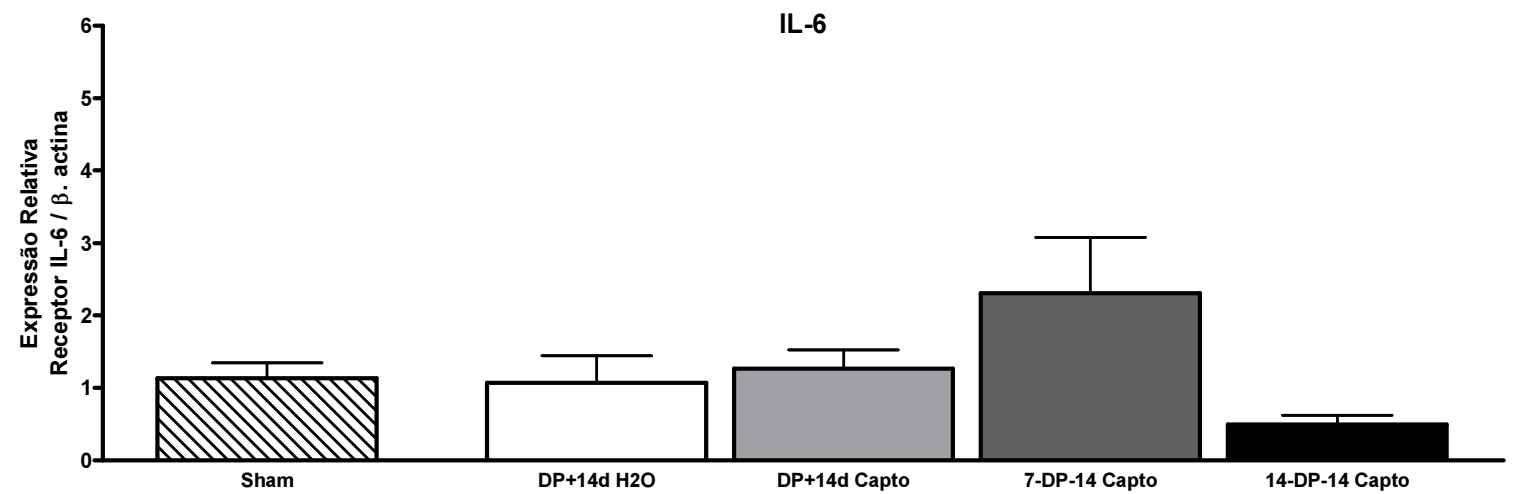

Figura 33 - Expressão de RNAm para IL-6 relativa à expressão de $\beta$-actina nos animais do grupo Sham ( $n=5$, submetidos a indução fictícia), do grupo DP-14 $\mathrm{H}_{2} \mathrm{O}$ ( $n=5$, Tratados com veículo durante 14 dias após a indução), do grupo DP-14 Capto ( $n=5$, Tratados com captopril durante 14 dias após a indução), do grupo 7-DP-14 Capto ( $n=5$, tratados com captopril 7 dias antes da indução e 14 dias após a indução), do grupo 14-DP-14 Capto $(n=5$, tratados com captopril 14 dias antes da indução e 14 dias após a indução). 


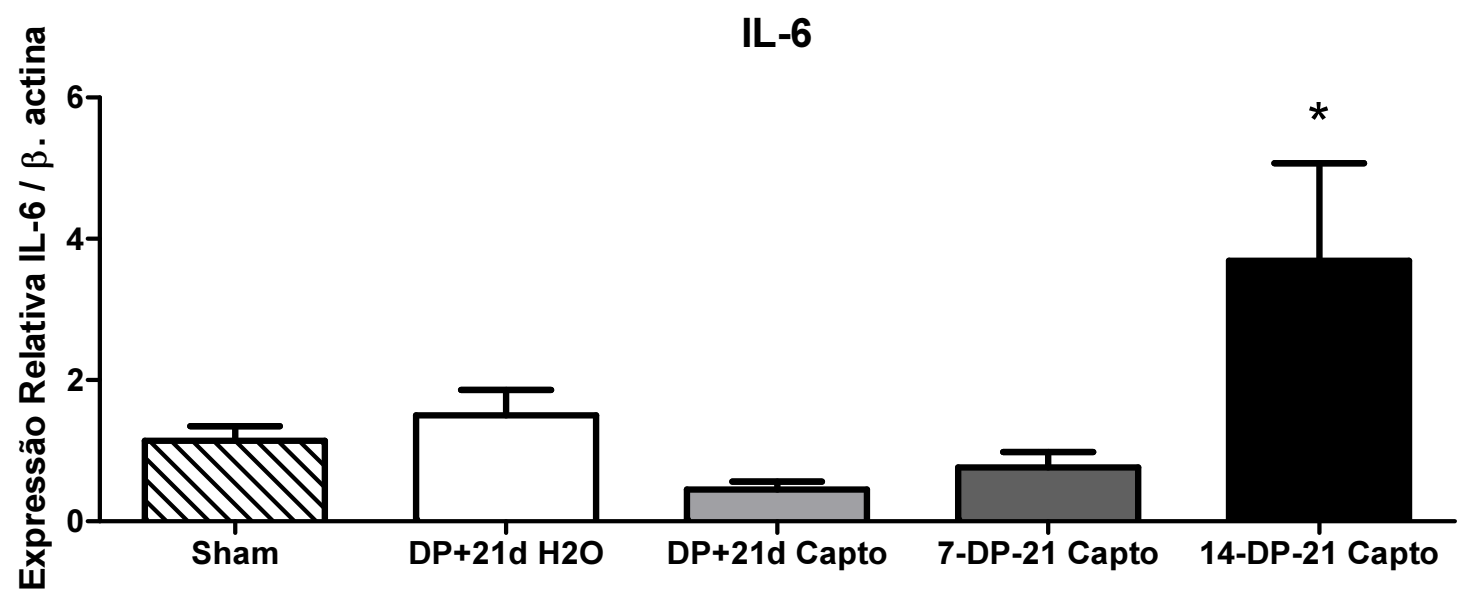

Figura 34 - Expressão de RNAm para IL-6 relativa à expressão de $\beta$-actina nos animais do grupo Sham ( $n=5$, submetidos a indução fictícia), do grupo DP-21 $\mathrm{H}_{2} \mathrm{O}$ ( $n=5$, tratados com veículo 21 dias após a indução), do grupo DP-21 Capto $(n=5$, tratados com captopril 21 dias após a indução), do grupo 7-DP-21 Capto $(n=5$, tratados com captopril 7 dias antes da indução e 21 dias após a indução) e do grupo 14-DP-21 Capto ( $n=5$, tratados com captopril 14 dias antes da indução e 21 dias após a indução). * vs 14-DP-21 $\mathrm{H}_{2} \mathrm{O}$ 


\subsubsection{Fator de Necrose Tumoral (TNF)- $\alpha$}

Com relação a expressão de RNAm para TNF- $\alpha$ não foi possível detectar nenhuma diferença significativa entre todos os grupos avaliados (Figura 35 e 36).

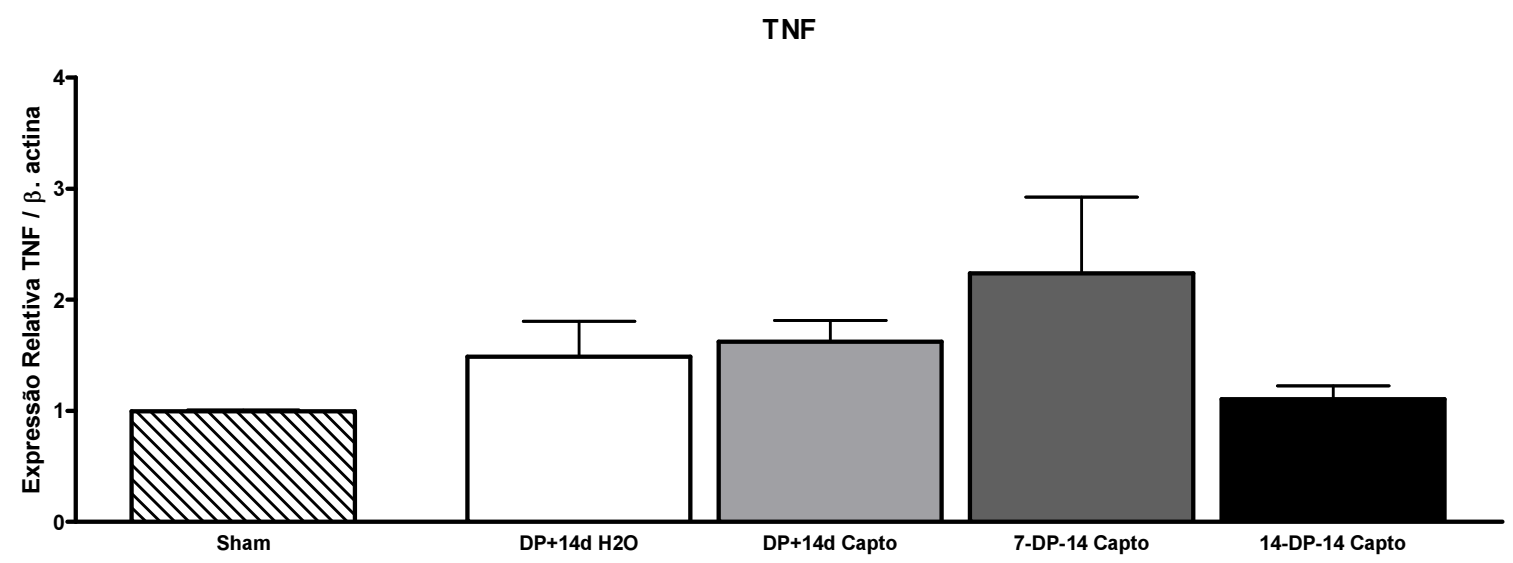

Figura 35 - Expressão de RNAm para TNF relativa à expressão de $\beta$-actina nos animais do grupo Sham ( $n=5$, submetidos a indução fictícia), do grupo DP-14 $\mathrm{H}_{2} \mathrm{O}$ $(n=5$, Tratados com veículo durante 14 dias após a indução), do grupo DP-14 Capto $(n=5$, Tratados com captopril durante 14 dias após a indução), do grupo 7-DP-14 Capto (tratados com captopril 7 dias antes da indução e 14 dias após a indução), do grupo 14-DP-14 Capto ( $n=5$, tratados com captopril 14 dias antes da indução e 14 dias após a indução). 


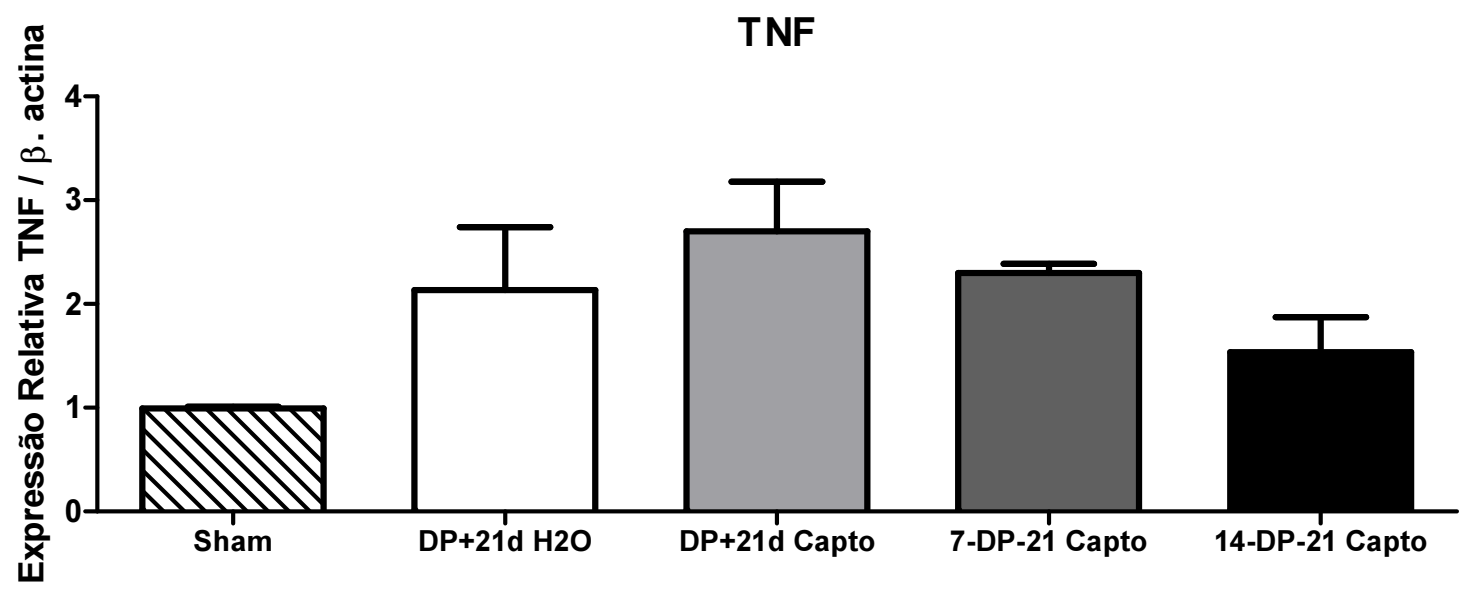

Figura 36 - Expressão de RNAm para TNF relativa à expressão de $\beta$-actina nos animais do grupo Sham ( $n=5$, submetidos a indução fictícia), do grupo DP-21 $\mathrm{H}_{2} \mathrm{O}$ ( $n=5$, tratados com veículo 21 dias após a indução), do grupo DP-21 Capto $(n=5$, tratados com captopril 21 dias após a indução), do grupo 7-DP-21 Capto $(n=5$, tratados com captopril 7 dias antes da indução e 21 dias após a indução) e do grupo 14-DP-21 Capto ( $n=5$, tratados com captopril 14 dias antes da indução e 21 dias após a indução). 


\subsubsection{Osteoprotegerina (OPG)}

Com relação a expressão de RNAm para OPG beta não foi possível detectar nenhuma diferença significativa entre todos os grupos avaliados (Figuras 37 e 38 ).

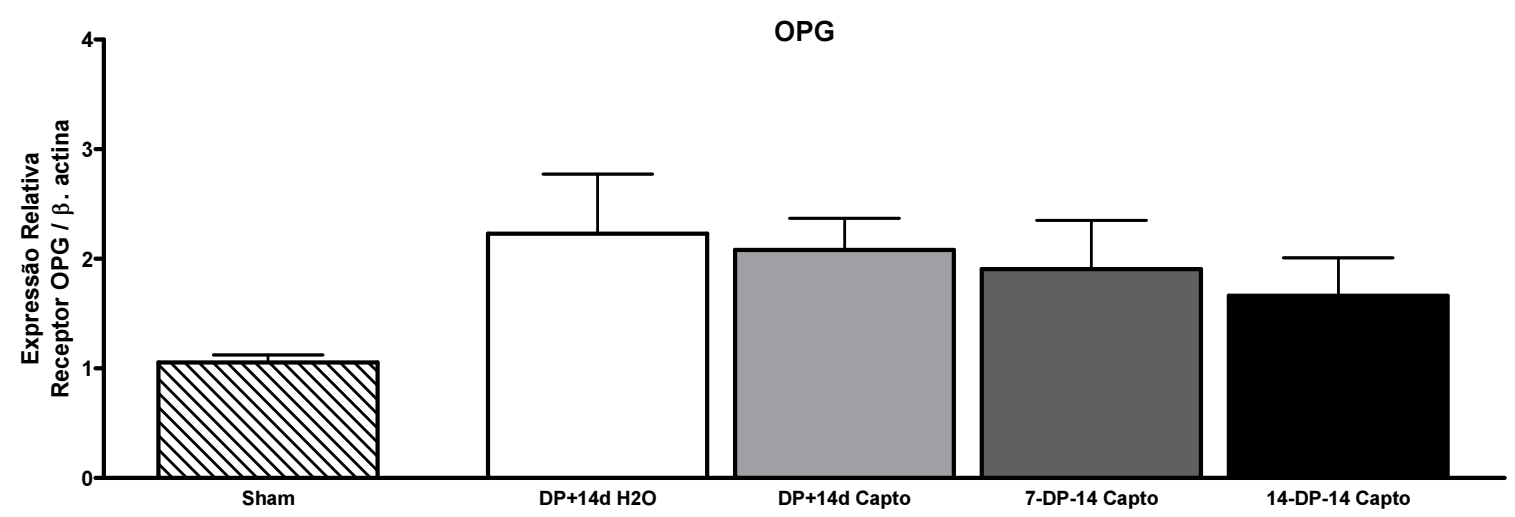

Figura 37 - Expressão de RNAm para OPG relativa à expressão de $\beta$-actina nos animais do grupo Sham ( $n=5$, submetidos a indução fictícia), do grupo DP-14 $\mathrm{H}_{2} \mathrm{O}$ $(n=5$, Tratados com veículo durante 14 dias após a indução), do grupo DP-14 Capto $(n=5$, Tratados com captopril durante 14 dias após a indução), do grupo 7-DP-14 Capto $(n=5$, tratados com captopril 7 dias antes da indução e 14 dias após a indução), do grupo 14-DP-14 Capto ( $n=5$, tratados com captopril 14 dias antes da indução e 14 dias após a indução). 


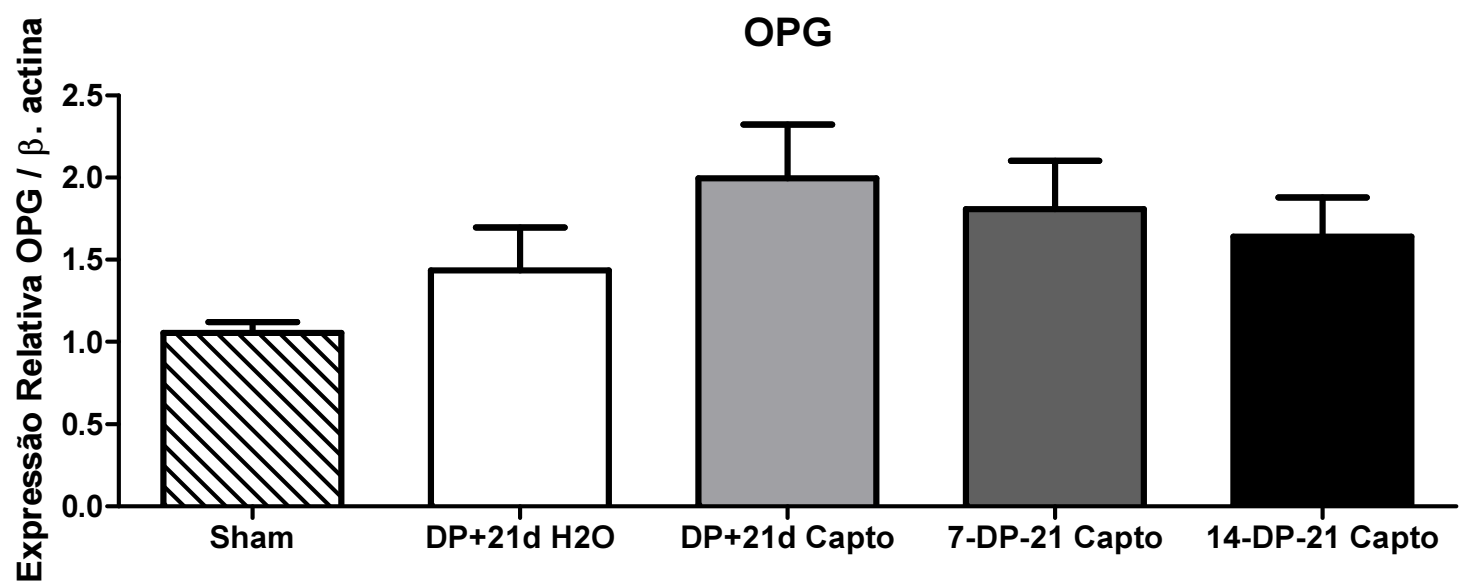

Figura 38 - Expressão de RNAm para OPG relativa à expressão de $\beta$-actina nos animais do grupo Sham ( $n=5$, submetidos a indução fictícia), do grupo DP-21 $\mathrm{H}_{2} \mathrm{O}$ ( $n=5$, tratados com veículo 21 dias após a indução), do grupo DP-21 Capto $(n=5$, tratados com captopril 21 dias após a indução), do grupo 7-DP-21 Capto $(n=5$, tratados com captopril 7 dias antes da indução e 21 dias após a indução) e do grupo 14-DP-21 Capto ( $n=5$, tratados com captopril 14 dias antes da indução e 21 dias após a indução). 


\subsubsection{Receptor Ativador de NF-K $\beta$ (RANK)}

Com relação a expressão de RNAm para RANK beta não foi possível detectar nenhuma diferença significativa entre todos os grupos avaliados (Figuras 39 e 40).

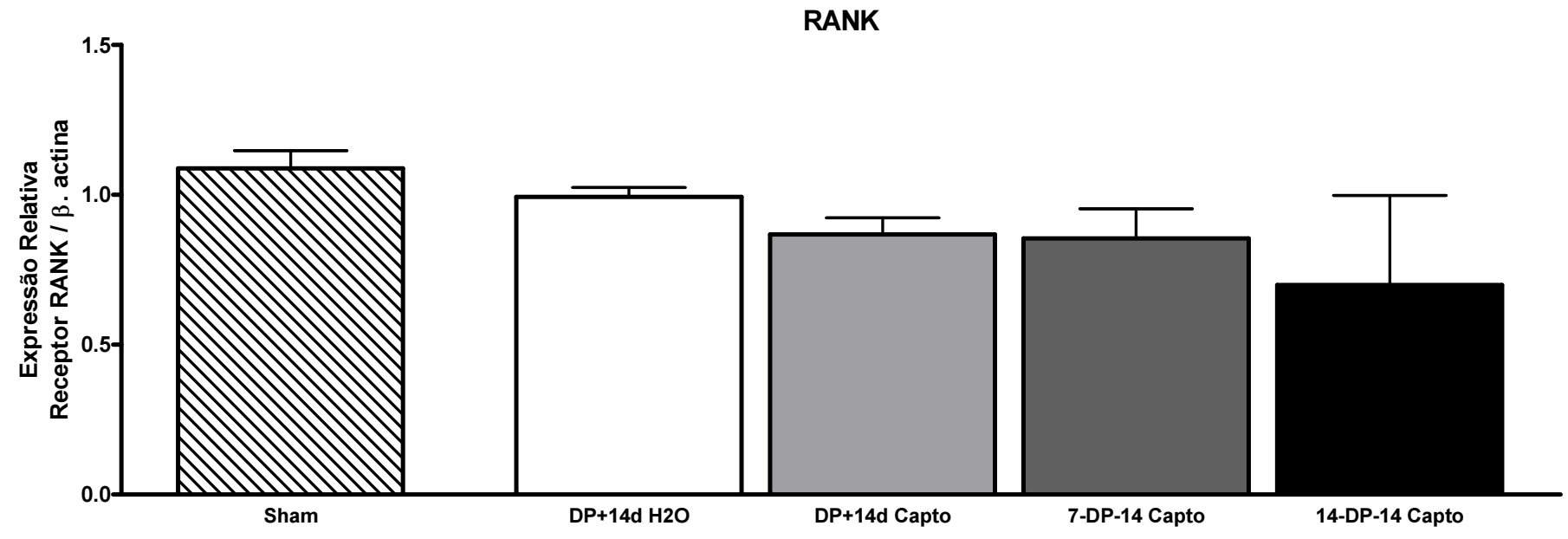

Figura 39 - Expressão de RNAm para RANK relativa à expressão de $\beta$-actina nos animais do grupo Sham ( $n=5$, submetidos a indução fictícia), do grupo DP-14 $\mathrm{H}_{2} \mathrm{O}$ $(n=5$, Tratados com veículo durante 14 dias após a indução), do grupo DP-14 Capto ( $n=5$, Tratados com captopril durante 14 dias após a indução), do grupo 7-DP-14 Capto (tratados com captopril 7 dias antes da indução e 14 dias após a indução), do grupo 14-DP-14 Capto ( $n=5$, tratados com captopril 14 dias antes da indução e 14 dias após a indução). 


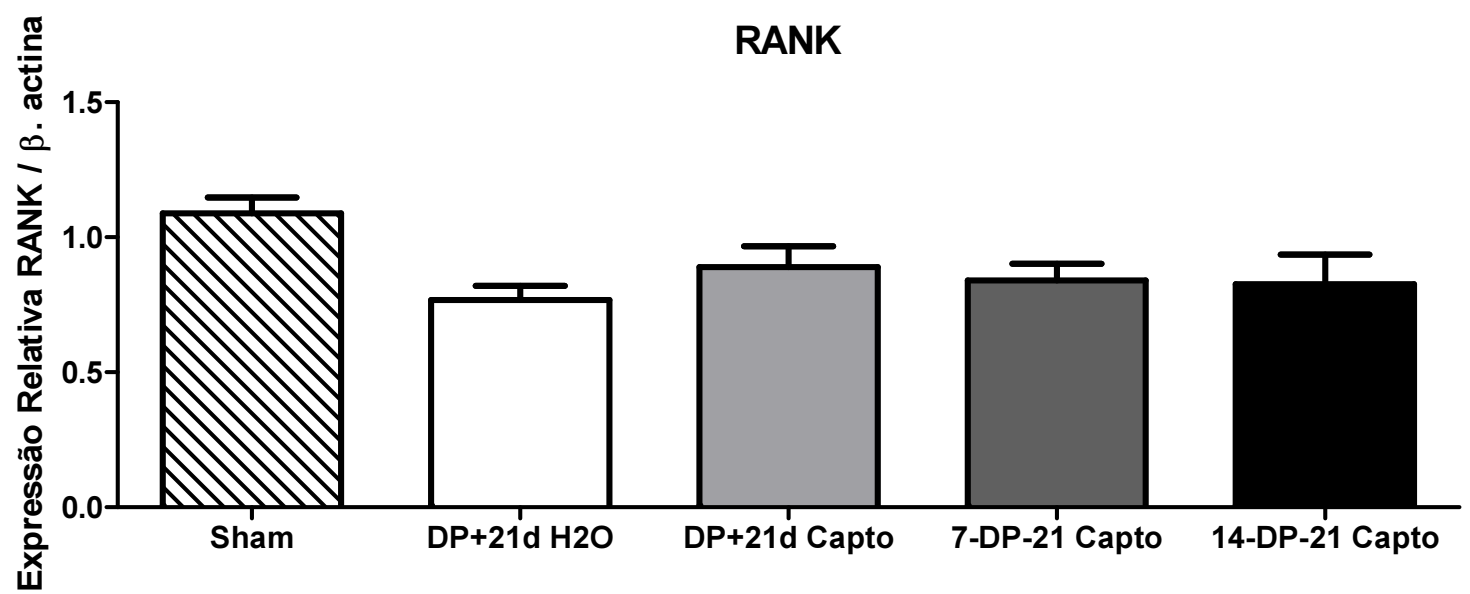

Figura 40 - Expressão de RNAm para RANK relativa à expressão de $\beta$-actina nos animais do grupo Sham ( $n=5$, submetidos a indução fictícia), do grupo DP-21 $\mathrm{H}_{2} \mathrm{O}$ ( $n=5$, tratados com veículo 21 dias após a indução), do grupo DP-21 Capto $(n=5$, tratados com captopril 21 dias após a indução), do grupo 7-DP-21 Capto $(n=5$, tratados com captopril 7 dias antes da indução e 21 dias após a indução) e do grupo 14-DP-21 Capto ( $n=5$, tratados com captopril 14 dias antes da indução e 21 dias após a indução). 


\subsubsection{Ligante do Receptor Ativador de NF-kB (RANKL)}

No grupo 7-DP-14 Capto observou-se um aumento na expressão de RNAm para RANKL comparado ao grupo Sham. O mesmo pôde ser visto após comparação entre os grupos 7-DP-14 Capto e DP-14 H2O (Figuras 41 e 42).

RANKL

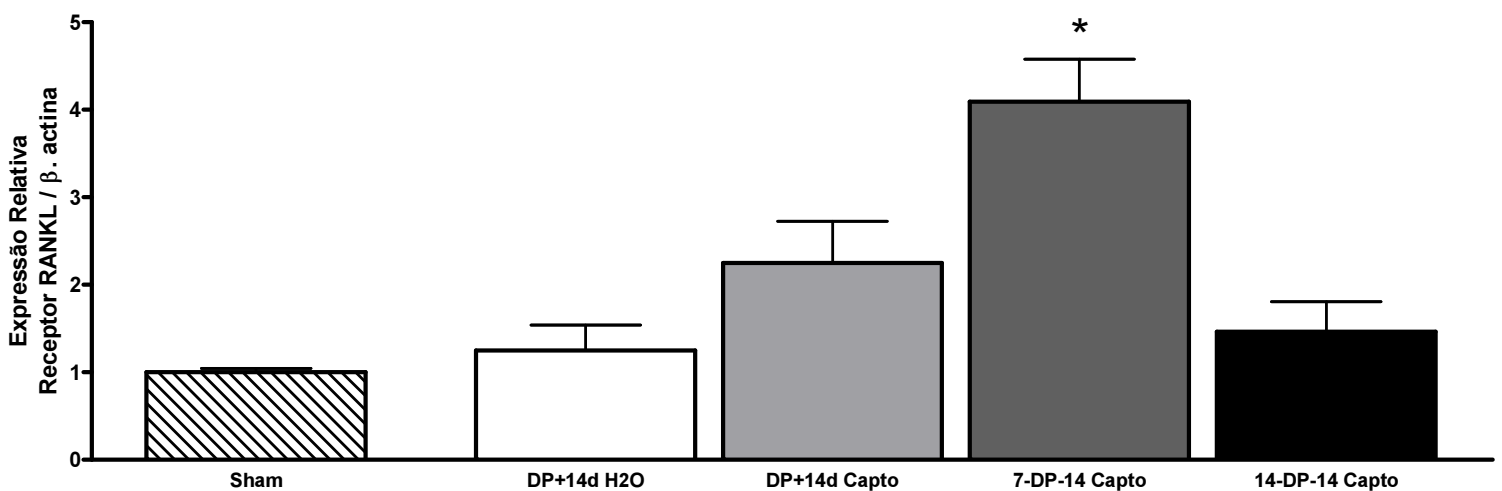

Figura 41 - Expressão de RNAm para RANKL relativa à expressão de $\beta$-actina nos animais do grupo Sham ( $n=5$, submetidos a indução fictícia), do grupo DP-14 $\mathrm{H}_{2} \mathrm{O}$ ( $n=5$, Tratados com veículo durante 14 dias após a indução), do grupo DP-14 Capto ( $n=5$, Tratados com captopril durante 14 dias após a indução), do grupo 7-DP-14 Capto $(n=5$, tratados com captopril 7 dias antes da indução e 14 dias após a indução), do grupo 14-DP-14 Capto ( $n=5$, tratados com captopril 14 dias antes da indução e 14 dias após a indução). * vs Sham e DP-14 $\mathrm{H}_{2} \mathrm{O}$ 


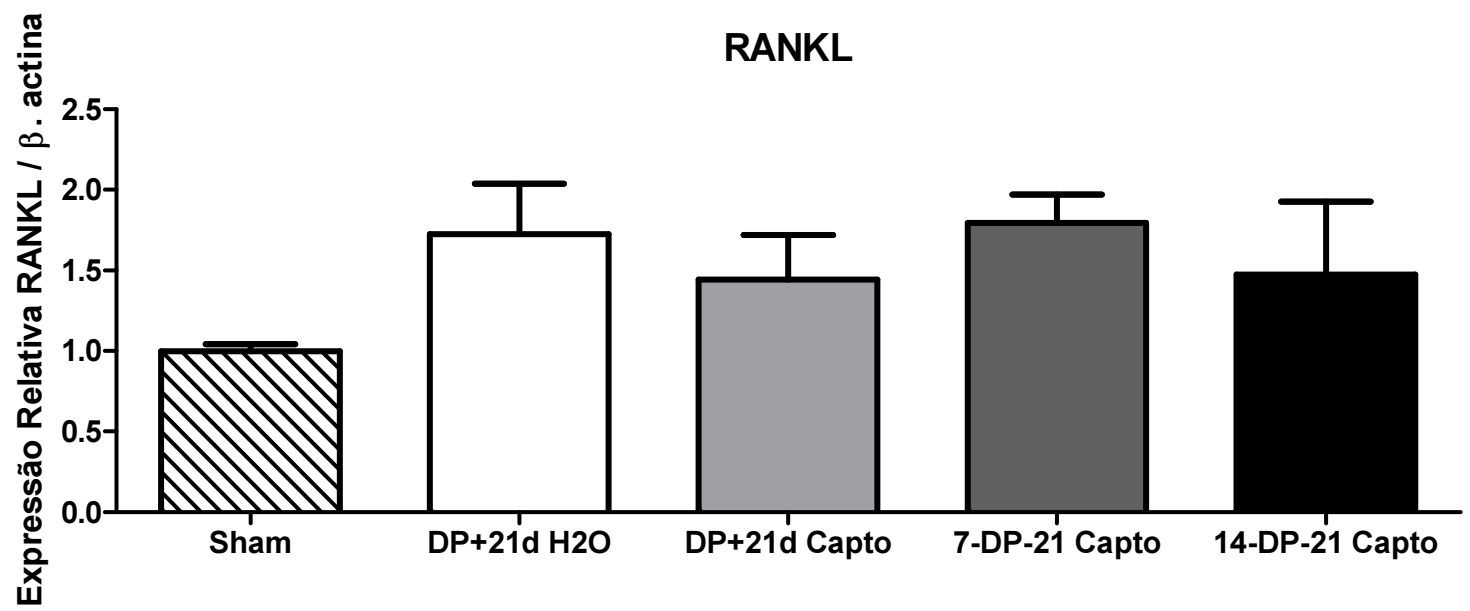

Figura 42 - Expressão de RNAm para RANKL relativa à expressão de $\beta$-actina nos animais do grupo Sham ( $n=5$, submetidos a indução fictícia), do grupo DP-21 $\mathrm{H}_{2} \mathrm{O}$ ( $n=5$, tratados com veículo 21 dias após a indução), do grupo DP-21 Capto $(n=5$, tratados com captopril 21 dias após a indução), do grupo 7-DP-21 Capto $(n=5$, tratados com captopril 7 dias antes da indução e 21 dias após a indução) e do grupo 14-DP-21 Capto ( $n=5$, tratados com captopril 14 dias antes da indução e 21 dias após a indução). 


\subsubsection{Fator de Crescimento Vascular Endotelial (VEGF)}

Com relação a expressão de RNAm para VEGF não foi possível detectar nenhuma diferença significativa entre todos os grupos avaliados (Figuras 43 e 44).

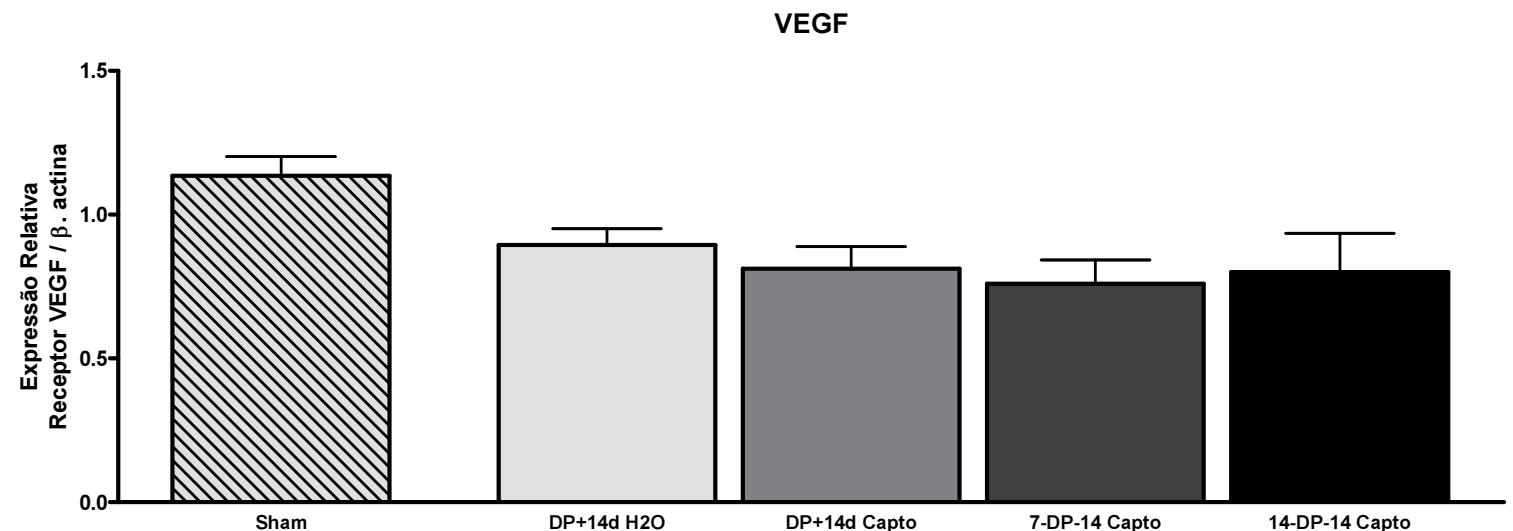

Figura 43 - Expressão de RNAm para VEGF relativa à expressão de $\beta$-actina nos animais do grupo Sham ( $n=5$, submetidos a indução fictícia), do grupo DP-14 $\mathrm{H}_{2} \mathrm{O}$ ( $n=5$, Tratados com veículo durante 14 dias após a indução), do grupo DP-14 Capto ( $n=5$, Tratados com captopril durante 14 dias após a indução), do grupo 7-DP-14 Capto ( $n=5$, tratados com captopril 7 dias antes da indução e 14 dias após a indução), do grupo 14-DP-14 Capto ( $n=5$, tratados com captopril 14 dias antes da indução e 14 dias após a indução). 


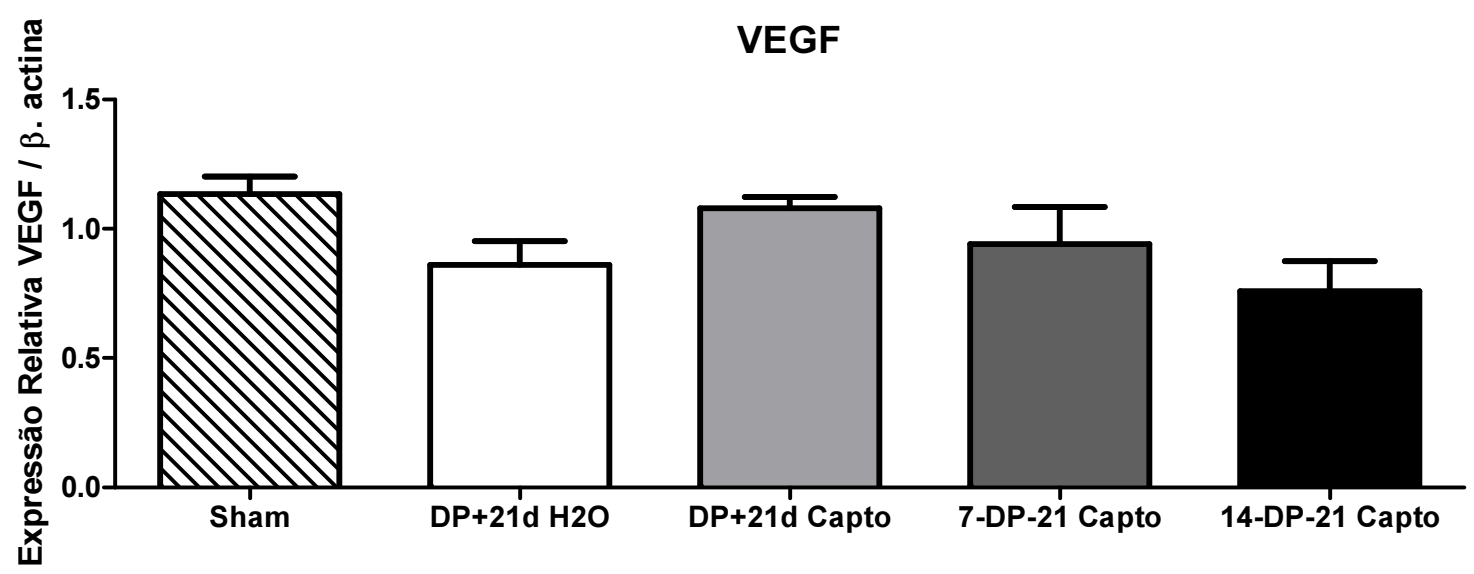

Figura 44 - Expressão de RNAm para VEGF relativa à expressão de $\beta$-actina nos animais do grupo Sham ( $n=5$, submetidos a indução fictícia), do grupo DP-21 $\mathrm{H}_{2} \mathrm{O}$ $(n=5$, tratados com veículo 21 dias após a indução), do grupo DP-21 Capto $(n=5$, tratados com captopril 21 dias após a indução), do grupo 7-DP-21 Capto $(n=5$, tratados com captopril 7 dias antes da indução e 21 dias após a indução) e do grupo 14-DP-21 Capto ( $n=5$, tratados com captopril 14 dias antes da indução e 21 dias após a indução). 


\subsubsection{Receptor 1 do Fator de Crescimento Vascular Endotelial (VEGF-R1)}

Os animais do grupo Sham apresentaram uma maior expressão de RNAm para o receptor 1 de VEGF (FLT) comparados aos animais dos grupos 7-DP-14 Capto, 14-DP-14 Capto, 7-DP-21 Capto e 14-DP-21 Capto. (Figuras 45 e 46)

VEGF-R1

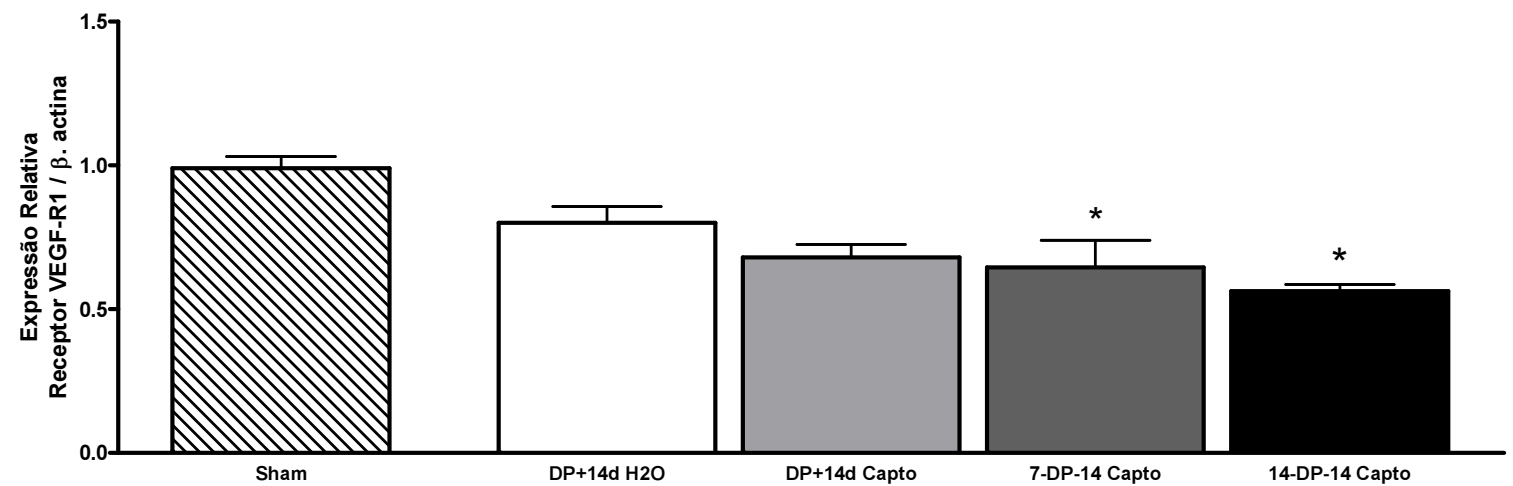

Figura 45 - Expressão de RNAm para VEGF-R1 relativa à expressão de $\beta$-actina nos animais do grupo Sham ( $n=5$, submetidos a indução fictícia), do grupo DP-14 $\mathrm{H}_{2} \mathrm{O}$ $(n=5$, Tratados com veículo durante 14 dias após a indução), do grupo DP-14 Capto $(n=5$, Tratados com captopril durante 14 dias após a indução), do grupo 7-DP-14 Capto $(n=5$, tratados com captopril 7 dias antes da indução e 14 dias após a indução), do grupo 14-DP-14 Capto ( $n=5$, tratados com captopril 14 dias antes da indução e 14 dias após a indução). * vs Sham. 


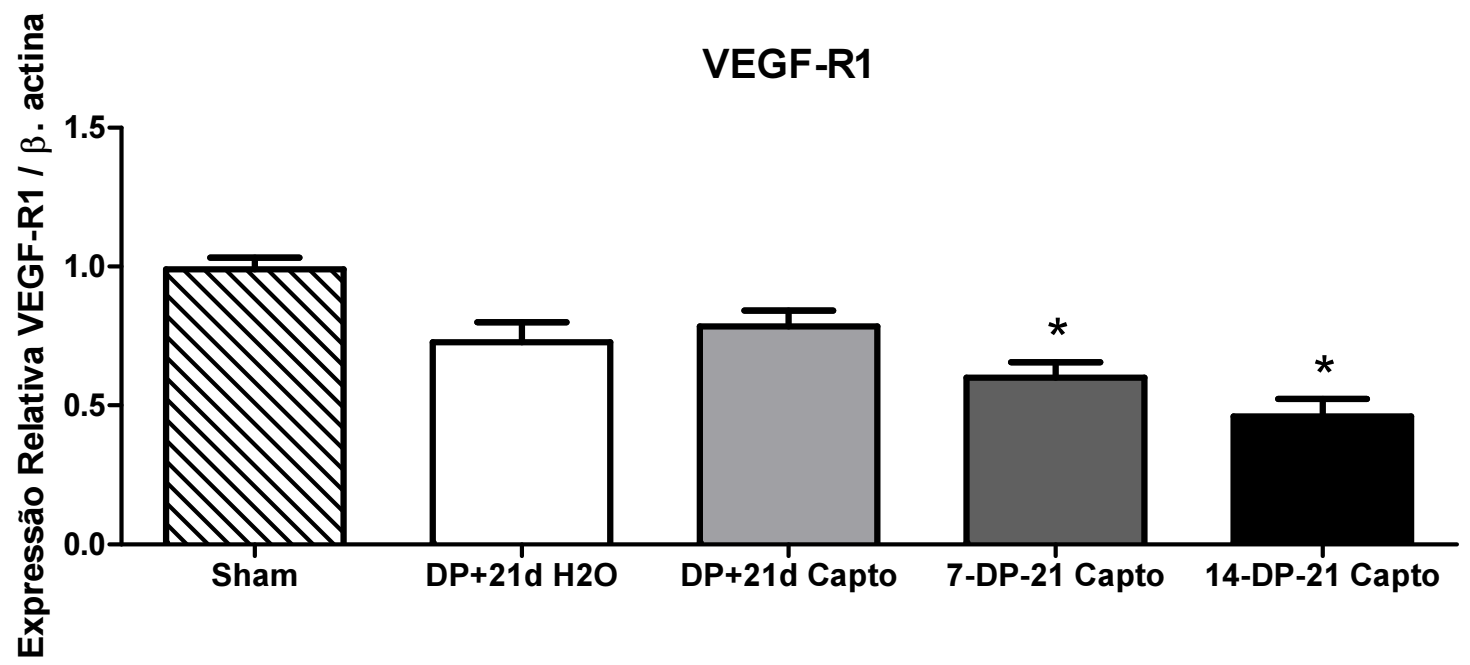

Figura 46 - Expressão de RNAm para VEGF-R1 relativa à expressão de $\beta$-actina nos animais do grupo Sham ( $n=5$, submetidos a indução fictícia), do grupo DP-21 $\mathrm{H}_{2} \mathrm{O}$ ( $n=5$, tratados com veículo 21 dias após a indução), do grupo DP-21 Capto $(n=5$, tratados com captopril 21 dias após a indução), do grupo 7-DP-21 Capto $(n=5$, tratados com captopril 7 dias antes da indução e 21 dias após a indução) e do grupo 14-DP-21 Capto ( $n=5$, tratados com captopril 14 dias antes da indução e 21 dias após a indução). * vs Sham. 


\subsubsection{Receptor 2 do Fator de Crescimento Vascular Endotelial (VEGF-R2)}

Exceto o grupo DP-14 H2O, todos os outros grupos apresentaram uma menor e significativa expressão de RNAm comparados aos animais do grupo Sham. (Figuras 47 e 48)

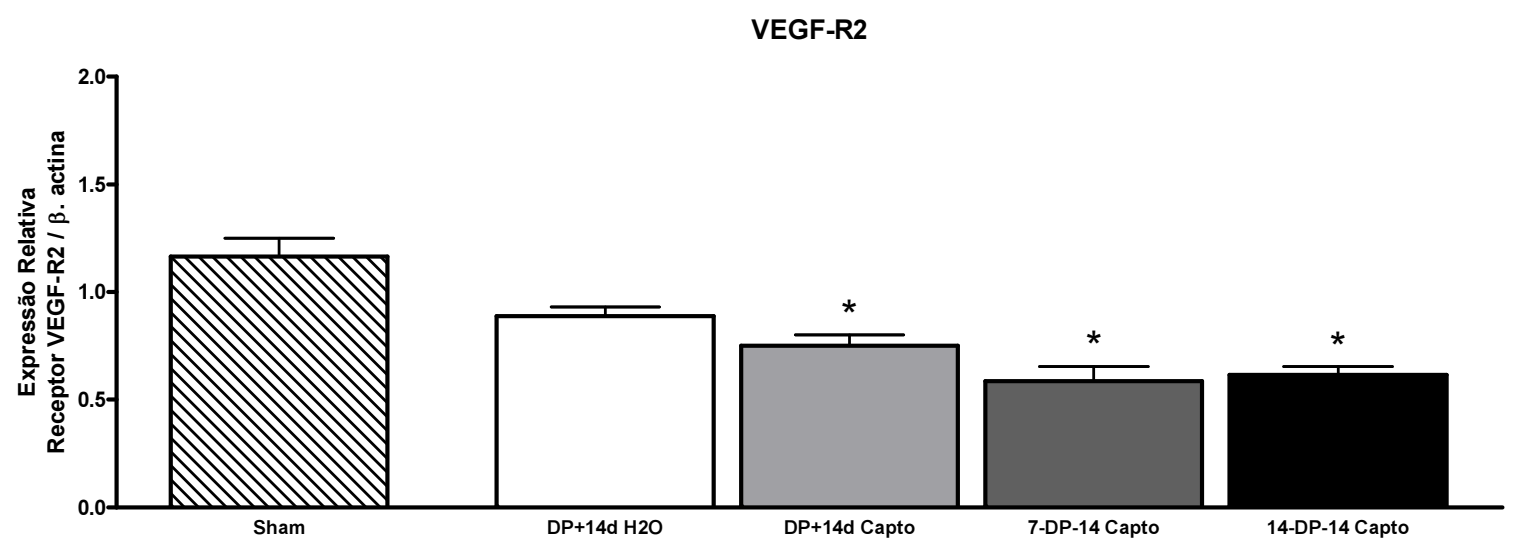

Figura 47 - Expressão de RNAm para VEGF-R2 relativa à expressão de $\beta$-actina nos animais do grupo Sham ( $n=5$, submetidos a indução fictícia), do grupo DP-14 $\mathrm{H}_{2} \mathrm{O}$ $(n=5$, Tratados com veículo durante 14 dias após a indução), do grupo DP-14 Capto $(n=5$, Tratados com captopril durante 14 dias após a indução), do grupo 7-DP-14 Capto $(n=5$, tratados com captopril 7 dias antes da indução e 14 dias após a indução), do grupo 14-DP-14 Capto ( $n=5$, tratados com captopril 14 dias antes da indução e 14 dias após a indução). * vs Sham. 


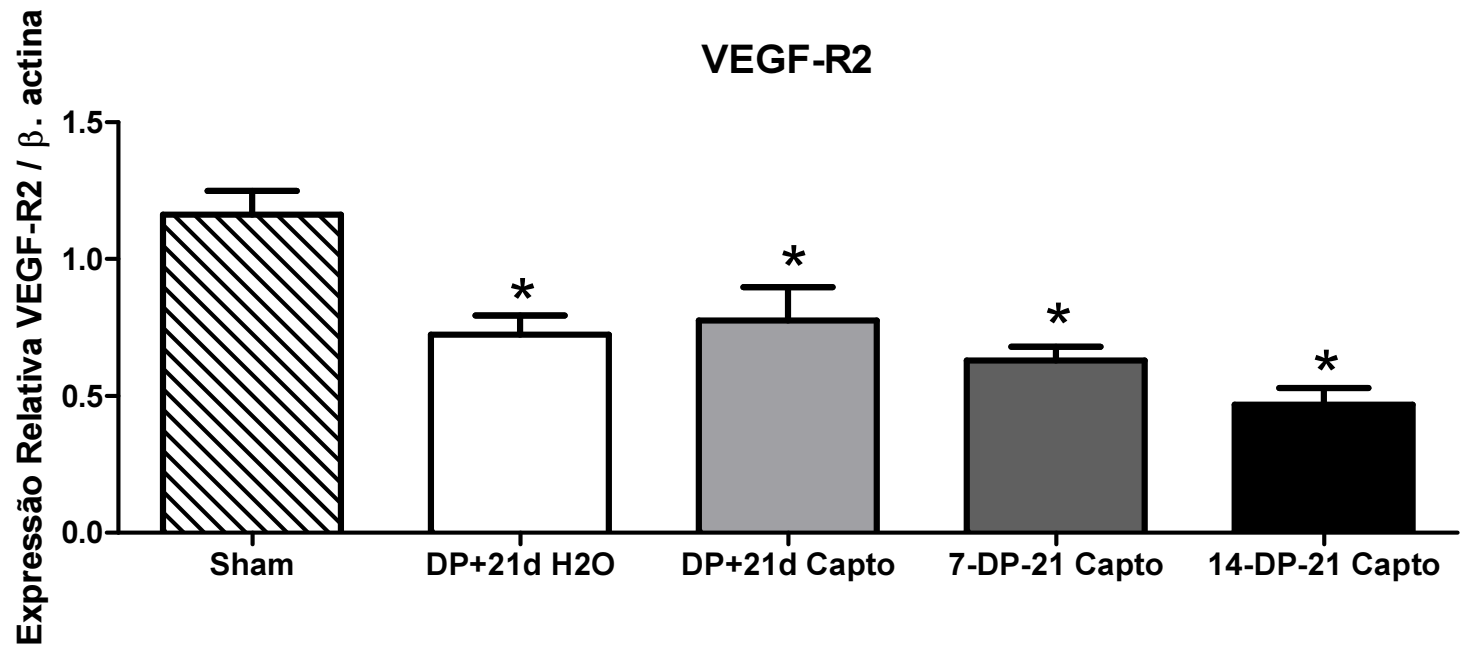

Figura 48 - Expressão de RNAm para VEGF-R2 relativa à expressão de $\beta$-actina nos animais do grupo Sham ( $n=5$, submetidos a indução fictícia), do grupo DP-21 $\mathrm{H}_{2} \mathrm{O}$ $(n=5$, tratados com veículo 21 dias após a indução), do grupo DP-21 Capto $(n=5$, tratados com captopril 21 dias após a indução), do grupo 7-DP-21 Capto $(n=5$, tratados com captopril 7 dias antes da indução e 21 dias após a indução) e do grupo 14-DP-21 Capto ( $n=5$, tratados com captopril 14 dias antes da indução e 21 dias após a indução). * vs Sham. 


\section{Figura 49. Escores histológicos.}

\section{Escore 1 - 49a}
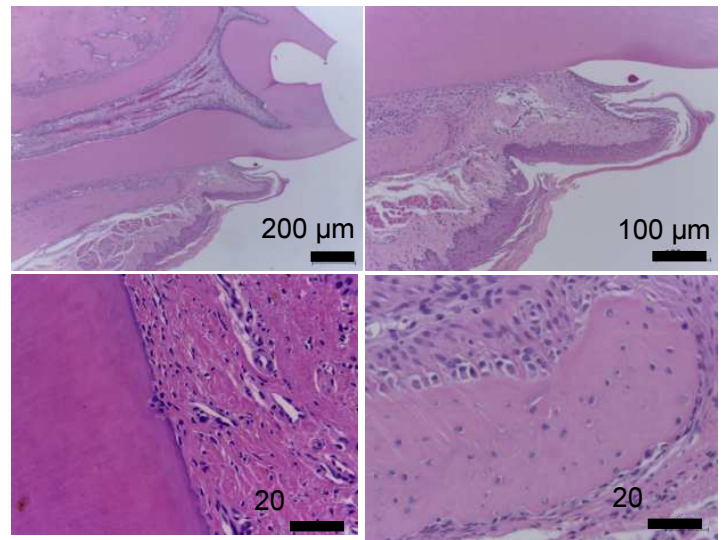

Escore 1. Infiltrado Inflamatório Ausente, Epitélio Juncional Normal, Cemento preservado ou com áreas eventuais de reabsorção cervical, Crista óssea alveolar preservada.

\section{Escore 3 -}
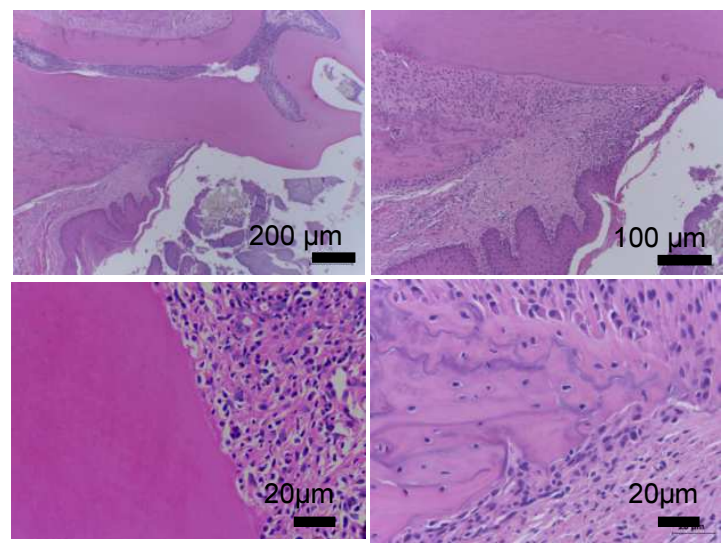

Escore 3. Infiltrado Inflamatório moderado, Epitélio Juncional Apical, Cemento parcialmente destruído, Crista óssea alveolar com reabsorção moderada.

\section{Escore 2-49b}

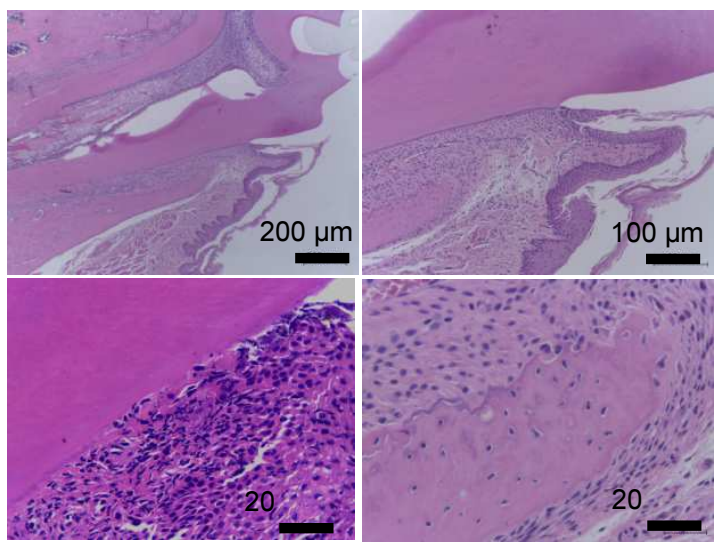

Escore 2. Infiltrado Inflamatório leve, Epitélio Juncional Normal, Cemento parcialmente destruído, Crista óssea alveolar com reabsorção mínima.

\section{Escore 4 - 49d}
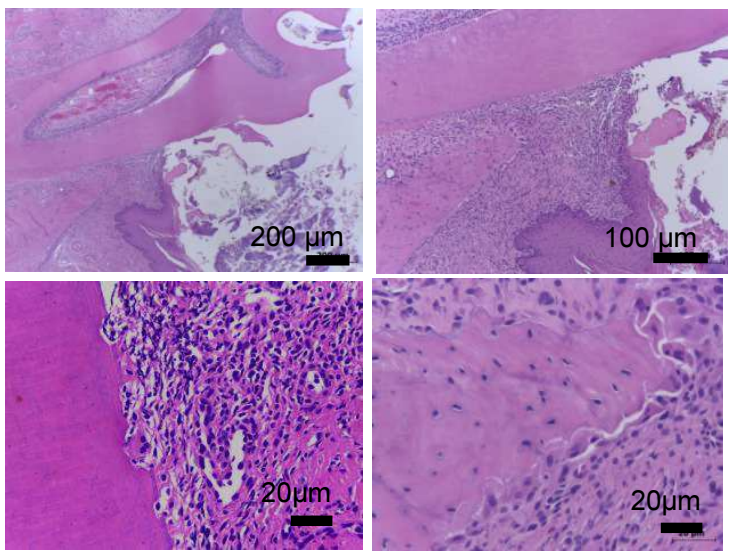

Escore 4. Infiltrado Inflamatório intenso, Epitélio Juncional Apical, Cemento gravemente destruído, Crista óssea alveolar com reabsorção intensa, ocasionalmente com sequestro ósseo. 


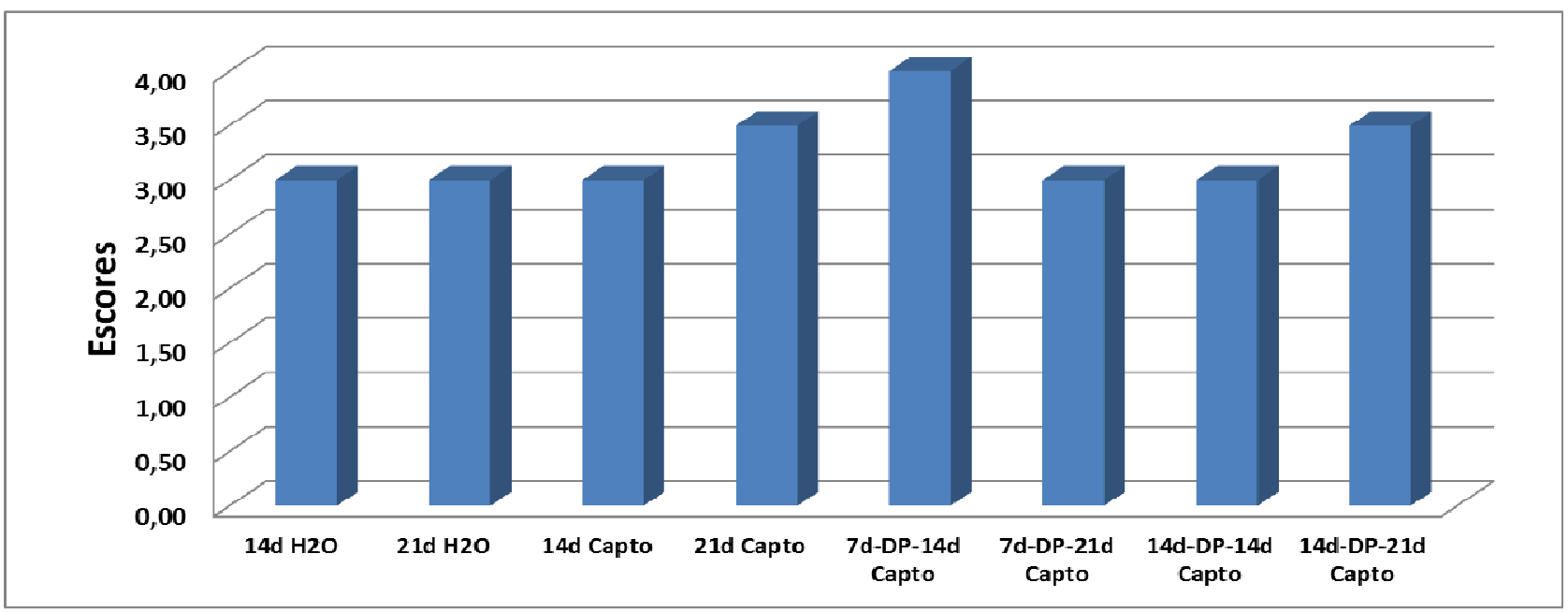

Figura 50. Escore histológico representativo das amostras de animais com doença periodontal induzida por 14 ou 21 dias. O escore representa a soma dos parâmetros de Infiltrado Inflamatório, posição de epitélio juncional, grau de reabsorção do cemento e crista óssea alveolar. Os escores estão descritos detalhadamente na figura 49 (a,b,c,d).

O gráfico representa escores de 1 a 4 que estão relacionados com a progressão da inflamação no tecido periodontal. Animais dos grupos DP-14 e DP-21 tratados com água apresentaram um escore 3, o que indica um grave processo inflamatório. Os animais submetidos aos tratamentos com captopril tanto após quanto prévios à indução da doença periodontal não apresentaram melhoras significativas. O processo estava inflamatório estava instaurado tanto nos tempos de 14 quanto 21 dias, e o tratamento com o captopril não interferiu na progressão da inflamação. 

5 Discussãa 



\section{DISCUSSÃO}

\subsection{DISCUSSÃO DA METODOLOGIA}

A metodologia do presente estudo foi baseada em trabalhos prévios, nos quais foi utilizada a mesma técnica de indução da doença periodontal experimental, os quais relatam que o período de maior ação de mediadores do processo inflamatório ocorre nas duas semanas após a colocação da ligadura (BEZERRA et al., 2000; RODINI et al., 2008; OLIVEIRA et al., 2008; DE ALMEIDA, 2008; GARCIA et al., 2009; LIMA et al., 2011). Por isso, a escolha dos tempos de tratamento de 14 e 21 após a indução da doença periodontal. Além disso, um fator de extrema importância para a escolha deste modelo animal envolve o rápido ciclo de vida que os ratos possuem.

Com relação à indução da doença periodontal em ratos, a metodologia escolhida consiste na colocação de uma ligadura ao redor da região cervical do primeiro molar inferior (MADDEN; CATON, 1994; LIMA, 2011; MACIEL, 2013). Com a ligadura, ocorre um acúmulo progressivo de bactérias presentes no próprio ambiente bucal do animal. A ligadura age, portanto, como um fator auxiliador na formação de biofilme, na área dento gengival.

Apesar de não ser uma doença espontânea, a manipulação do animal para sua indução é feita uma única vez e, a partir de então, a doença periodontal inflamatória progride naturalmente (BEZERRA et al., 2000).

\subsection{DISCUSSÃO DOS RESULTADOS}

A doença periodontal experimentalmente induzida em ratos mostrou-se bem estabelecida nos grupos, ao passo que, foi capaz de promover a perda óssea alveolar no presente estudo, assim como em outros trabalhos (MACIEL, 2013; LIMA, 2011; OLIVEIRA, 2007). Na figura 15 , podemos notar que ao compararmos os grupos tratados com veículo ao grupo tratado com captopril, é possível observar que o captopril não foi capaz de diminuir a perda óssea alveolar, independente do tempo 
de tratamento e da existência ou não de um pré-tratamento. Estes resultados sugerem que o tratamento com o captopril não foi capaz de bloquear a progressão da doença periodontal.

Por outro lado, há evidências na literatura de que o captopril poderia exercer algum efeito anti-inflamatório em uveíte induzida por endotoxina em ratos (ILIEVA et al., 2006). Inibidores da ECA, incluindo captopril, têm provado ser benéficos em encefalomielite autoimune induzida experimentalmente (CONSTANTINESCU et al. de 1995), miocardite (GODSEL et al., 2003), artrite adjuvante de Freund (AGHA; MANSOUR, 2000) e colite experimentais (JAHOVICH et al., 2005). Efeitos antitumoral, antifibrótico e citoprotetor do captopril também têm sido demonstrados (WILLIAMS et al, 2005.; REGAN et al, 1996.; MURLEY et al., 2004). Captopril foi claramente demonstrado capaz de atuar como regulador imunológico e com propriedades anti-inflamatórias.

Em trabalhos prévios do laboratório onde foram utilizadas outras drogas antihipertensivas que afetam o sistema renina-angiotensina foi comprovado que o tratamento com enalapril (outro inibidor da ECA) interfere na progressão da doença periodontal (MACIEL, 2013; LIMA, 2011), diferente do resultado obtido no presente estudo com o captopril. E em outro trabalho, losartan (antagonista de receptores da Ang II) e alisquireno (inibidor de renina) foram capazes de diminuir a perda óssea alveolar na doença periodontal, apesar de tratar-se de drogas atuantes do SRA, cada uma possui o seu mecanismo de ação, o que pode justificar a eficácia do losartan e alisquireno na diminuição da perda óssea (LIMA, 2011).

Uma possível explicação para a ineficácia destas drogas na progressão da DP poderia ser o aumento da biodisponibilidade de bradicinina no ambiente inflamado. Isto devido ao fato de outro efeito causado pelos inibidores da ECA, ou seja, a não clivagem da bradicinina, a qual seria inativada também pela ação da ECA. É de conhecimento comum as ações vasoativas da bradicinina, as quais favorecem a instalação e progressão da inflamação. Além disso, a biodisponibilidade de Ang II no tecido pode não ter sido alterada com o tratamento com captopril, uma vez que sabe da presença de quimases e catepsinas no tecido inflamado, o que pode ter gerado Ang II independentemente da ação da ECA. Outra possibilidade seria um aumento da produção local de elastase-2, outra via não sensível aos inibidores da ECA e que também leva à formação de Ang II (PAULA, 1998; SANTOS, 2002a, 2002b). 
Outras drogas que interferem no SRA, alisquireno e losartan, demonstraram efetividade com relação à perda óssea alveolar durante a doença periodontal experimentalmente induzida em ratos (LIMA, 2011). Isto se deve ao fato da importante diminuição da interação da Ang II com os receptores AT1, uma vez que esta interação promove a ativação de osteoclastos (LI et al., 2008). Esta diminuta interação entre Ang II e receptores AT1 após o tratamento com Losartan se deve ao antagonismo irreversível promovido pela droga (LI et al., 2008 e RAJIKUMAR et al., 2013). Já com relação ao tratamento com alisquireno, há menor atividade da enzima renina promovendo, assim, menor formação de Ang I e, consequentemente, Ang II. Esta atividade aumentada devido a uma maior ativação de osteoclastos está associada ao aumento da expressão de RANKL pelos osteoblastos, ligante este que quando se acopla ao receptor RANK na superfície dos osteoclastos promove o aumento da reabsorção óssea. Os osteoclastos têm papel fundamental no metabolismo ósseo, com atuação no processo de formação óssea

No trabalho de Hagiwara et al. (1998), foi demonstrado que a Ang II ligada aos receptores AT1, causa a inibição da expressão de RNAm para osteocalcina.

O SRA circulante é um sistema endócrino que promove a liberação de Ang II, a qual exerce seus efeitos pela interação com receptores específicos (PEACH, 1977; LEUNG, 2004; PAUL; MEHR; KREUTZ, 2006). Tem sido demonstrado que a Ang II ligada aos receptores AT1 pode desencadear um processo inflamatório (KANEKO et al., 2011). Durante o processo inflamatório podem ser encontrados diversos mediadores tais como: TGF- $\beta$, IL-1 $\beta$, TNF- $\alpha$, OPG, RANK-L, VEGF. No presente estudo, além de todos os componentes do SRA, foram avaliadas as expressões de RNAm para estes mediadores, dos quais somente RANK-L, IL-6, AT1a, ECA-2 e COX-2 apresentaram diferenças significativas entre os grupos avaliados, o que pode justificar a progressão da doença periodontal, tanto a presença de infiltrado inflamatório em alguns grupos, migração do epitélio juncional para a região apical, destruição de cemento, áreas ocasionais de sequestro ósseo e perda óssea.

No presente estudo os níveis de Ang II local e circulante não foram avaliados, já a expressão de RNAm para AGT no tecido gengival foi avaliada e não foram encontradas diferenças significativas entre os grupos. Foi detectado um aumento na expressão de RNAm para o receptor AT1a nos animais do grupo 14-DP-21 Capto em comparação aos animais do grupo DP-21 $\mathrm{H}_{2} \mathrm{O}$. Por outro lado, há na literatura um estudo que apresenta diminuição da expressão desse receptor nos ventrículos 
esquerdos de ratos WKY e SHR após tratamento com captopril (MIGUELCARRASCO et al., 2010). Vale destacar que nesse estudo a dose utilizada foi de 80 $\mathrm{mg} / \mathrm{kg} / \mathrm{dia}$ e o tempo de tratamento foi de 12 semanas, ou seja, o triplo do adotado em nosso trabalho.

No mesmo trabalho citado acima também foram encontrados decréscimos na expressão de RNAm para IL-1 $\beta$ e IL-6 nos grupos submetidos ao tratamento com captopril. No atual trabalho, muito provavelmente por conta do diferente tecido e modelo aplicado, não foi possível detectar o mesmo efeito do tratamento. Por outro lado, detectou-se no presente estudo aumento na expressão de IL-6 no grupo 14DP-21 CAPTO em comparação aos animais tratados com água durante o mesmo período experimental. Como a IL-6 possui atividades pró-inflamatórias, é plausível que esta se encontre aumentada no desenvolvimento da DP, no qual foram dosadas citocinas em pacientes com doença periodontal severa, onde estes apresentaram grande perda óssea e aumento de expressão de IL-6, IL-8 e TNF-a (NOH et al. 2013).

No trabalho de Bartold e Haynes (1991), no qual foram analisados fibroblastos humanos para dosar a produção de IL-6 na doença periodontal, também foi observado que um nível mais elevado de IL-6 foi expresso em tecidos gengivais inflamados quando comparados a tecidos saudáveis. Além disso, Sawada et al. (2012), demonstraram que possa existir um sinergismo entre IL-1 $\beta$ e IL-6, durante o processo inflamatório, uma vez que estas citocinas encontram-se aumentadas em células advindas da gengival de indivíduos com periodontite.

Era esperado que a expressão de RNAm para IL-1 $\beta$ aumentasse na DP, o que não ocorreu no presente estudo. Já no trabalho de Araújo et al. (2013), no qual a droga utilizada foi olmesartan, foi possível observar aumento nos níveis dessa proteína indicando a participação da IL-1 $\beta$ na progressão da DP. É possível que o momento de maior produção de RNAm para IL-1 $\beta$ tenha ocorrido antes daquele analisado no presente estudo, sendo necessário assim nos estudos futuros, a análise de períodos mais precoces na tentativa de se detectar os surtos de produção de RNAm para as citocinas inflamatórias.

TNF- $\alpha$ é considerada uma das principais citocinas envolvidas na progressão da inflamação na doença periodontal, auxiliando na destruição do tecido e na perda óssea decorrente da doença (BOSTRÖM L; LINDER LE; BERGSTRÖM J, 1998). É produzida por monócitos e macrófagos em resposta a componentes bacterianos 
orais, tais como LPS (BROOK, 2006; KURIYAMA et al., 2006). Aumento nos níveis de TNF- $\alpha$ podem promover a libertação da colagenase de fibroblastos gengivais humanos (OKADA H; MURAKAMI S, 1998), levando à destruição de colágeno e reabsorção óssea (BOSTRÖM L; LINDER LE; BERGSTRÖM J, 1998). No presente trabalho os níveis de TNF-a não se mostraram aumentados. É possível que o momento de maior produção de RNAm para TNF- $\alpha$ tenha ocorrido antes daquele analisado no presente estudo, sendo necessário, assim, nos estudos futuros, a análise de períodos mais precoces na tentativa de se detectar os surtos de produção de RNAm para as citocinas inflamatórias.

Com relação à expressão de RNAm para AT1a foram encontradas diferenças estatisticamente significativas quando comparados os grupos 14-DP-21 Capto com DP-21 $\mathrm{H}_{2} \mathrm{O}$, sendo observado um aumento na expressão no grupo tratado com a droga. Trabalhos prévios indicam que utilizando o mesmo protocolo de pesquisa, mas com outra droga inibidora da ECA, o enalapril, ocorreu o inverso, a droga nesse caso causou uma diminuição na expressão de RNAm para o grupo tratado com a droga (LIMA, 2011; MACIEL, 2013).

Assim como em trabalhos prévios do laboratório utilizando o mesmo tecido (LIMA, 2011; MACIEL, 2013), não foi possível detectar a expressão de RNAm para a Renina. Sendo esta uma enzima relacionada com a produção de Ang I por clivar o AGT, é constantemente encontrada em células endoteliais presentes nas arteríolas deferentes dos tecidos e da circulação sanguínea. Por este motivo, era esperado que não fossem detectadas essas expressões de RNAm para a Renina no tecido estudado, uma vez que provavelmente a renina detectada no tecido gengival seja captada da circulação (LIMA, 2011; SANTOS et al. 2009).

Com relação ao receptor AT1b, os dados obtidos não foram suficientes para a confecção de gráfico, porém em trabalhos prévios do laboratório (LIMA, 2011; MACIEL, 2013), também não foi possível detectar uma forte expressão de RNAm para esse receptor durante a DP, o que pode estar relacionado ao tratamento com captopril, ao passo que este é um inibidor da ECA, o que pode ter feito com que fosse diminuída a biodisponibilidade de Ang II, com isso uma menor expressão desses receptores.

Os receptores AT2 e MAS são caracterizados por apresentarem efeitos semelhantes, porém contrários aos efeitos associados ao receptor AT1. Tem sido demonstrados efeitos anti-inflamatório, antifibrose, antiapoptose e regeneração 
neuronal, associados aos receptores AT2 e MAS, o que pode contrabalançar processos patológicos e permitir a recuperação de doenças (NAMSOLLECK et al., 2014). No presente estudo não foram constatados aumentos dos receptores AT2 e MAS, e este resultado possivelmente está associado com a progressão da DP não ter sido bloqueada. Portanto, o captopril não apresentou, nesse modelo experimental, um efeito anti-inflamatório, como apresentado em outros modelos experimentais (WILLIAMS et al, 2005.; REGAN et al, 1996.; MURLEY et al., 2004).

Em tecidos saudáveis o receptor AT2 é pouco expresso (NAMSOLLECK et al., 2014; STECKELINGS UM, ROMPE F, KASCHINA E, NAMSOLLECK P, GRZESIAK A, FUNKE-KAISER H, et al., 2010). Então, era esperado que a expressão de RNAm para AT2 nos animais do grupo SHAM fosse menor em relação aos animais com a DP tratados com o veículo, o que não foi constatado nos resultados de RT-PCR. É possível que o momento de maior produção de RNAm para AT2 tenha ocorrido antes daquele analisado no presente estudo, assim como ocorreu no caso de outros alvos, sendo necessário, assim, nos estudos futuros, a análise de períodos mais precoces na tentativa de se detectar os surtos de produção de RNAm para a expressão de receptores na membrana celular.

O receptor ativador de NF-кB (RANK) é expresso na superfície de osteoclastos e possui um importante papel no processo de reabsorção óssea. Seu ligante RANKL, expresso na superfície de osteoblastos, liga-se a ele e impulsiona sinais de diferenciação e ativação celular em precursores osteoclásticos, promovendo, assim, a reabsorção óssea (NAGASAWA et al., 2000). No presente estudo, a expressão de RNAm para RANK não se apresentou aumentada quando comparados os grupos tratados com veículo ou captopril ao grupo SHAM. Portanto, assim como o ocorrido para outros alvos, esse resultado pode estar correlacionado ao momento de expressão no qual foi feita a RT-PCR, pois era de se esperar que em animais com a doença periodontal, os quais de fato apresentaram grandes perdas ósseas, fosse constatado um aumento de RANK, ao passo que este em conjunto com o RANKL atuaria no processo de reabsorção óssea.

Quando analisada a relação RANK-L/OPG é possível observar que ocorreu um aumento na expressão de RANK-L em um dos grupos estudados, enquanto OPG não foi mais expresso em nenhum dos grupos. Possivelmente essa maior expressão de RANK-L é que justificaria um maior escore observado no grupo 7-DP14 tratado com captopril, o mesmo grupo apresentou então maior expressão de 
RANK-L e alto escore, próximo de 4, o que indica presença de infiltrado inflamatório intenso, epitélio juncional na região apical, cemento gravemente destruído, crista óssea alveolar com intensa reabsorção e sequestro ósseo ocasional.

Em contrapartida, poderíamos dizer que os níveis de OPG aumentados justificariam a diminuição da perda óssea, já que entre os grupos tratados e o SHAM, não foram encontradas diferenças significativas; então poderíamos dizer que a expressão de RNAm para OPG, não se mostrou alterada com a presença dos tratamentos em animais com a DP, e que esta apresentou-se próxima à normalidade. Porém, a quantidade de OPG no tecido, não foi suficiente para diminuir a progressão da perda óssea, ao passo que a resposta imune contra patógenos periodontais pode afetar grandemente o curso da DP, porém a perda óssea continua a ser estabelecida (CHEN et al., 2014; T. NAGASAWA et al., 2000). Portanto, a proporção entre RANKL e OPG é o que irá determinar a atividade osteoclástica e a reabsorção óssea. No grupo 7-DP-14 Capto, os níveis de RANKL mostraram-se aumentados, quando comparados ao grupo SHAM e ao grupo DP-14 $\mathrm{H}_{2} \mathrm{O}$, o que justifica, então, os animais terem apresentado perda óssea (CHEN et al, 2014; N. UDAGAWA; N. TAKAHASH; E. JIMI et al., 1999).

A expressão de RNAm para VEGF mostrou-se sem diferenças significativas quando comparados os grupos entre si e com o grupo SHAM, porém por tratar-se de uma análise de expressão de RNAm e não tendo sido quantificados os níveis de proteínas, pode-se supor que a proteína VEGF já havia sido formada. $\mathrm{Na} \mathrm{DP}$, o VEGF deveria mostrar-se bastante expresso, já que é um dos moduladores que atuam no processo inflamatório (OLIVEIRA et al., 2008) e, por isso, a expressão de RNAm para esta citocina não se mostrou alterada no momento da análise por RTPCR. Esse fato pode ser confirmado após compararmos a expressão de RNAm para os receptores de VEGF, VEGF-R1 e VEGF-R2 nos grupos com a DP com o grupo SHAM, os quais se mostraram menos expressos quando comparados ao grupo SHAM.

Os experimentos de RT-PCR para VEGF-R1 nos grupos 7-DP-14 Capto, 14DP14 Capto, 7-DP-21 Capto e 14-DP-21 Capto mostraram menor expressão de RNAm do que no grupo SHAM, o que era esperado. A expressão de VEGF-R2 nos grupos DP-14 Capto, 7-DP-14 Capto, 14-DP-14 Capto, DP-21 H $2 \mathrm{O}$, DP-21 Capto, 7DP-21 Capto e 14-DP-21 Capto mostraram também menor expressão de RNAm assim como na expressão de RNAm para o VEGF-R1. Quando observados os 
resultados da expressão de RNAm para VEGF não houve alteração ao compararmos os dados dos grupos tratados com o grupo SHAM, o que indica que provavelmente o RNAm já havia produzido a proteína, por isso a expressão de RNAm para VEGF não mostrou-se maior, e por isso uma menor expressão de RNAm para seus receptores.

Em suma, os resultados dessa pesquisa mostraram que o captopril não foi capaz de diminuir a progressão da perda óssea na doença periodontal induzida experimentalmente em ratos. Porém, também pode ser observado que o captopril, de alguma forma, altera alguns mediadores do processo inflamatório, atuando assim nos mediadores presentes no tecido periodontal. Estudos futuros serão necessários, principalmente no que diz respeito à quantificação de proteínas no tecido, ao passo que neste estudo foi analisada apenas a expressão de RNAm. 
6 Conclusões 



\section{CONCLUSÕES}

Com base nos resultados obtidos neste trabalho, foi possível concluir que o captopril não é capaz de diminuir a perda óssea na doença periodontal induzida experimentalmente em ratos, apesar desta droga alterar a expressão de RNAm para alguns mediadores do processo inflamatório no tecido periodontal, tais como AT1a, COX-2, ECA-2, IL-6, RANKL, VEGF-R1 e VEGF-R2. 

Referências 



\section{REFERÊNCIAS}

Agha AM, Mansour M. Effects of captopril on interleukin-6, leukotriene $B(4)$, and oxidative stress markers in serum and inflammatory exudate of arthritic rats: evidence of antiinflammatory activity. Toxicol Appl Pharmacol. 2000 Oct $15 ; 168(2): 123-30$.

Anderson D, Maraskovsky E, Billingsley W, Dougall W, Tometsko M, Roux E, Teepe M, DuBose R, Cosman D, Galibert L. A homologue of the TNF receptor and its ligand enhance T-cell growth and dendritic-cell function. Nature. 1997; 390:175-9.

Araújo AA, Lopes de Souza G, Souza TO, de Castro Brito GA, Sabóia Aragão K, Xavier de Medeiros CA, Lourenço $Y$, do Socorro Costa Feitosa Alves M, Fernandes de Araújo R Jr. Olmesartan decreases IL-1 $\beta$ and TNF- $\alpha$ levels; downregulates MMP2, MMP-9, COX-2, and RANKL; and upregulates OPG in experimental periodontitis. Naunyn Schmiedebergs Arch Pharmacol. 2013 Oct;386(10):875-84.

Arikan F, Buduneli N, Kütükçüler N. Osteoprotegerin levels in peri-implant crevicular fluid. Clin Oral Implants Res. 2008; 19:283-8.

Baud'huin M, Lamoureux F, Duplomb L, Rédini F, Heymann D, Rankl RANK. osteoprotegerin: key partners of osteoimmunology and vascular diseases. Cell Mol Life Sci. 2007; 64:2334-50.

Barksby HE, Lea SR, Preshaw PM, Taylor JJ. The expanding family of interleukin-1 cytokines and their role in destructive inflammatory disorders. Clin Exp Immunol. 2007; 149: 217-225.

Bartold PM, Haynes DR.Interleukin- 6 production by human gingival fibroblasts. J Periodontal Res. 1991 Jul;26(4):339-45.

Bernstein KE, Martin BM, Edward AS, Bernstein EA. Mouse angiotensin-converting enzyme is a protein composed of two homologous domains. J Biol Chem. 1989; 264: $11945-51$.

Bezerra MM, de Lima V, Alencar VB, Vieira IB, Brito GA, Ribeiro RA, Rocha FA. Selective cyclooxygenase-2 inhibition prevents alveolar bone loss in experimental periodontitis in rats. J Periodontol. 2000 Jun;71(6):1009-14. 
Boström L, Linder LE, Bergström J. Clinical expression of TNF-alpha in smokingassociated periodontal disease. J Clin Periodontol. 1998 Oct;25(10):767-73.

Brook I. The role of anaerobic bacteria in mediastinitis. Therapy in practice. Drugs. 2006; 66(3): 315-320.

Campbell DJ, Habener JF. Angiotensinogen gene is expressed and differentially regulated in multiple tissues of the rat. J Clin Invest. 1986; 78:31-9.

Cassis LA, Saye J, Peach MJ. Location and regulation of rat angiotensinogen messenger RNA. Hypertension. 1988; 11:591-6.

Cassis LA, Fettinger MJ, Roe AL, Shenoy UR, Howard G. Characterization and regulation of angiotensin II receptors in rat adipose tissue. Angiotensin receptors in adipose tissue. Adv Exp Med Biol. 1996;396:39-47.

Chen Z, Tan F, Erdös EG, deddish PA. Hydrolysis of angiotensin peptides by human angiotensin I-converting enzyme and the resensitization of B2 kinin receptors. Hypertension. 2005; 46(6): 1368-73.

Chen B, Wu W, Sun W, Zhang Q, Yan F, Xiao Y. RANKL expression in periodontal disease: where does RANKL come from? Biomed Res Int. 2014;2014:731039.

Constantinescu CS, Ventura E, Hilliard B, Rostami A. Effects of the angiotensin converting enzyme inhibitor captopril on experimental autoimmune encephalomyelitis. Immunopharmacol Immunotoxicol. 1995 Aug;17(3):471-91.

Cornish KG, Joyner WL, Gilmore JP.Direct evidence for the presence of a different converting enzyme in the hamster cheek pouch. Circ Res. 1979 Apr;44(4):540-4.

Duarte PM, de Mendonça AC, Máximo MB, Santos VR, Bastos MF, Nociti Júnior FH. Differential cytokine expressions affect the severity of peri-implant disease. Clin Oral Implants Res. 2009; 20:514-20.

Efrati S, Berman S, Goldfinger $\mathrm{N}$ et al. Enhanced angiotensin II production by renal mesangium is responsible for apoptosis/proliferation of endothelial and epithelial cells in a model of malignant hypertension. J Hypertens 2007; 25: 1041-1052. 
Efrati S, Berman S, Hamad RA, Siman-Tov Y, Ilgiyaev E, Maslyakov I, Weissgarten $\mathrm{J}$. Effect of captopril treatment on recuperation from ischemia/reperfusion-induced acute renal injury. Nephrol Dial Transplant. 2012 Jan;27(1):136-45.

Ferrara N, Gerber HP, LeCouter J. The biology of VEGF and its receptors. Nat Med 2003;9:669-676.

Ferrara N. Molecular and biological properties of vascular endothelial growth factor. J Mol Med 1999;77:527-543.

Ferrara N. The role of VEGF in the regulation of physiological and pathological angiogenesis. EXS 2005; 94:209-231.

Ferrero-Miliani L, Nielsen OH, Andersen OS, Girardin SE. Chronic inflammation: importance of NOD2 and NALP3 in interleukin- $1^{2}$ generation. Review. British Society for Immunology, Clinical and Experimental Immunology. 2006; 147: 227-235.

Genest J, Kuchel O, Leduc G, Granger P, Boucher R, Rojo-Ortega JM, Nowaczynski W. Screening programs for hypertension. Can Med Assoc J. 1974 Jul 20;111(2):1479 .

Giannobile WV. Host-response therapeutics for periodontal diseases. J Periodontol. 2008; 79(8 Suppl):1592-1600.

Godsel LM, Leon JS, Wang K, Fornek JL, Molteni A, Engman DM. Captopril prevents experimental autoimmune myocarditis. J Immunol. 2003 Jul 1;171(1):346-52.

Györfi A, Fazekas A, Suba Z, Ender F, Rosivall L. Neurogenic component in ligatureinduced periodontitis in the rat. J Clin Periodontol. 1994 Oct;21(9):601-5.

Hinz B, Brune K. Cyclooxygenase-2 : 10 years later. J. Pharmacol Exp Ther. 300 (2), 2001, 367-375.

Hiruma Y, Inoue A, Hirose S, Hagiwara H. Angiotensin II stimulates the proliferation of osteoblast-rich populations of cells from rat calvariae. Biochem Biophys Res Commun. 1997 Jan 3;230(1):176-8. 
Ilieva I, Ohgami K, Jin XH, Suzuki Y, Shiratori K, Yoshida K, Kase S, Ohno S. Captopril suppresses inflammation in endotoxin-induced uveitis in rats. Exp Eye Res. 2006 Sep;83(3):651-7.

Ikeda F, Nishimura R, Matsubara T, Tanaka S, loune J, Reddy S, Hata K, Yamashita K, Hiraga T, Watanabe T, Kukita T, Yoshioka K, Rao A, Yoneda T. Critical roles of cJun signaling in regulation of NFAT family and RANKL-regulated osteoclast differentiation. J Clin Invest. 2004; 114:475-84.

Jahovich N, Ercan F, Gedik N, Yuksel M, Sener G, Alican I. The effect of angiotensinconverting enzyme inhibitors on experimental colitis in rats. Regul. Pept. 2005. 130: $67-74$.

Kim YD, Kim SS, Hwang DS, Kim SG, Kwon YH, Shin SH, Kim UK, Kim JR, Chung IK. Effect of low-level laser treatment after installation of dental titanium implantimmunohistochemical study of RANKL, RANK, OPG: an experimental study in rats. Lasers Surg Med. 2007; 39:441-50.

Kramkowiski K, Mogielnicki A, Buczko W. The physiological significance of the alternative pathways of angiotensin II production. 2006; 57(4):529-39.

Kuriyama T, Karasawa T, Williams DW, Nakagawa K, Yamamoto E. An increased prevalence of $\beta$-lactamase-positive isolates in Japanese patients with dentoalveolar infection. J. Antimicrob. Chemother. 2006; 58(3): 708-709.

Kwan Tat S, Padrines M, Théoleyre S, Hemann D and Fortun Y. IL-6, RANKL, TNFalpha/IL-1: interrelations in bone resorption pathophysiology. Cytokine Growth Factor Rev. 2004; 15: 49-60.

Lacey DL, Timms E, Tan HL, Kelley MJ, Dunstan CR, Burgess T, Elliott R, Colombero A, Elliott G, Scully S, Hsu H, Sullivan J, Hawkins N, Davy E, Capparelli C,Eli A, Qian YX, Kaufman S, Sarosi I, Shalhoub V, Senaldi G, Guo J, Delaney $\mathrm{J}$, Boyle WJ. Osteoprotegerin ligand is a cytokine that regulates osteoclast differentiation and activation. Cell. 1998 Apr 17;93(2):165-76.

Lamparter S, Kling L, Schrader M, Ziegler R, Pfeilschifter J. Effects of angiotensin II on bone cells in vitro. J Cell Physiol. 1998 Apr;175(1):89-98. 
Leung PS. The peptide hormone angiotensin II: its new functions in tissues and organs. Curr Protein Pept Sci. 2004; 5(4):267-73.

Li Y, Yamada H, Kita Y, Suzuki M, Endo Y, Horita S, Yamazaki O, Shimizu T, Seki G, Fujita T. Arachidonic acid metabolites inhibit the stimulatory effect of angiotensin II in renal proximal tubules. Hypertens Res. 2008 Dec;31(12):2155-64.

Lima MC. O sistema renina-angiotensina na doença periodontal induzida experimentalmente em ratos. Departamento de Ciências Biológicas. Bauru. Faculdade de Odontologia de Bauru/Universidade de São Paulo, 2011. 145p. Tese (Doutorado em Ciências) - Programa de Pós-Graduação em Ciências Odontológicas Aplicadas - Faculdade de Odontologia de Bauru/Universidade de São Paulo, 2011.

Lodha S, Dani D, Mehta R et al. Angiotensin II-induced mesangial cell apoptosis: role of oxidative stress. Mol Med 2002; 8: 830-840.

Lohinai Z, Benedek P, Fehér E, Györfi A, Rosivall L, Fazekas A, Salzman AL, Szabó C.Protective effects of mercaptoethylguanidine, a selective inhibitor of inducible nitric oxide synthase, in ligature-induced periodontitis in the rat. $\mathrm{Br} \mathrm{J}$ Pharmacol. 1998 Feb;123(3):353-60.

Lundergan WP, Ferry D, Kobayashi H, Snowdowne KW. Angiotensin-II increases cytoplasmic calcium, cell number and total DNA for human periodontal ligamental cells in vitro. J Periodontal Res. 1999 May;34(4):223-8.

Maciel RP. Efeitos da Inibição da Enzima Conversora de Angiotensina Sobre a Doença Periodontal Induzida Experimentalmente em Ratos. Departamento de Ciências Biológicas. Bauru. Faculdade de Odontologia de Bauru/Universidade de São Paulo: 2013, 103p. Dissertação (Mestrado em Ciências) - Programa de PósGraduação em Ciências Odontológicas Aplicadas - Faculdade de Odontologia de Bauru/Universidade de São Paulo, 2013.

Madden TE, Caton JG. Animal models for periodontal disease. Methods Enzymol. 1994;235:106-19

Mallow H, Trindl A, Löffler G. Production of angiotensin II receptors type one (AT1) and type two (AT2) during the differentiation of 3T3-L1 preadipocytes. Horm Metab Res. 2000 Nov-Dec;32(11-12):500-3. 
Mackiewicz A. Acute phase proteins and transformed cells. Int Rev Cytol. 1997; 170: 225-300.

Marcic B, Deddish PA, Jackman HL, Erdös EG. Enhancement of bradykinin and resensitization of its B2 receptor. Hypertension. 1999; 33(3): 835-43.

Miguel-Carrasco JL, Monserrat MT, Mate A, Vázquez CM. Comparative effects of captopril and I-carnitine on blood pressure and antioxidant enzyme gene expression in the heart of spontaneously hypertensive rats. Eur J Pharmacol. $2010 \mathrm{Apr}$ 25;632(1-3):65-72.

Miguel-Carrasco JL, Zambrano S, Blanca AJ, Mate A, Vázquez CM. Captopril reduces cardiac inflammatory markers in spontaneously hypertensive rats by inactivation of NF-kB. J Inflamm (Lond). 2010 May 12;7:21.

Mine $\mathrm{Y}$, Makihira S, Nikawa H, Murata H, Hosokawa R, Hiyama A, Mimura S. Impact of titanium ions on osteoblast-, osteoclast- and gingival epithelial-like cells. J Prosthodont Res. 2010; 54:1-6.

Monov G, Strbac GD, Baron M, Kandler B, Watzek G, Gruber R. Soluble RANKL in crevicular fluid of dental implants: a pilot study. Clin Implant Dent Relat Res. 2006; 8:135-41.

Montón C, Rañó A, Torres A. Inflammatory response in pneumonia. Arch Bronconeumol. 1998 Nov;34 Suppl 2:11-6.

Murley JS, Kataoka Y, Cao D, Li JJ, Oberley LW, Grdina DJ. Delayed radioprotection by NFkappaB-mediated induction of Sod2 (MnSOD) in SA-NH tumor cells after exposure to clinically used thiol-containing drugs. Radiat Res. 2004 Nov;162(5):53646.

Nagasawa T, Kiji M, Yashiro R, Hormdee D, Lu H, Kunze M, Suda T, Koshy G, Kobayashi H, Oda S, Nitta H, Ishikawa I. Roles of receptor activator of nuclear factorkappaB ligand (RANKL) and osteoprotegerin in periodontal health and disease.Periodontol 2000. 2007;43:65-84.

Namsolleck P, Recarti C, Foulquier S, Steckelings UM, Unger T. AT(2) receptor and tissue injury: therapeutic implications. Curr Hypertens Rep. 2014 Feb;16(2):416. 
Narducci P, Nicolin V. Differentiation of activated monocytes into osteoclast-like cells on a hydroxyapatite substrate: an in vitro study. Ann Anat. 2009; 191:349-55.

Nickenig G, Sachinidis A, Seewald S, Böhm M, Vetter H. Influence of oxidized lowdensity lipoprotein on vascular angiotensin II receptor expression. J Hypertens Suppl. 1997 Dec;15(6):S27-30.

Noh MK, Jung M, Kim SH, Lee SR, Park KH, Kim DH, Kim HH, Park YG. Assessment of IL-6, IL-8 and TNF- $\alpha$ levels in the gingival tissue of patients with periodontitis. Exp Ther Med. 2013 Sep;6(3):847-851.

Okada $\mathrm{H}$, Murakami S. Cytokine expression in periodontal health and disease. Crit Rev Oral Biol Med. 1998;9(3):248-66.

Okunishi H, Miyazaki M, Toda N.Evidence for a putatively new angiotensin IIgenerating enzyme in the vascular wall. J Hypertens. 1984 Jun;2(3):277-84.

Oliveira MA, Fortes ZB, Santos RA, Kosla MC, De Carvalho MH. Synergistic effect of angiotensin-(1-7) on bradykinin arteriolar dilation in vivo. Peptides. 1999;20(10):1195-201.

Oliveira TM. Fator de crescimento endotelial vascular na doença periodontal inflamatória induzida experimentalmente em ratos. Departamento de Ciências Biológicas. Bauru. Faculdade de Odontologia de Bauru/Universidade de São Paulo: 2007, 124p. Tese (Doutorado em Odontopediatria) - Programa de Pós-Graduação em Ciências Odontológicas Aplicadas - Faculdade de Odontologia de Bauru/Universidade de São Paulo, 2017.

Oliveira TM, Sakai VT, Machado MAAM, Dionisio TJ, Cestari TM, Taga R, Amaral SL, Santos CF. Cox-2 inhibition decreases VEGF expression and the alveolar bone loss during the progression of experimental periodontitis in rats. J Periodontol. 2008; 79: 1062-1069.

Paul M, Mehr AP, Kreutz R. Physiology of local renin-angiotensin systems. Physiol Rev. 2006; 86:747-803.

Paula CA, Sousa MV, Salgado MC, Oliveira EB. Purification and substrate specificity of na angiotensin converting Elastase-2 from the rat mesenteric arterial bed perfusate. Biochim Biophys Acta. 1998; 1388(1): 227-38. 
Peach MJ. Renin-angiotensin system: biochemistry and mechanisms of action. Physiol Rev. 1977; 57:313-70

Raizada MK, Ferreira AJ. ACE2: a new target for cardiovascular disease therapeutics. J Cardiovasc Pharmacol. 2007 Aug;50(2):112-9.

Ramer R, Brune K, Pahl A, Hinz B. R(+)-methanandamide induces cyclooxygenase-2 expression in human neuroglioma cells via a non-cannabinoid receptor-mediated mechanism. Biochem Biophys Res Commun. 2001 Sep 7;286(5):1144-52.

Regan CP, Anderson PG, Bishop SP, Berecek KH. Captopril prevents vascular and fibrotic changes but not cardiac hypertrophy in aortic-banded rats. Am J Physiol. 1996 Sep;271(3 Pt 2):H906-13.

Rodini CO, Batista AC, Dionísio TJ, Santos CF, Cunha FQ, Lara VS. Morphologic evaluation and expression of matrix metalloproteinases-2 and 9 and nitric oxide during experimental periodontal disease in rat. J Mol Histol. 2008 Jun;39(3):275-82.

Santos CF, Paula CA, Salgado COM, Oliveira EB. Kinetic characterization and inhibition of the rat MAB Elastase-2, an angiotensin I-converting serine protease. Can J Physiol Pharmacol. 2002a; 80(1):42-7.

Santos CF, Oliveira EB, Salgado MCO, Greene AS. Molecular cloning and sequencing of the cDNA for rat mesenteric arterial bed Elastase-2, na angiotensin IIforming enzyme. J Cardiovasc Pharmacol. 2002b; 39(5):628-35.

Santos CF, Caprio MA, Oliveira EB, Salgado MC, Schippers DN, Munzenmaier DH, et al. Functional role, cellular source and tissue distribution of rat Elastase-2, na angiotensin II-forming enzyme. Am J Physiol Heart Physiol. 2003; 285(2):H775-83.

Santos CF, Greene AS, Salgado MCO, Oliveira EB. Conversion of renin substrate tetradecapeptide to angiotensin II by rat MAB Elastase-2. Can J Physiol Pharmacol. 2004; 82(11):1000-5.

Santos RAS, Brosnihan KB, Chappell MC, Pesquero JL, Chernick CL, Greene LJ, et al. Converting enzyme activity and angiotensin metabolismo in the dog brainstem. Hypertension. 1988; 11:153-7. 
Santos RAS, Campagnole-Santos MJ. Central and peripheral actions of Ang 1-7. Braz J Med Biol Res. 1994; 27: 1033-47.

Sawada S, Chosa N, Ishisaki A, Naruishi K. Enhancement of gingival inflammation induced by synergism of IL-1 $\beta$ and IL-6. Biomed Res. 2013 Feb;34(1):31-40.

Segawa M, Nakao S, Ogata Y, Sugiya H, Furuyama S. Angiotensin II induces prostaglandin $E(2)$ release in human gingival fibroblasts. Life Sci. 2003 Jan 3;72(7):795-803.

Sipe JD.Acute-phase proteins in osteoarthritis. Arthritis Reum. 1995; 25: 75-86.

Snyder RA, Wintroub BU. Inhibition of angiotensin-converting enzyme by des-Leu10angiotensin I: a potential mechanism of endogenous angiotensin-converting enzyme regulation. Biochim Biophys Acta. 1986; 871(1): 1-5.

Soubrier F, Alheng-Gelas F, Hubert C, Allegrini J, John M, Tregear G, et al. Two putative active centers in human angiotensin I- converting enzyme revealed by molecular cloning. Proc Natl Acd Sci USA. 1988; 85:9386-90.

Steckelings UM, Rompe F, Kaschina E, Namsolleck P, Grzesiak A, Funke-Kaiser H, Bader M, Unger T.J Renin Angiotensin Aldosterone Syst. 2010 Mar;11(1):67-73.

Suda T, Takahashi N, Udagawa N, Jimi E, Gillespie MT, Martin TJ. Modulation of osteoclast differentiation and

function by the new members of the tumor necrosis factor receptor and ligand families," Endocrine Reviews. 1999; 20 (3): 345-357.

Taga T, Kishimoto T. Gp130 and interleukin-6 family of cytokines. Annu Rev Immunol. 1997; 15: 797-819.

Trask AJ, Ferrario CM. Angiotensin 1-7: Pharmacology and new perspectives in cardiovascular treatments. Cardio Vasc Reviews. 2007; 25 (2): 162-74.

Udagawa N, Takahashi N, Jimi E, Matsuzaki K, Tsurukai T, Itoh K, Nakagawa N, Yasuda H, Goto M, Tsuda E, Higashio K, Gillespie MT, Martin TJ, Suda T. Osteoblasts/stromal cells stimulate osteoclast activation through expression of 
osteoclast differentiation factor/RANKL but not macrophage colony-stimulating factor: receptor activator of NF-kappa B ligand.Bone. 1999 Nov;25(5):517-23.

Urata H, Healy B, Stewart RW, Bumpus FM, Husain A. Angiotensin II-forming pathways in normal and failing human hearts. Circ Res. 1990a; 66(4):883-90

Urata $\mathrm{H}$, Kinoshita A, Misono KS, Bumpus FM, Husain A. Identification of a highly specific chymase as the major angiotensin II-forming enzyme in the human heart. $J$ Biol Chem 1990b; 265(36):22348-57.

Vallés G, González-Melendi P, Saldaña L, Rodriguez M, Munuera L, Vilaboa N. Rutile and titanium particles differentially affect the production of osteoblastic local factors. J Biomed Mater Res A. 2008; 84:324-36.

Van Dyke TE, SERHAN CH. Resolution of inflammation: a new paradigm for the pathogenesis of periodontal diseases. J Dent Res 2003 Feb;82(2): 82-90.

Virtej A, Løes SS, Berggreen E, Bletsa A. Localization and signaling patterns of vascular endothelial growth factors and receptors in human periapicallesions. J Endod. 2013 May;39(5):605-11.

Weinberg MA1, Bral M. Laboratory animal models in periodontology. J Clin Periodontol. 1999 Jun;26(6):335-40.

Williams RN, Parsons SL, Morris TM, Rowlands BJ, Watson SA. Inhibition of matrix metalloproteinase activity and growth of gastric adenocarcinoma cells by an angiotensin converting enzyme inhibitor in in vitro and murine models. Eur J Surg Oncol. 2005 Nov;31(9):1042-50.

Wilson M. Biological activities of lipopolysaccharides from oral bacteria ant their relevance to the pathogenesis of chronic periodontitis. Sci Prog 1995;78(Pt 1): 19-34.

Wong B, Rho J, Arron J, Robinson E, Orlinick J, Chao M, Kalachikov S, Cayani E, Bartlett F, Frankel W, Lee S, Choi Y. TRANCE is a novel ligand of the tumor necrosis factor receptor family that activates c-Jun $\mathrm{N}$-terminal kinase in $\mathrm{T}$ cells. J Biol Chem. $1997 ; 272: 25190-4$.

Wright JW, Yamamoto BJ, Harding JW. Angiotensin receptor subtype mediated physiologies and behaviors: New discoveries and clinical targets. Prog Neurobio. 2008; 84(2): 157-81. 
Yasuda H, Shima N, Nakagawa N, Yamaguchi K, Kinosaki M, Mochizuki S, Tomoyasu A, Yano K, Goto M, Murakami A, Tsuda E, Morinaga T, Higashio K, Udagawa N, Takahashi N, Suda T. Osteoclast differentiation factor is a ligand for osteoprotegerin/osteoclastogenesis-inhibitory factor and is identical to TRANCE/RANKL. Proc Nat Acad Sci. 1998; 95:3597-602. 